\title{
Environmental Management Technology Leveraging Initiative
}

\author{
Topical Report
}

October 1, 1995 - September 30, 1996

Work Performed Under Contract No.: DE-FC21-94MC31179

For

U.S. Department of Energy

Office of Environmental Management

Office of Technology Development

1000 Independence Avenue

Washington, DC 20585
U.S. Department of Energy

Office of Fossil Energy

Morgantown Energy Technology Center P.O. Box 880

Morgantown, West Virginia 26507-0880

DISTRIBUTION OF THIS DOCUMENT IS UNLIMITED

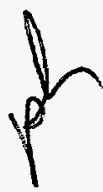

By

Global Environment and Technology Foundation

7010 Little River Turnpike, Suite 300

Annandale, Virginia 22003 


\section{Disclaimer}

This report was prepared as an account of work sponsored by an agency of the United States Government. Neither the United States Government nor any agency thereof, nor any of their employees, makes any warranty, express or implied, or assumes any legal liability or responsibility for the accuracy, completeness, or usefulness of any information, apparatus, product, or process disclosed, or represents that its use would not infringe privately owned rights. Reference herein to any specific commercial product, process, or service by trade name, trademark, manufacturer, or otherwise does not necessarily constitute or imply its endorsement, recommendation, or favoring by the United States Government or any agency thereof. The views and opinions of authors expressed herein do not necessarily state or reflect those of the United States Government or any agency thereof. 


\section{DISCLAIMER}

Portions of this document may be illegible electronic image products. Images are produced from the best available original document. 


\section{GETE}

\section{TABLE OF CONTENTS}

PURPOSE 3

BACKGROUND 4

METHODOLOGY 5

I. BUSINESS ASSISTANCE 6

Market Assessments 11

Technology Brokering

Business Planning and Startup

Financial Development

Strategic Partnerships

II. INFORMATION 16

Global Network for Environmental Technology

Database Integration

GNET Structure and Tools

III. OUTREACH 21

Outreach Materials

Public Participation

ISO 14000

CONCLUSION 27

REFERENCES 


\section{INDEX OF FIGURES}

Figure 1.0 - Technology Commercialization: DOE and Commercial Market Views ........7

Figure 2.0 - American Internet User Survey $\ldots \ldots \ldots \ldots \ldots \ldots \ldots \ldots \ldots \ldots \ldots \ldots$

Figure 3.0 - GNET Individual Users Growth Graph (May to Sept. 1996)

19

\section{LIST OF APPENDICES}

Appendix 1

Appendix 2

Appendix 3

Appendix 4

Appendix 5

Appendix 6

Appendix 7

Appendix 8

Appendix 9

Appendix 10
GETE Brochures

Examples of Market Assessments

Examples of Mini-Market Assessments

GETE Screening Methodology

GETE Business Plan Format

GETE Work Plan Format

Catalytic Initiatives, Seeking Innovative Financing Approaches for Environmental

Technologies

GETF/WSRC Memorandum of Understanding

Example of Focus Area on GNET

Example of GETE Update 


\section{Executive Summary}

The "Environmental Management Technology Leveraging Initiative," a cooperative agreement between the Global Environment \& Technology Foundation and the Department of Energy-Morgantown Energy Technology Center, has completed its second year. This program, referred to as the Global Environmental Technology Enterprise (GETE) is an experiment to bring together the public and private sectors to identify, formulate, promote and refine methods to develop more cost-effective clean-up treatments. Working closely with Department of Energy officials, National Laboratory representatives, business people, academia, community groups, and other stakeholders, this program attempts to commercialize innovative, DOE-developed technologies. The methodology to do so incorporates three elements: business assistance, information, and outreach. This methodology has evolved since the project began in 1994 to take advantage of communication advances, such as the Internet, and to capture larger regulatory movements, such as ISO 14000 and improve business methods.

A key advance this year was the development of a commercialization guidance document which can be used to diagnose the commercialization level and needs for innovative technologies. The model provides analytical tools and information that include:

1. selection screening

2. workplans

3. viability studies

4. performance-based market assessments

5. planning assistance

6. licensing assistance

7. testing sites

8. performance verification

9. strategic and financial brokering

10. technical decision support to users

Partnerships between important stakeholders were built this year under GETE. This includes the development and launching of a National Affiliates Program which makes it easier for companies to bridge a commercialization barrier by making DOE technologists available. Three facilities have become involved with the program: Oak Ridge National Laboratory, Idaho National Engineering Laboratory, and Savannah River Site.

Discussions and negotiations are underway with other National Laboratories. Other partnerships were advanced, including the Site Technology Coordination Groups, the U.S. Army, and the National Association of State Development Agencies.

The Global Network of Environment and Technology (GNET) progressed considerably this year. Formerly a communication system which enabled specific users to share information and messages to others in the environmental technology community, GNET has changed and expanded to a robust, internationally-accessible, award-winning DOE technology information center. Of greater importance, GNET has made significant steps in addressing its goal to promote DOE technologies to industry. Development of Focus 
and Crosscutting Area on-line information centers includes weekly updated data, news, and Intranet, or virtual private networks for DOE users and the public. Reports show that commercial users alone exceed 8,000 .

In order to provide stakeholders and the public with more information about DOEdeveloped technologies, innovative methods to overcome barriers, and success stories, a monthly GETE Update was created. The newsletter is sent to over 500 interested parties, and is published on-line to reach more readers. In addition, GETE attended conferences and meetings to discuss the project with stakeholders. Brochures have been developed to assist marketing efforts, such as promoting the National Affiliates Program.

ISO 14000 has become an important element of GETE. ISO 14000 is a series of voluntary environmental standards and guideline documents in the areas of environmental management systems, environmental audits, environmental performance evaluations, evaluation labeling and claims, and environmental life cycle assessment. The ISO 14000 standards could be a benefit or a potential barrier for DOE-EM. This year, GETE monitored the nationwide progression, introduction, and modifications to the ISO 14000 environmental standards. GETE has participated in the U.S. TAG meetings on the standards and continues to gather information from all interested stakeholders. This information will be synthesized into an analysis of how the standards will impact DOE.. EM.

GETE has progressed considerably during Fiscal Year 1996. Progress has occurred within all three major elements. With the advent of DOE-EM's "10 Year Plan," GETE is refocusing portions of the program to be responsive to DOE-EM's near-term needs. GETE will strive to enhance the deployment initiatives in order to bring proven and stakeholder accepted technologies to the sites. GETE will continue to develop partnerships with the private sector and assist the Focus and Crosscutting Areas in the commercialization and deployment of innovative technologies. 


\section{Purpose}

This topical report provides a synopsis of the "Environmental Management Technology Leveraging Initiative," a three-year cooperative agreement between the Global Environment \& Technology Foundation and the Department of Energy-Morgantown Energy Technology Center (DOE-METC) which began October 1, 1994. This partnership has lead to the creation of the Global Environmental Technology Enterprise (GETE) Program. GETE's objective is to "develop and implement strategies and methods to transfer DOE developed solutions into practice for environmental remediation and waste management problems." "This report describes the activities and progress undertaken during Fiscal Year 1996 (FY96), plans for Fiscal Year 1997 (FY97), and will explore each task, including significant changes.

The objectives of the Cooperative Agreement include:

Developing approaches and methodologies for environmental technology partnering and transfer, which means facilitating the commercialization and licensing of DOE-developed EM technologies;

Assessing DOE-developed EM technologies at various development stages, evaluating the commercial potential of the technologies, and identifying and assessing domestic and/or international markets;

Establishing a central location for gathering, maintaining, and disseminating environmental technology information;

Promoting coordination between DOE and U.S.-based industry to address environmental technology development issues of mutual interest;

Creating the methodology for an Environmental Technology Catalytic Fund to attract investments for commercialization of the technologies; and

Establishing and maintaining an information and communications system capable of promoting a working knowledge of technology development and technology transfer requirements.

While these activities were described initially, some changes have occurred. For example, a task involving ISO 14000 , clearly a very important change in the international environmental technology sector, was added. This task evolved from the requirement to address barriers to commercialization described in the program. Difficulties regarding federal law in the development of the Environmental Technologies Catalytic Fund raised questions about its existence in the GETE project. This report will describe these and similar changes.

\footnotetext{
${ }^{1}$ U.S. Department of Energy, "Environmental Management Technology Leveraging Initiative," Amendment M002, Cooperative Agreement Number DE-FC21-94MC31179, December 8, 1994, page 1.
} 


\section{Background}

The Office of Environmental Management (EM) was established in 1989 and was charged to clean up environmental pollution at $\mathrm{DOE}$ facilities, prevent further environmental contamination, and institute responsible environmental management. The environmental challenges of the DOE complex are unique and, as such, cannot follow a standardized, industrial approach. The mission cannot be fully achieved using existing technology without incurring high costs and long delays. Additionally, barriers exist that prevent newly developed or innovative technologies from entering the marketplace.

The DOE's Office of Science \& Technology (OST) promotes programs to make new, innovative, and more effective technologies available for transfer to users through progressive development. Projects are demonstrated, tested, and evaluated to produce solutions to current problems. The transition of technologies into more advanced stages of development is based on technological, regulatory, economic, and institutional criteria. New technologies are made available for use in eliminating radioactive, hazardous, and other wastes in compliance with regulatory mandates. The primary goal is to protect human health and prevent further contamination to its clean-up and waste management programs.

DOE-EM technology development programs seek to address five major remediation and waste management "problem areas" that were initially identified within the DOE weapons complex. These major problem areas (now called Focus Areas) were:

- Contaminant Plume Containment and Remediation (Plumes)

- Mixed Waste Characterization, Treatment, and Disposal (Mixed Waste)

- High-Level Waste Tank Remediation (Tanks)

- Landfill Stabilization

- Facility Transitioning, Decommissioning, and Final Disposition (D\&D)

During the past year, DOE-EM combined the problem areas "Contaminant Plume Containment and Remediation" and "Landfill Stabilization" to form the "Subsurface Contaminants" Focus Area. In addition, the Cross Cutting Focus Areas were initiated and are designated as:

- Robotics

- Efficient Separation \& Processing Crosscutting Focus Area

- Characterization, Monitoring \& Sensor Technology 


\section{Methodology}

The GETE experiment has three major elements incorporating nine tasks. They include:

- Global Network for Environmental Technology (GNET) Information

- Database Integration

- GNET Structure and Tools

- Technology Identification

- Technology Assessment

- Technology Commercialization Barrier Assistance

- National Laboratory and DOE Complex Interface Assistance

- Market Assessment

- Technology Brokering

- Business Planning and Startup

- Financial Development

- Outreach Materials

- Public Participation Initiative

- ISO 14000

GETE was designed to help move technologies from the applied research stage to production and implementation in both the public and private sectors. Identifying innovative technologies, overcoming barriers, and providing marketing assistance to new technologies are encompassed in Business Assistance. Data and public participation to promote DOE-developed technologies are developed and disseminated in different mediums throughout the commercialization process in the Information and Outreach sections.

At the end of its second year, this project has been refined and expanded. The first year of GETE involved gathering considerable information and data on technologies, and organizing flexible methods and systems to assist each promising innovations at their different stages in the commercialization process. Ongoing efforts since the beginning have included introducing many stakeholders to GETE and developing key partnerships with the private sector and with a number of governmental and non-governmental organizations with unique skills and similar commercialization goals. The second year put those efforts and partnerships into use. Positive results are beginning to show.

This report provides results on each major element. 


\section{BUSINESS ASSISTANCE}

GETE's activities during FY96 have incorporated the needs of many stakeholders seeking successful commercialization of DOE-supported, EM-related technologies. The second year was dedicated to developing a commercialization methodology. It was clear that a comprehensive set of methods was needed which is responsive to a wide range of technology development situations.

Also in FY96, formal Points of Contact (POCs) were established to interact and participate with the Focus and Crosscutting Areas in order to facilitate rapid response to their needs. In addition, the POCs act as a facilitator for the private sector to commercialize and deploy their technologies within the DOE Complex.

By working together, GETE and the DOE-EM Focus and Crosscut Areas have developed a guideline for a commercialization system. This system is designed around ten services backed by a series of "tools," or documents. The tools were designed to assist those seeking to move a technology from research and development to production. The system was peer reviewed by members of industry and the government in order to provide additional guidance and to identify future needs and current gaps.

It has been recognized that two dual-track processes are underway during the commercialization of a DOE-EM technology. The first is described in the DOE-EM Technology Investment Decision Model. The second is the status of a commercial partner's efforts to bring the technology to market.

The evolution of each technology is different. Commercialization can take a considerable amount of time, and movement is dependent upon the maturity of the technology and the relationship with a commercial partner. However, there are three clear phases within the commercialization process:

Phase I: Selection

Phase II: Qualification

Phase III: Commercialization 


\section{Technology Commercialization: DOE and Commercial Market Views}

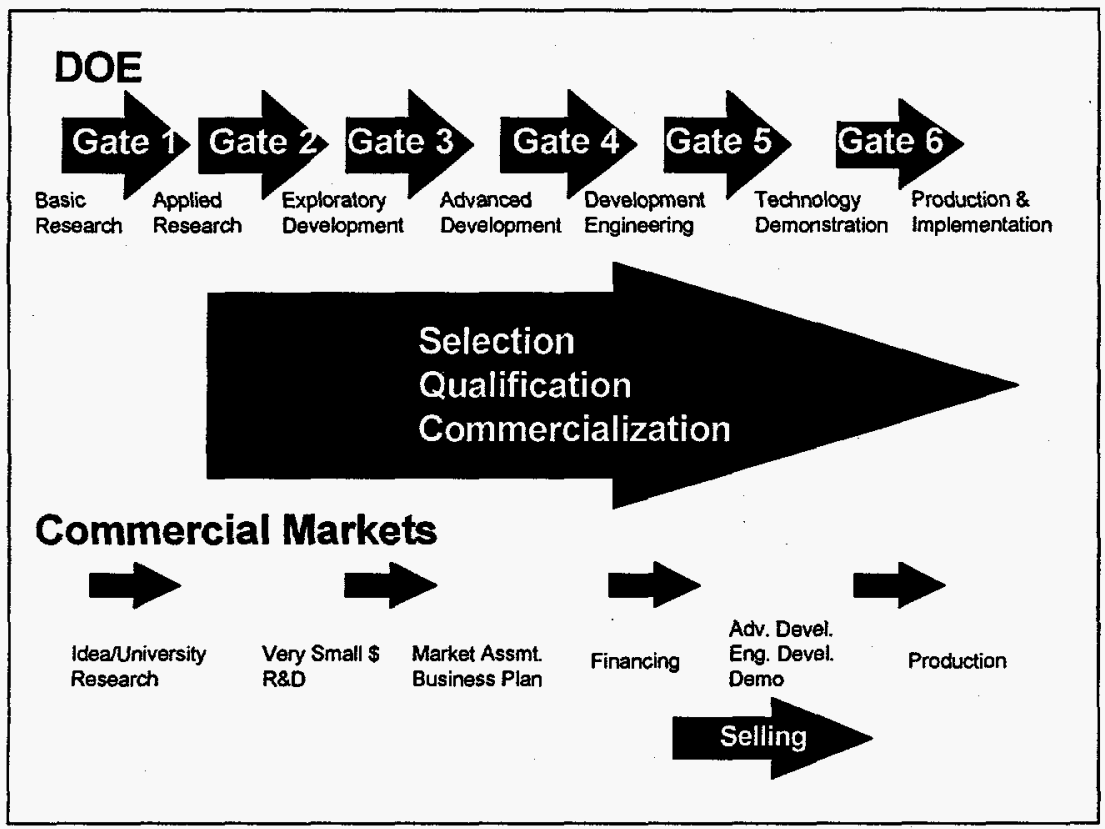

Figure 1.0 - Technology Commercialization

The ten services offered by a commercialization organization, such as GETE, fall within those three phases. They are:

- Selection Screening

- Workplans

- Viability Studies

- Performance-Based Market Assessments

- Planning Assistance

- Licensing Assistance

- Testing Sites

- Performance Verification

- Strategic and Financial Brokering

- Technical Decision Support to Users

Since every technology has unique attributes in different stages of development, a customized package of activities is required to produce a cost-effective process. Each step may not be necessary for every technology. Some are associated with commercial partners, which move them into a higher phase of commercialization. Others have not yet been identified as potentially successful products, and could use assistance at an earlier phase. Thus, not every phase is appropriate, so only those required for successful completion are executed. 
The services outlined above are being fulfilled by GETE. GETE also carries on the critical activities of interface and information, in which potential partners are identified and data on technologies collected. The GETE Program works jointly with the Focus and Crosscut Areas at all times and seek to become integral members in the Focus and Crosscut Area teams.

The tools, all of which are guidelines and continue to be revised as experience is gained, are described below :

Commercialization Assistance Guidance Document: This document describes the GETE commercialization process and assistance package and is a formal methodology used to ensure that all factors in the commercialization process are considered. It includes as appendices the tools that follow.

GETE Process (for Technologies) Screen Document: This document is in database format and is used to collect information on a technology and its associated company. The database also identifies information short falls or issues which would prevent full commercialization. More than a dozen technologies have been subjected to this intensive screen.

Company Discussion Agenda Document: This tool focuses on discussions with technology holders, or private companies to identify which commercialization services are applicable.

GETE Workplan: This document is a formal proposal of work to be completed to assist a technology to become commercially available. It describes the effort required and recommends roles and responsibilities between GETE and the Focus Areas, coupled with proposed funding levels.

Business Plan Checklists: This guide is used to determine if a company has a thorough business, or strategic plan. It includes pertinent financial information.

Strategic Planning Ad: This is a decision tool used to identify crucial factors in finding partners for commercialization activities.

Company Valuation Guide: This document helps a company decide the worth of the company for financial planning and the infusion of capital.

Change of Status Report: This document reports that a technology will no longer be actively assisted by GETE or its associated processes. 
One vitally-important task in this project calls upon GETE to "provide assistance to technology developers, technology commercializing organizations, and problem holders of identified [DOE-developed] technologies, in resolving barriers to commercialization."2

One considerable barrier, the "Valley of Death," described in a recent study in The Journal of Technology Transfer, ${ }^{3}$ is an ongoing problem for innovative technologies. The success of the pharmaceutical industry dealing with this matter can be very helpful. Some answers and suggestions are found which could be addressed in FY97 by GETE.

The strategy for lowering the barriers to technology acceptance, in particular, regulatory acceptance, has emphasized working with state regulators and permit writers through interstate cooperative efforts. The primary objective of this strategy is to have the states move toward the acceptance of each others' testing and verification data. In the role as facilitator, communications provider, and bridge-builders, GETE has identified five key steps in concert with other programs. These include:

1. Working with groups of regulators and stakeholders such as the Interstate Technology and Regulatory Cooperation Working Group (ITRC). The ITRC was created out of the DOIT process, a cooperative effort initiated and supported by the Western Governors Association and federal agencies. GETE works with the ITRC to assist and facilitate their efforts to develop technology testing protocols and policy recommendations for expediting the use of new technologies.

2. Providing communications capability both among the participants and to the outside; that is, the environmental community including technology developers, users, regulators, project managers, and other stakeholders.

3. Building bridges between the environmental regulatory community and voluntary consensus standards organizations to further the acceptance of environmental technologies and products to both industry and the state regulatory community.

4. Identifying opportunities for synergism matching the cooperatively developed testing protocols with demonstrations of DOE-developed technologies.

5. Linking new or existing verification and certification program test evaluation activities with the interstate cooperative activities for the purpose of building confidence among the state regulators in the results of the certification and verification programs.

All of these activities mentioned above are underway or are in the process of being initiated. At this time, the ITRC is the focal point of much of the activity. It has the largest state participation; 26 states are directly participating, and a number of others are

\footnotetext{
${ }^{2}$ Ibid, p.4.

${ }^{3}$ Clyde Frank, Claire Sink, LeAnn Mynatt, Richard Rogers, and Andee Rappazzo, "Surviving the "Valley of Death': A Comparative Analysis," The Journal of Technology Transfer, (Spring-Summer 1996), 61-69.
} 
represented by organizations of states. In addition the ITRC has been operating successfully for about 18 months. GETE monitors the activities that are associated with reducing regulatory barriers to the introduction of new technologies.

Progress in FY96 activities included:

- Reviewing ITRC progress and participating in several of their task groups.

- Facilitating links among the participants in several interstate cooperative programs have been established. In addition, we have established Home Pages on the GNET World Wide Web Site for the ITRC and Rapid Commercialization Initiative (RCI) programs; this provides outreach to the broader communities that these projects must reach, including policy and regulatory decision makers in the participating states.

- Working with the American Society for Testing \& Material (ASTM), we have facilitated participation of ITRC members in the review and comment of draft standards for an Expedited Site Characterization (ESC) Guide. ESC is a methodology developed by the Characterization, Monitoring, and Sensor Technology (CMST) Focus Area. A provisional ASTM ESC Guide is projected to be issued by the end of 1996, and the final ASTM ESC Guide would be formally issued next summer according to the established ASTM standards development methods. ASTM Standards \& Guides are developed through a "consensus" process that involves stakeholders from all areas that are affected by the standard. This is a process that has been developed over the past 100 years and is widely utilized by industry. The ITRC will be looking at other standards development opportunities through ASTM during this fiscal year. The increased use of voluntary consensus standards will greatly reduce the regulatory and stakeholder resistance to the introduction of new technologies.

- Working with other agency programs we have assisted in linking several technology demonstrations with the work of the ITRC task groups. The object will be to make use of existing ITRC testing protocols or jointly develop test protocols for the technologies to be demonstrated. A few demonstrations have been selected by the ITRC for participation, and a number of other demonstration opportunities are being evaluated for possible participation. A number of the demonstration opportunities are associated with DOE sites and directly address the DOE-EM clean-up needs.

- The Consortium for Site Characterization Technologies (CSCT) through the Environmental Protection Agency (EPA) Environmental Technology Verification program will be working with members of the ITR.C in evaluating the performance of technologies undergoing verification tests. There are between 10 and 20 demonstrations planned for this fiscal year; the ITRC members will be participating on those projects that are consistent with the ITRC work schedule and of greatest interest to the states. The extent and nature of ITRC participation in the verification review process is being defined by the Accelerated Site Characterization working 
group. We will be helping both groups to support this effort to facilitate this joint cooperative activity. This state/federal regulatory cooperation will further strengthen the ability to obtain permitting on DOE sites of new technologies.

\section{Affiliates Program}

Another major step this year has been the development and launching of a National Affiliates Program. This program make it easier for companies to work with DOE technologists for short periods; in this case, up to 50 days a year. The Affiliates Program is a complement to the commercialization process of DOE-EM technologies. Companies can obtain assistance from highly-skilled DOE engineers and scientists with in-depth knowledge of a variety of specialized, unique DOE-developed technologies to solve environmental problems.

A pilot program began at Oak Ridge National Laboratory in February of this year. In July, the Idaho National Engineering Laboratory informed GETE that it will participate in the program and their pilot was launched in September. In late September, the Savannah River Site initiated their pilot. In addition, discussions and negotiations are underway with other facilities interested in participating in the program. Facilities that are interested include Argonne National Laboratory, Sandia National Laboratory, Pacific Northwest Laboratory, Los Alamos National Laboratory, Lawrence Berkeley Laboratory, and Lawrence Livermore National Laboratory.

Marketing efforts began, including a coordinated national effort, such as mass mailing. Brochures were designed and printed and are given out at participating laboratories, conferences, and meetings (see Appendix 1).

\section{Market Assessments}

GETE continues to research, summarize, and publish market data on GNET to bolster the efforts to commercialize DOE-EM environmental technologies. One comprehensive market study was recently delivered to METC. This study discussed Concrete Decontamination for the Decontamination and Decommissioning (D\&D) Focus Area. A second and on-going assessment explored the need for Containment Barriers for the Subsurface Contaminant Focus Area (see an executive summary of each in Appendix 2). GETE has also reviewed a number of Characterization, Monitoring; \& Sensor Technology Crosscutting (CMST) technologies for mini-market studies. Three of these assessments were provided to METC for approval of general content prior to proceeding. Comments have now been received and it is likely that these studies will be expanded in the coming year. (See Appendix 3 for examples of mini-market studies.) 


\section{Technology Brokering}

GETE's activities to broker DOE-EM technologies have involved working closely with a number of innovative technologies which are further along on the commercialization process. These brokering activities are needed, as the GETE experience has shown that often the resources required for successful commercialization may not be found with the company that holds the rights to the new technology. Therefore, GETE has sought to find both strategic and other partners whose contributions are vital to the commercialization process. These efforts, as might be expected, have centered around those technologies that are more fully developed.

In addition, GETE has found that this task includes the brokering of technology both inside and outside of DOE technology consumers. This has included promotion via various GETE outreach materials, both in hard copy and electronically. Using the relationships formed over the last two years, GETE is now in a position to introduce technologies undergoing demonstration at one site (Hanford, for example) to solve similar problems at a second site (Savannah River Site). GETE has discovered that it is in a unique position to interact with not only the Focus Areas, but also the Site Technology Coordination Groups to make these kind brokering activities occur. Linkages that are not occurring alone.

A new and exciting dimension to this activity involves the joining of technology packages to solve environmental problems. This full system approach has resulted in very positive initial feedback where GETE has become the catalyst for offering solutions to site problems with EM-50 developed technologies. One example of such efforts is the creation of a team that unites several independently developed but very complementary technologies to decontaminate concrete. A second example of this is GETE's work with the Saint Louis Formerly Utilized Sites Remedial Action Program (FUSRAP), where a full package of DOE EM-50 technologies is being considered for site remediation. These models started in Year 2 and will be completed in Year 3.

Other activities include publicizing technologies and partnerships between companies and DOE-EM via GNET and the GETE Update.

An on-line Who's Who Directory highlighting major environmental companies was completed and updated in FY96, and a survey on the needs of participants is underway.

\section{Business Planning and Startup}

GETE continues to review business plans for small- and medium-sized companies. Business plans are reviewed to understand the situation of the company and its future plans. For those companies that have business or commercialization plans, GETE is able to give an opinion as to the completeness of these plans and to point out what might have been overlooked. 
GETE accomplishes this activity by using the company's business plan to complete the GETE screening questionnaire (see Appendix 4). This questionnaire, developed over the last two years is, we believe, an excellent way to get to understand the company and determine how GETE can assist the company in the commercialization process. We have completed this questionnaire on over a dozen technologies and the response has been very favorable and the comments that we have received are that the process has made the company aware of areas that they have not considered.

If a company has no business plan or a very weak one, we now have the mechanism in place to introduce them to the EM-50 funded Dawnbreaker program. Dawnbreaker has an intense nine month program to help a company develop both a business plan and professional presentation. Their efforts culminate in a presentation to investors. GETE will then commence further assistance and work with those companies of highest Focus Area interest.

For those companies that do not have a business plan, GETE has provided a sample outline in which to follow. This outline (see Appendix 5), contains what we believe are the required elements for a successful business plan. It is also used as a checklist by GETE personnel in evaluating the business plan for omissions.

GETE personnel realize that these activities constitute a contact sport. Therefore, GETE personnel find that once the GETE questionnaire is filled out and evaluated by the company, an in-person visit is required. This ensures that the company and the GETE personnel can develop a relationship of cooperation and mutual trust. During these sessions, goals and strategies are discussed, objectives and timelines defined, and shortcomings identified. All of these elements are then written up in a GETE workplan (see Appendix 6) which is evaluated together with concerned parties to ensure that GETE is conducting appropriate activities. This workplan is likely to be modified as conditions change, and will be updated periodically.

GETE continues to research, identify, and summarize business startup and planning information for review and placement on GNET. This section is located under the Market Section of GNET, under the sub-heading of Business and Finance. It contains a wealth of information for the small- and medium-sized companies and includes a business incubator section for start-up companies. Other sources of information are listed and linked, making the site a valuable resource for entrepreneurs. According to GNET's most recent statistical reports, the Market Section of GNET was visited by 4,991 World Wide Web users in September.

\section{Financial Development}

GETE continues to review financial plans as part of the business plan review process. It has been GETE's experience that most of the business plans reviewed call for an infusion 
of capital. Often, however, the amounts of capital sought by the business plans have not: been well thought out.

In order to acquire capital, a company generally must give up a percentage of managerial control to its investors. This is based on the projected value of the company. In order to define how much capital can be acquired and at what cost, GETE has developed a work sheet. This tool can help the company estimate projected earnings in order to determine a fair market value. This enables a fledgling company to determine how much capital they can request, and thus, how much control it will likely be asked to yield. This "raising money" valuation questionnaire remains under development, but has already been used on several occasions with varied results.

In once case, completing the work sheet resulted in a company choosing not to seek outside investment because it would have to give up a greater share of the company. Specifically, GETE conducted an independent and thorough review of the company. Although the company had invested almost $\$ 3$ million to set up an independent company around a new technology, the actual value of the company projected out for the next five years was less than $\$ 600,000$. This caused the company to change its strategy and not look for an investment partner, but rather continue to self-finance the project in order to eventually recover its investment over the next ten years.

In another case, after working with GETE, a company was able to investigate the possibilities for additional money after discussions demonstrated that the company could ask for this additional capital without giving up a larger percentage of company ownership.

In other related matters, GETE continues discussions within METC concerning the Environmental Technologies Catalytic Initiative. In August 1996 a draft report, "Catalytic Initiatives, Seeking Innovative Financing Approaches for Environmental Technologies" was submitted (see Appendix 7).

This document discusses the concept of Catalytic Investment Initiatives designed to accelerate the development of increased levels of funding to support early stage developmental companies seeking to commercialize environmental technologies. A Catalytic Investment Initiative is a leveraging mechanism that utilizes public/private partnering to stimulate increased capital availability for investment in small businesses. The prospective Catalytic Investment Initiatives described in this document are primarily targeted at stimulating investment capital consolidation for financing the commercialization of environmental technologies, and in particular, to stimulate accelerated commercialization of those technologies developed by the DOE that are being introduced into the private sector by new or developing companies.

Since the lack of financial resources continues to be a significant problem for companies attempting to bring new and innovative technologies to market, it is anticipated that the Catalytic Initiative will be explored jointly by METC and GETE in the coming year. 
In order to share more information and assistance to stakeholders and the public, GETE continues to research, identify, and summarize business financial and planning information for review with commercial partners and placement on GNET. This section is located under the Market Section of GNET, under the sub-heading of Business and Finance.

\section{Strategic Partnerships}

GETE has continued to meet with stakeholders to facilitate the commercialization of DOE-EM environmental technologies. This year, a number of discussions in various organizations both within and outside the DOE complex have been underway. Among these discussions and results are included within the following:

\section{EM-54 and Stakeholders}

With agreement with EM-50, GETE facilitated a meeting of all participants in DOE's commercialization program which included GETE, Dawnbreaker, Mohawk, Office of Technology Alliance, California Environmental Enterprise, Northeast Environmental \& Waste Management Enterprise, National Institute for Environmental Renewal and several Focus Area managers. The meeting established the basis for meeting EM-54's national program goals and the roles and responsibilities of the participating organizations.

\section{Site Technology Coordination Group (STCG)}

The Site Technology Coordination Groups (STCGs) were established by DOE in 1994 as part of an overall effort to consolidate environmental restoration/waste management technology needs across the country. The STCGs were developed to enhance communications between environmental management programs, state and federal regulators and other stakeholders on technology development activities within and across the DOE complex. GETE began participating with the Oak Ridge STCG in FY96 to assist in formally developing the STCG's methodologies to successfully deploy DOE technologies. By bringing the commercialization aspects, technology developers' concerns and restrictions to the table improvement in information flow and deployment time can be achieved. It is anticipated that GETE can assist other DOE sites with their deployment of technologies where appropriate. Since each site operates differently but has the same goals, facilitation expertise in the deployment area may provide added value to those sites' deployment efforts.

\section{EM-50 and the U.S. Army}

With agreement with EM-50, GETE facilitated a partnership between the U.S. Army and DOE at the Aberdeen Site in Maryland. GETE assisted in the creation of the Center for NBC Environmental Technologies which will focus on the potential environmental impacts from the destruction of biological and chemical weapons. This partnership will allow the Center to review DOE technologies for application to Department of Defense (DOD) environmental problems. It also provides a forum for GETE to review DOD technologies and their potential application for solving DOE environmental problems. 


\section{National Association of State Development Agencies (NASDA)}

Working with GETE's NASDA partner, GETE facilitated a new approach regarding the use of technologies for the states to implement. Although each state has an economic development group, an environmental group, and a regulatory group, communication between them has not been successful. As a result, when the private sector attempts to initiate a new technology, the roles, responsibilities, and internal communications capacities of various groups begin to differ from state to state. In order to assist industry and the state, GETE recommended that NASDA act as the focal point linking all the states, and have each state agree on a protocol for internal use. Once established, GETE will assist NASDA and the states via GNET to reach the private sector. NASDA has met with states and has received agreement by many to consider the development of such a protocol. GETE will continue to facilitate this activity and provide GNET to those states that chose to participate.

\section{Westinghouse Savannah River Company MOU}

Signed a Memorandum of Understanding (MOU) with the Westinghouse Savannah River Company (WSRC) to facilitate the exchange of information on environmental technologies (see Appendix 8). This MOU recognized that GETE and WSRC will work to bring technology developers and commercial activities together to solve common problems and commercialize technologies.

\section{INFORMATION}

\section{Global Network for Environmental Technology}

The Global Network of Environment and Technology (GNET) (changed from the original name to better describe its role) has progressed considerably. Formerly a communication system which enabled specific users to share information and messages to others in the environmental technology community, GNET has changed and expanded to a robust, internationally-accessible, award-winning DOE technology information center. Of greater importance, GNET has made significant steps in addressing its goal to bring together DOE technologies and industry for commercialization.

A significant step was the development of centralized sites for each Focus Area on GNET. These sites were created for several reasons. First, they clearly addressed the spirit of the GETE Cooperative Agreement which called upon GNET to "contain and provide access to the following database sections with respect to DOE-developed EM technologies." "The initial GNET concept had been to highlight DOE technologies together, where industry could learn more about innovative technologies in one place. However, this approach did not address accurately DOE-EM's framework and coordination efforts. Starting in 1994, DOE-EM had begun establishing Focus Areas to address its most pressing environmental restoration and waste management problems. It

\footnotetext{
${ }^{4}$ U.S. Department of Energy, page 2.
} 
became clear that a site section for each Focus Area would best reflect the news, reports, progress, and technologies in each.

Second, centralizing the Focus Areas helped make them more accessible by stakeholders. Each Focus Area has individual home page information, but they can be difficult to find. Moreover, they are not centralized in areas where many stakeholders, such as industry, academia, non-governmental organizations, and others might investigate. GNET, however, has been developed to attract those outside DOE to learn about DOE technologies.

Specialized interactive sections for each Focus and Crosscutting Areas include (see Appendix 9):

Technologies - Descriptions of Focus and Crosscutting Areas-related technologies from information received from DOE publications.

Forum - An on-line bulletin board focused upon each Focus and Crosscutting Area.

Homepage - World Wide Web site developed by each Focus and Crosscutting Area.

Intranet, or Virtual Private Network (VPN) - Password-protected World Wide Web site dedicated to Focus and Crosscutting Area users only. Two have been established. Others will be installed in FY97.

Content sections in each Focus and Crosscutting Areas' site include:

News - Updated weekly abstracts of articles published in international, national, and trade publications focused upon topics on each Focus and Crosscutting Area. Archives of previous articles are also included.

GETE Update - A monthly newsletter published by GETE highlighting DOE-EM environmental technologies, commercialization, progress in the project, etc. To find out more about the GETE Update, see page 21.

Journals - Free, regularly updated, on-line journals focusing upon each Focus and Crosscutting Area topics. For instance, journals available via the D\&D Site includes Atomic Energy Insight, Association of Radioactive Metal Recyclers Newsletter, Official Journal of the Radiation Research Society, Radioactive Waste Bulletin, and the Green Business Letter.

Links - Recent reports, identified technology needs, and other information located elsewhere on the World Wide Web specific to each Focus and Crosscutting Area. 
Listserves - Information on listserves associated with data related to each Focus and Crosscutting Area, including instructions on subscribing. Listserves provide updated news and comments distributed via e-mail on specific topics.

The development of GNET has grown with the Internet. A report published by Internet. World found that eight to 43 million people worldwide use the Internet. Furthermore, an American Internet User Survey undertaken by FIND/SVP shows that the use of the Web is growing rapidly and could soon become as popular as e-mail.

\section{American Internet User Survey}

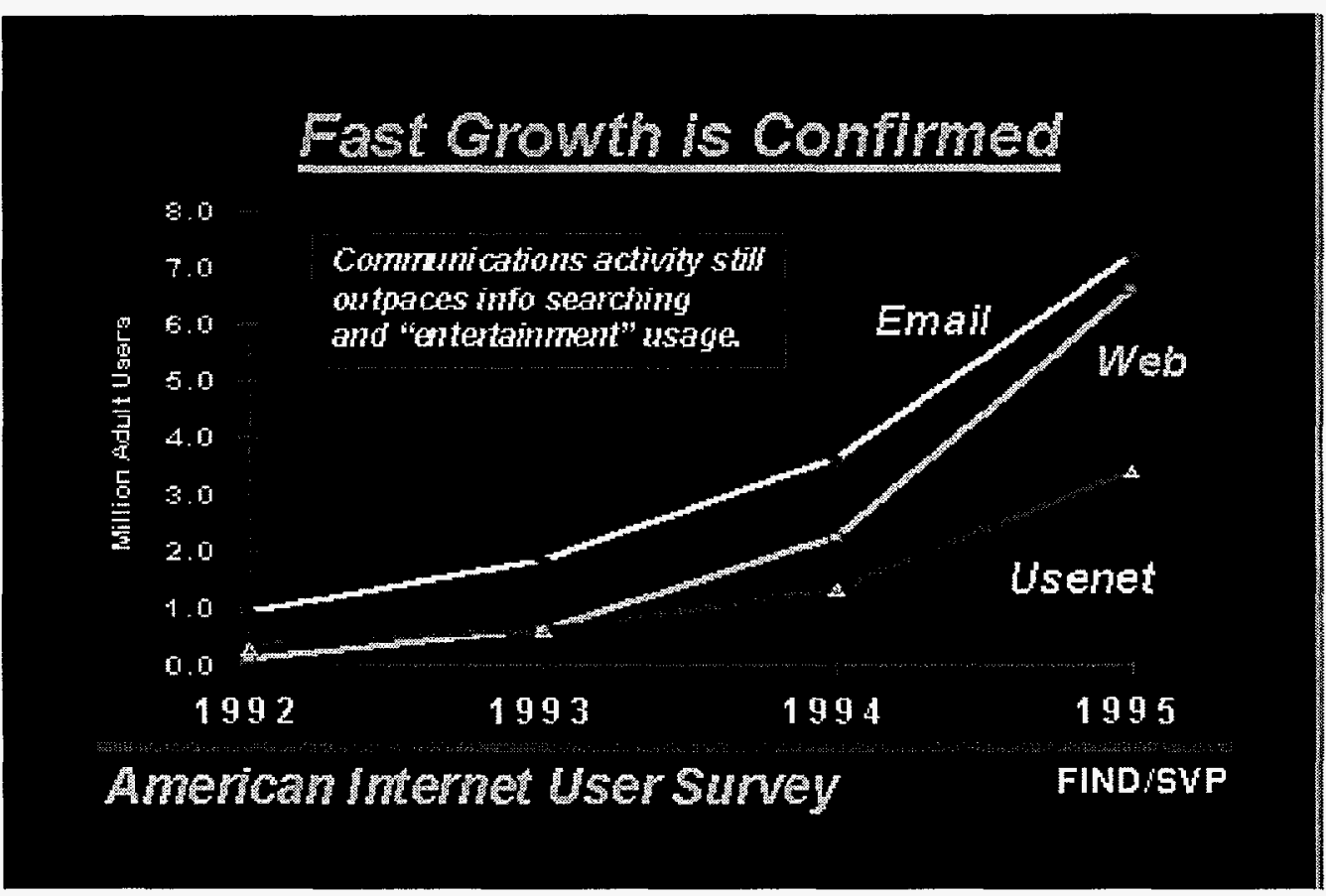

Figure 2.0: American Internet User Survey

In order to measure its growth, a statistical package was installed to monitor the GNET community. It continues to be modified and analyzed to identify the needs and key interest areas of the user community. It reports that active individual users of GNET now exceed 10,000 per month. It is likely that number is a low estimate, however, due to the Internet-wide challenge of identifying users.

Such growth was caused because of several reasons. First is clearly due to the growth of the Internet itself. Second is that GNET content has remained important. Technical information is only a portion of GNET. It was clear that the site needed more data to attract a sizable, targeted audience.

When GNET was updated in FY96, a daily news feed was included. Each day, fresh abstracts on articles regarding environment and technology news from leading 
newspapers and periodicals are offered. The Daily Regulatory Reporter provides daily rulemaking information, documents, press releases, and other data for environmental health and safety professionals. Documents such as recently-released reports and studies by the Department of Energy and outside researchers are featured in prominent sites on GNET. The goal of these changes has been to address representatives of business, academia, and various communities which could benefit the overall goal of GETE to commercialize innovative DOE-developed technologies.

GNET's monthly statistics demonstrate that these changes have made dramatic, positive changes in audience interest. The graph below demonstrates the increased number of visits following changes to GNET.

\section{GNET Individual Users Growth Graph (May to Sept. 1996)}

\begin{tabular}{|l|c|c|c|}
\hline \multicolumn{3}{|c|}{ MONTH TOTAL INDIVIDUAL USERS } & N/A \\
\hline May' 96 & 3,671 & $-9 \%$ \\
\hline June' '96 & 3,354 & & $67 \%$ \\
\hline *July' 96 & 5,616 & & $45 \%$ \\
\hline **August ' 96 & 8,139 & & $3 \%$ \\
\hline September'96 & 8,350 & & \\
\hline
\end{tabular}

*GNET Site Re-Design Occurs

${ }^{\star *}$ GNET Advertising Begins

\section{GNET Individual Users- Summer ' 96}

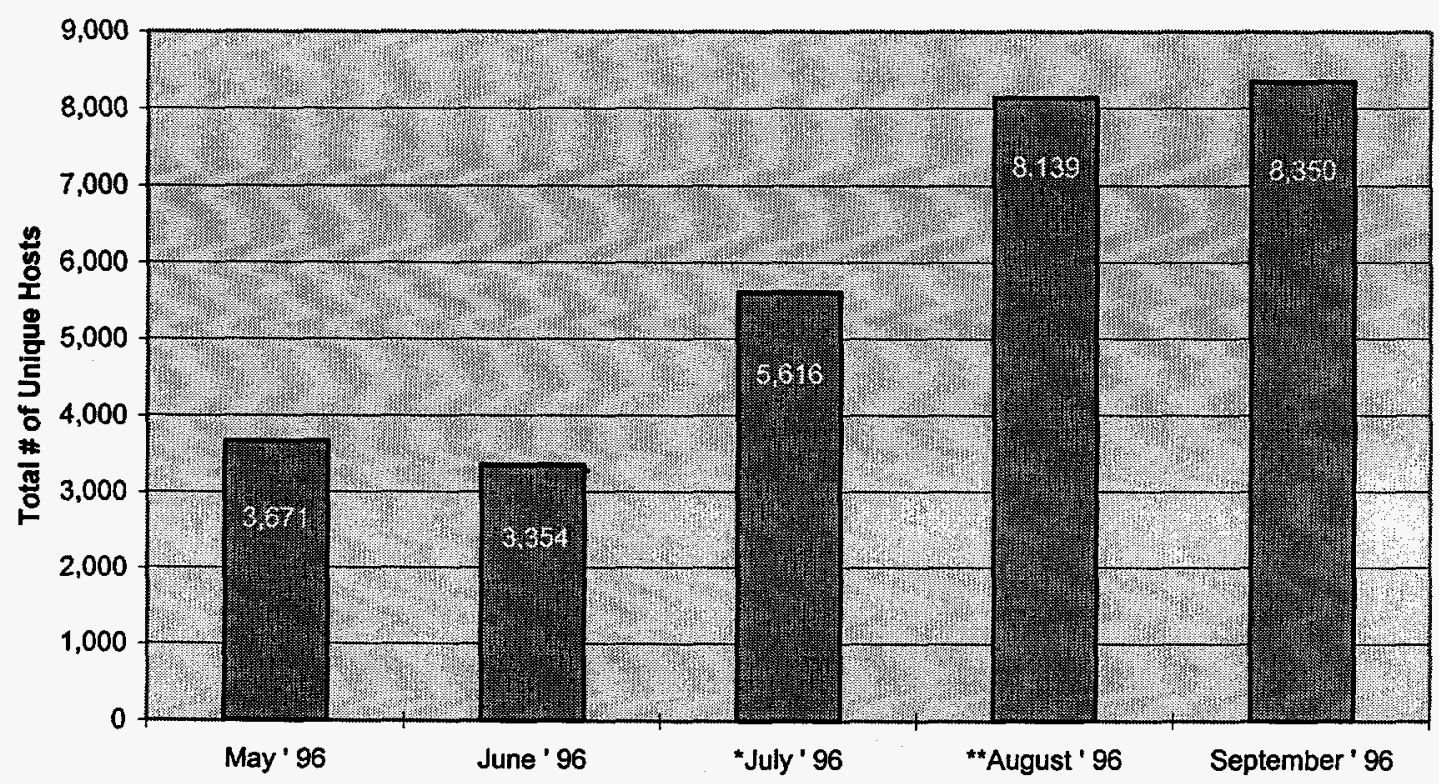

Figure 3.0 - GNET Individual Users Growth Graph (May to Sept. 1996) 
In addition, GNET has won a number of awards this year. They include:

\section{The Gold Tiger Award - March, 1996}

GNET was awarded the Gold Tiger award in March, 1996. Wordclass gives awards to the "best of the best" global business sites. Award recipients are chosen based on their usefulness to world commerce, timeliness, ease of use and information presentations. An award as a business site supports the claim that GNET is reaching industry by providing services that benefit users in their decision-making processes for remediation technologies.

\section{The New World Award - July, 1996}

The New World Award is given to recognize excellence in commercial web sites. "These awards are for solid, attractive business sites that do the job they are supposed to and look good doing it. For businesses planning on making the leap into cyber marketing, this is where to see how it's done," said Marketing Associates, Inc. This award provides important recognition to the site that will improve efforts toward sustainability.

\section{Coolest Environmental Business and Technology Site - $19 \overline{96}$}

GNET was named as a "Coolest Environmental Business and Technology Site." EcoNetwork honors the "Coolest Environmental 100!" sites on the Internet. This is a special selection of socially- and environmentally-active enterprises, entrepreneurs, organizations, investors and professionals on the World Wide Web.

\section{Database Integration}

Several databases including Vendor Facts, Envirotrade, DOE Information for Decisions (IFD) and Vendor Information System for Innovative Treatment Technologies (VISITT) are being reviewed for incorporation/links. The plan for information exchange with DOE's system has been agreed to with the EM-54 Office Director. However, most integration will occur in FY97.

An industry database is complete. This will be integrated with other external databases as they are identified. The database will be used in support of market assessment efforts.

\section{GNET Structure and Tools}

A listserve has been established to distribute "What's New" and other featured items to registered users as we build the community towards sustainability.

The C3 First Class system was upgraded to a newer version but the entire First Class system will be phased out in FY97. 
A fax on-demand system has been installed. It allows users to receive faxes via telephone. By calling the system, users are given a choice of options for ordering documents. This system will be used to send out free information on DOE technologies. This will provide "full circle service" to DOE stakeholders. Public announcement and access will commence in FY97.

The underlying database engine integration is near completion to allow full Application Program Interface (API) interfacing at better speeds than Common Gateway Interface (CGI) scripting.

A technology database has been built as a Structured Query Language (SQL) application for the WWW. This will improve speed, updating costs and QA/QC on technology presentations. Industry will be capable of posting their technology information without GETE data input.

\section{OUTREACH}

\section{Outreach Materials}

The Cooperative Agreement states that this task is to "provide outreach materials in a monthly Clearinghouse Newsletter. The participant shall develop, circulate, and update a monthly Clearinghouse Newsletter which shall include, but not necessarily be limited to, information concerning commercialization of DOE-developed EM technologies, brochures, and articles."

This year, GETE began publishing a monthly printed and on-line newsletter, the GETE Update (see Appendix 10). Previously, a one-page progress update and distributed at DOE was prepared on a biweekly basis. Articles this year have included:

"Market Trends"

"ISO 14000: A Paradigm Shift for the Technology Sector"

"Prospects for Environmental Market in the "90s"

"Vapor Detector Developers "Sniffing" Their Way to Marketplace Success With Help of Department of Energy"

"Innovation"

"Bioremediation: INEL's Innovative Cleanup Approach"

"Encouraging Innovation through Environmental Policy"

"ISOTRON's Electronic "Tools"

"DOE: Sharing Information/Cleaning Sites"

"Defining "The End" of Technology Testing: Need to Develop a Roadmap to

Certification Identified"

"EM-50 Technologies Showcased on GNET"

${ }^{5}$ Ibid, p. 7. 
"DOE Affiliates Program to Ease Access to Environmental S'olutions for Industry" "Doing Business with DOE"

"A NIER Success: The Carbondale Rail Yard Project"

"DOE Procurement: Procedure and Points of Contact"

"DOE Green Books Show Promise for the Future"

"1997 Defense Budget Authorization Holds the Line for DOE Technology Development"

“International Interest in DOE's Environmental Technologies at World's Largest

Industrial Fair"

"High Energy Corona Reactor Gets High Marks"

"Environmental Market Holds Promise for Chemical Sensor Systems"

"DOE/DOD Partnership Addresses Environmental Technology Needs"

"Promising Monitoring Technology Goes for the Gold at 1996 Olympics"

"ISO 14000: Impacts for the DOE Office of Environmental Management"

"Asbestos Rendered Harmless at Hanford Site by Innovative Technology"

"Spectrum '96 Shows Off Hanford and Innovative Technologies in Seattle"

"Report on Weapons Complex Cleanup Estimates \$265 Billion Over 75 Years"

This newsletter is mailed monthly to approximately 500 readers. Many are with DOE and private industry. Key DOE recipients are given bulk copies each month so they can. be distributed. Emphasis on distribution, however, is upon GNET, since electronic publishing is much more cost-effective and can reach targeted readers more easily. Improvements are scheduled for FY 97.

Brochures were designed and printed for:

GNET

The Affiliates Program

The Oak Ridge Affiliates Program

The Idaho National Engineering Laboratory Affiliates Program

ISO 14000 Information

These brochures (see Appendix 2) are distributed at conferences, meetings, those seeking information via mail, etc.

\section{Public Participation}

Under Public Participation activities, GETE continues to assist stakeholders with their relations with DOE-EM and teaching them about innovative environmental technologies. Several key elements of this task included developing an Intellectual Property Plan, a Fairness of Opportunity Plan, and a Conflict of Interest Plan. These plans have been completed and have been implemented.

GETE participated in a number of conferences and workshops in FY96. A portable booth was designed and built to promote GETE and its related projects and was on display at a number of conferences. 
Decisions on which conferences to participate with were based on reaching as many members in a targeted audience as possible (i.e., representatives of business, potential customers for DOE-EM technologies, environmental problem-holders in the public and private sectors).

Conferences GETE participated in this past year included:

\section{Environmental Technology Development Through Industry Partnership Morgantown, West Virginia October 1995}

GETE took part with this meeting, which was sponsored by the Morgantown Energy Technology Center and was developed to bring together industry and DOE technology developers. GETE participated in a poster session, and published a paper in the proceedings titled, "The GETE Approach to Facilitating the Commercialization and Use of DOE-Developed Environmental Technologies."

\section{Oak Ridge Model Conference - Oak Ridge, Tennessee}

October 1995

GETE participated in this conference, in which more than 800 representatives of the DOE complex and others devoted to the development and use of new technologies at DOE sites.

\section{Environmental Opportunities in Central and Eastern Europe and the New} Independent States - Washington, D.C.

November 1995

GETE hosted this conference that invited government officials and environmental business executives to discuss opportunities for the public and private sectors to work together to remediate environmental problems using innovative technologies in Central and Eastern Europe and the New Independent States.

\section{Environmental Partnership Initiative: U.S./Canada Connection - Seattle,} Washington

January 1996

GETE was invited to take part this is conference, in which over 100 environmental companies attended. GETE provided a display which highlighted GNET and the GETE Update, both of which were well-received.

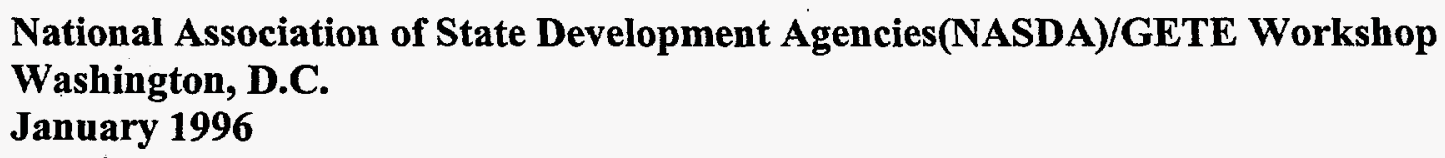
states. The purpose of the workshop was to demonstrate the GNET system, to discuss the business assistance programs of GETE, and to provide a conduit to the innovative technologies supported by the DOE. 
Environmental Business '96

Washington, D.C.

April 1996

GETE provided information and GNET demonstrations at this annual summit meeting for environmental business leaders.

\section{Hannover Messe '96/PARTNER USA - Hannover, Germany April 1996}

The world's largest industry trade show in Hannover, Germany this year focused upon environmental technology. A short article on GETE was published in a German magazine, Techniches Review, which resulted in eight other media requests on the program.

National Association of State Development Agencies -

Washington, D.C.

April 1996

GETE participated in this NASDA sponsored conference. Demonstrations of GNET were performed. In addition, discussions with the participating state representatives were held.

Weapons Complex Waste Management and Cleanup: Fostering the Needed Partnerships, Doing the Necessary Science to Support Technology Development, Commercialization, Deployment

Phoenix, Arizona

April-May 1996

This conference showed off new initiatives between DOE's EM Office of Science and Technology and Environmental Restoration and the Operations Office to accelerate the deployment of environmental remediation technologies; the progress and accomplishments of the DOIT Advisory Committee; and other activities. GETE provided GNET demonstrations, participated in a number of meetings and presented the paper "Supporting the Development of Alliances with Industry to Accelerate the Acquisition of Innovative Technologies."

DOE's Environmental Cleanup: Coping with the Cost Squeeze Washington, D.C.

May 1996

GETE presented a paper with the theme "Coping with the Cost Squeeze" which emphasized the role of GETE with DOE and the private sector.

Hazardous Waste Action Coalition's 1996 Annual Meeting - Washington, D.C. June 1996

This meeting was attended by various representatives of the government and private sector to discuss, "Teaming for Environmental Solutions" and the future of cleanup activities. GETE provided continuous demonstrations of GNET. 
National Association of Environmental Professionals $21^{\text {st }}$ Annual Conference Houston, Texas

June 1996

GETE presented a paper about exporting innovative technologies at this conference, the theme of which was, "Innovative Technologies: Will They Prevail in the Global Environmental Marketplace?”

Environet Conference - Cambridge, Massachusetts

July 1996

GETE presented a presentation on GNET at this conference.

\section{2nd Annual Richland Operations Office Conference - Richland, Washington} August 1996

GETE attended this conference, in which the theme was deployment of innovative technology and privatization at Hanford.

\section{Spectrum ' 96 - Seattle, Washington August 1996}

This conference centered upon communicating information on the progress and accomplishments of nuclear and hazardous waste remediation accomplishments. GETE held meetings at the conference with various focus group members on a wide variety of issues. In addition, GETE provided ongoing demonstrations of GNET.

\section{Eighth Annual Weapons Complex Monitor Decisionmakers' Forum} Amelia Island Plantation, Florida

September 1996

GETE participated in this conference which featured DOE-EM's 10-year vision. Numerous discussions were held with the DOE problem holders.

\section{$\underline{\text { ISO } 14000}$}

This year, GETE identified and reviewed ISO 14000 as a key issue for the EM program. ISO 14000 is a series of voluntary environmental standards and guideline documents in the areas of environmental management systems, environmental audits, environmental performance evaluations (EPE), environmental labeling and claims, and environmental life cycle (ELC) assessment. The ISO 14000 standards could be a benefit or a potential barrier for DOE-EM.

The ISO 14001 standard was finalized by the International Organization for Standardization on September 1, 1996. The U.S. version of the standards will be adopted soon. Many U.S. organizations have already taken steps to utilize the standards in their existing framework. The guideline documents in the ISO 14000 series, including EPE and ELC, are being formulated, and continued input from the DOE-EM community is critical at this stage. 
The ISO 14001 standards will certainly have an impact on the environmental remediation industry and the DOE complex. While the ISO 14001 standard is a relatively short document, its application is extremely complex and has wide-ranging impacts on all of DOE. In developing a strategy for organizational awareness building within EM-50, it is essential to include inputs from all viewpoints in order to maximize the benefits of the standards to EM-50. It is only through a holistic approach to the standards that EM-50 will realize their full potential.

In FY96, GETE has continued to monitor the nationwide progression, introduction, and modifications to the ISO 14000 environmental standards. GETE has participated in the U.S. TAG meetings on the standards and continues to gather information from all interested stakeholders. This information will be synthesized into an analysis of how the standards will impact DOE-EM.

A conference in Philadelphia was conducted to gather information on the standards, their implementation and to enhance awareness and create a dialogue. A METC representative presented a DOE perspective.

Strategic partnerships are being established to ensure that DOE gets the most accurate information possible. GETF has partnered with ANSI, the U.S. representative to the ISO, to provide ISO 14000 information to DOE through the IIS On-Line system. Partnership discussions are also being held with CEEM, the premier ISO 14000 newsletter; Irwin Publishing, the premier ISO 9000 newsletter and the developer of a new ISO 14000 newsletter; the PETE community college network, and other groups to provide content information.

A summary two hour version of ISO training will be offered in the form of two briefings, one at DOE Headquarters and one at METC. These briefing will provide an introductory overview of the ISO 14001 standard and will allow for a Q\&A period.

Regional workshops were held at the Florida Environmental Expo and at a conference in Boston. Both the State of Florida and EPA Region 1 in Boston are at the forefront of the awareness, acceptance, and utilization of the standards. These highly successful workshops included an introductory awareness session on the standard as well as incorporating the viewpoints of all relevant stakeholders. These sessions served to disseminate information about ISO 14000 and its import on environmental technologies, as well as a means to gather information and perspectives from the leading states and regions on the standards. A general awareness session was presented at the DOE Superfund conference. 


\section{Conclusion}

GETE has progressed considerably during FY96. Progress has occurred within all three major elements of the program: Business Assistance, Information, and Outreach. With the advent of DOE-EM's "10 Year Plan," GETE is refocusing portions of the program to be responsive to DOE-EM's near-term needs. GETE will strive to enhance the deployment initiatives in order to bring proven and stakeholder acceptable technologies to the sites. GETE will continue to develop partnerships with the private sector and assist the Focus and Crosscutting Areas in the commercialization and deployment of innovative technologies. 


\section{References}

U.S. Department of Energy. "Environmental Management Technology Leveraging Initiative," Amendment M002. Cooperative Agreement Number DE-FC21-94MC31179. December 8, 1994: 1-7.

Clyde Frank, Claire Sink, LeAnn Mynatt, Richard Rogers, and Andee Rappazzo. "Surviving the 'Valley of Death': A Comparative Analysis." The Journal of Technology Transfer. (Spring-Summer 1996): 61-69. 


\section{List of Acronyms}

ANSI: $\quad$ American North Standards Institute

API: $\quad$ Application Program Interface

ASTM: $\quad$ American Society for Testing and Material

CGI: $\quad$ Common Gateway Interface

DOE: $\quad$ United States Department of Energy

CMST: Characterization, Monitoring, and Sensor Technology Focus Area

CSCT: Consortium for Site Characterization Technologies

D\&D: Decontamination \& Decommissioning Focus Area

DOD: $\quad$ United States Department of Defense

DOIT: Develop On-Site Innovative Technologies

ELC: $\quad$ Environmental Life Cycle

EM: $\quad$ United States Department of Energy Office of Environmental

Management

EPA: United States Environmental Protection Agency

EPE: Environmental Performance Evaluation

ESC: $\quad$ Expedited Site Characterization Guide

FUSRAP: $\quad$ Formerly Utilized Sites Remedial Action Program

GETE: Global Environmental Technology Enterprise

GNET: Global Network for Environment and Technology

IFD: $\quad$ Information for Decisions

IIS: $\quad$ ANSI/GETF ISO 14000 Integrated Solutions TM

ISO: International Standardization Organization

ITRC: $\quad$ Interstate Technology and Regulatory Cooperation Working Group 
METC: $\quad$ Morgantown Energy Technology Center

MOU: $\quad$ Memorandum of Understanding

NASDA: National Association of State Development Agencies

OST: $\quad$ United States Department of Energy EM's Office of Science \& Technology

PETE: $\quad$ Partnership for Environmental Technology Education

POC: $\quad$ Point of Contact

RCI: $\quad$ Rapid Commercialization Initiative

SQL: $\quad$ Structured Query Language

STCG: $\quad$ Site Technology Coordination Group

TAG: $\quad$ Technical Advisory Group

VISITT: Vendor Information System for Innovative Treatment Technologies

VPN: $\quad$ Virtual Private Network

WWW: $\quad$ World Wide Web 
APPENDIX 1

GETE BROCHURES 


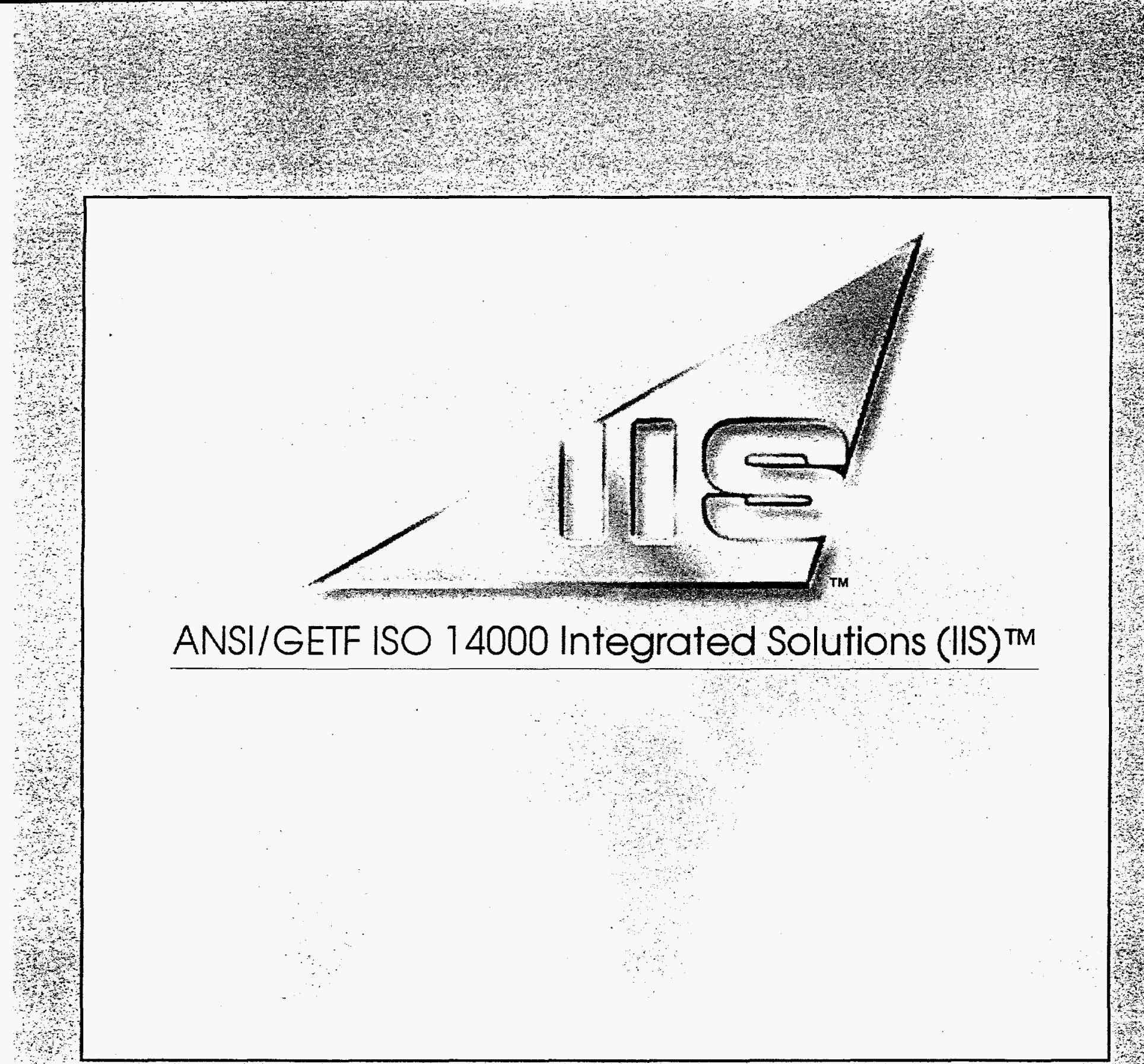

iSO $14000-A$ new approach to environmental protection in organizations. ISO 14000 relies on voluntary initiative to establish the foundation for a consistent and rational application of resources and management know-how to environmental obligation and challenges. It merges elements of recent public and private initiatives that encourage voluntary commitments and programs. In fact, ISO 14000 goes two steps further. It defines the operational framework to fulfill those commitments and provides for third party verification to give a wholly new level of credibility to voluntary action. ISO 14000 has the potential to revolutionize environmental pro tection as we have known it in the last quarfer century.?

Joe Cascio, Chairman, U.S. Technical Advisory Group to ISO TC207 


\section{ANSI/GETF ISO 14000 Integrated Solutions (IIS)}

ANSI/GETF ISO 14000 Integrated Solutions (IIS) is the product of a collaborative partnership between the American National Standards Institute (ANSI) and the Global Environment \& Technology Foundation (GETF). Developed out of the need to educate, train, and inform American industry, government, and non-governmental organizations about the changing dynamics of international environmental management standards, IIS brings together the talents of ANSI and GETF to fulfill these needs through training, conferencing, on-line information services, and publications.

ANSI facilitates the U.S. voluntary standards system, operates the Environmental Management Standards (EMS) National Accreditation Program, and is the officially recognized U.S. representative to the International Organization for Standardization (ISO) in Geneva, Switzerland. GETF is a non-profit foundation committed to facilitating the cooperative integration of enterprise, tech nology, and the environment into sustainable systems in the United States and abroad.

Together, these two organizations bring the depth, experience, and extensive networks necessary to provide IIS with the authority and integrity needed to accelerate the environmental paradigm shift required for competitiveness in the international marketplace.

\section{VISION}

To raise competitiveness, improve environmental protection, and encourage an environmental ethic by assisting public and private sector organizations to leverage the ISO 14000 standards.

MISSION

To accelerate the dissemination of the $15 O$ 14000 message to the largest number of potential beneficiaries.

\section{GOAL}

To make ANSI/GETF ISO 14000 Integrated Solutions (IIS) the premier repository, disseminator, and facilitator of ISO 14000 information in the United States. 


\section{ANSI/GETF ISO 14000 Integrated Solutions (IIS)}

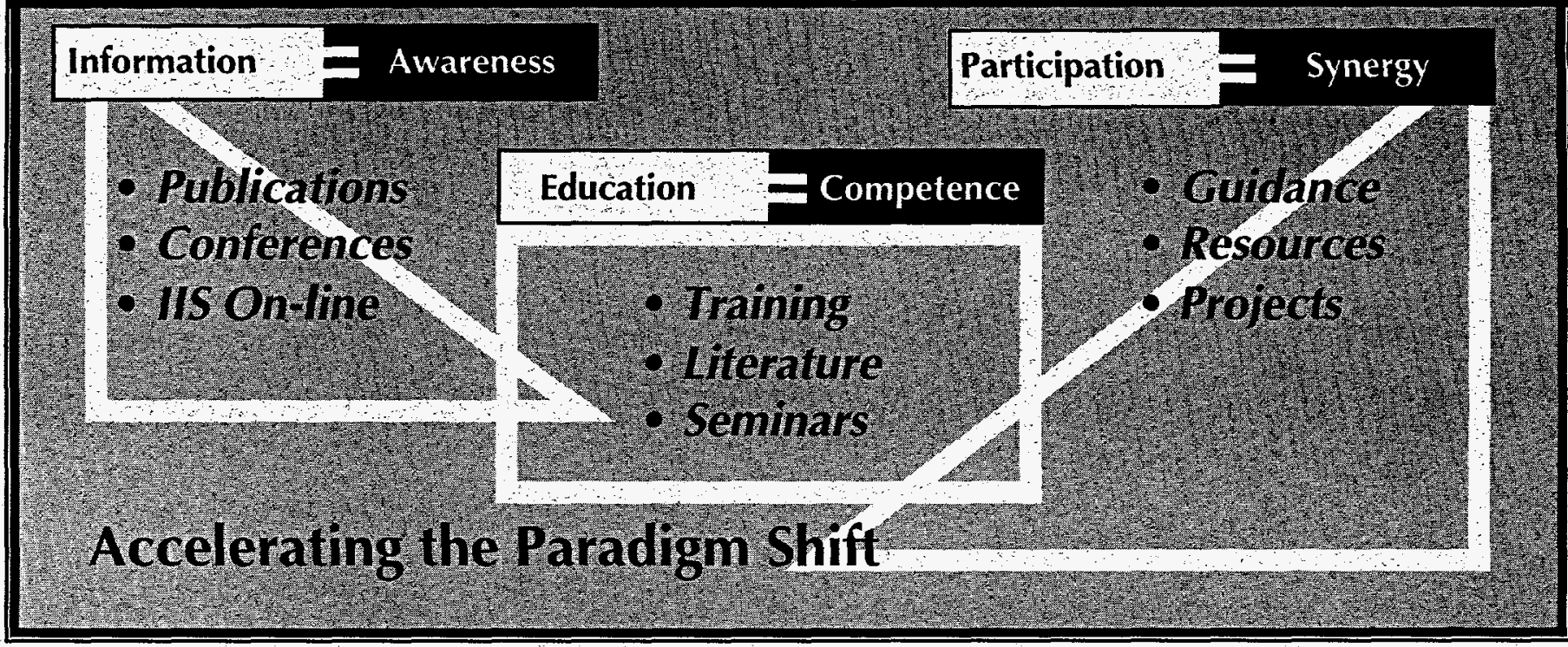

\section{IIS ACTIVITIES}

\section{Education \& Training Services}

IIS offers a variety of high quality, expert training courses which are customized, current, and relevant to the needs of each seminar participant. Training sessions provide case study activities, winning strategies for implementing ISO 14000 , and opportunities to solve common problems.

\section{Conferencing Services}

IIS brings a strong, experienced, and professional team of conference and project management specialists to meet the challenge of organizing and facilitating successful ISO 14000 conferences. Each conference organized by IIS will be tailored to the individual needs of the participants.

\section{IIS On-Line}

IIS On-Line is a state-of-the-art World Wide Web presence that supports the activities of IIS by providing access to complete and comprehensive information, tools, forums, individuals and organizations that make up the ISO 14000 community.

\section{Publications}

Recognizing that not everyone can utilize an On-Line system to access information, IIS is developing hard copy materials and publications that offer various levels of value-added content, resources, and capabilities to the ISO 14000 community. 
1 ISO 14000 can be used by organizations to better manage their environmental affairs and to show a commitment to environmental protection.

2 Evidence of conformance to ISO 14000 may factor into alternative regulatory relief programs, the exercise of prosecutorial and sentencing discretion, and into government consent decrees and other legal instruments.

3 ISO 14000 could become a test of standard commercial practice in courts of law.

4 ISO 14000 may become a condition of some customer/supplier transactions, especially in Europe and with the U.S. Government. Within the U.S.

Government, the EPA, DOD, DOE and other agencies have taken an active interest in these standards.

5 As a factor in multilateral trade agreements, the ISO 14000 standard might be used to gauge whether governments are making serious efforts to improve the environmental situation within their countries.

To participate in upcoming 15014000 activities and to recelve additional IIs fritormation. complete the form below and tax it to GETF at 703-750-6506.

I would like additional information about:

Publications

Training Courses

IIS On-Line

Conferences

Becoming an IIS implementing partner

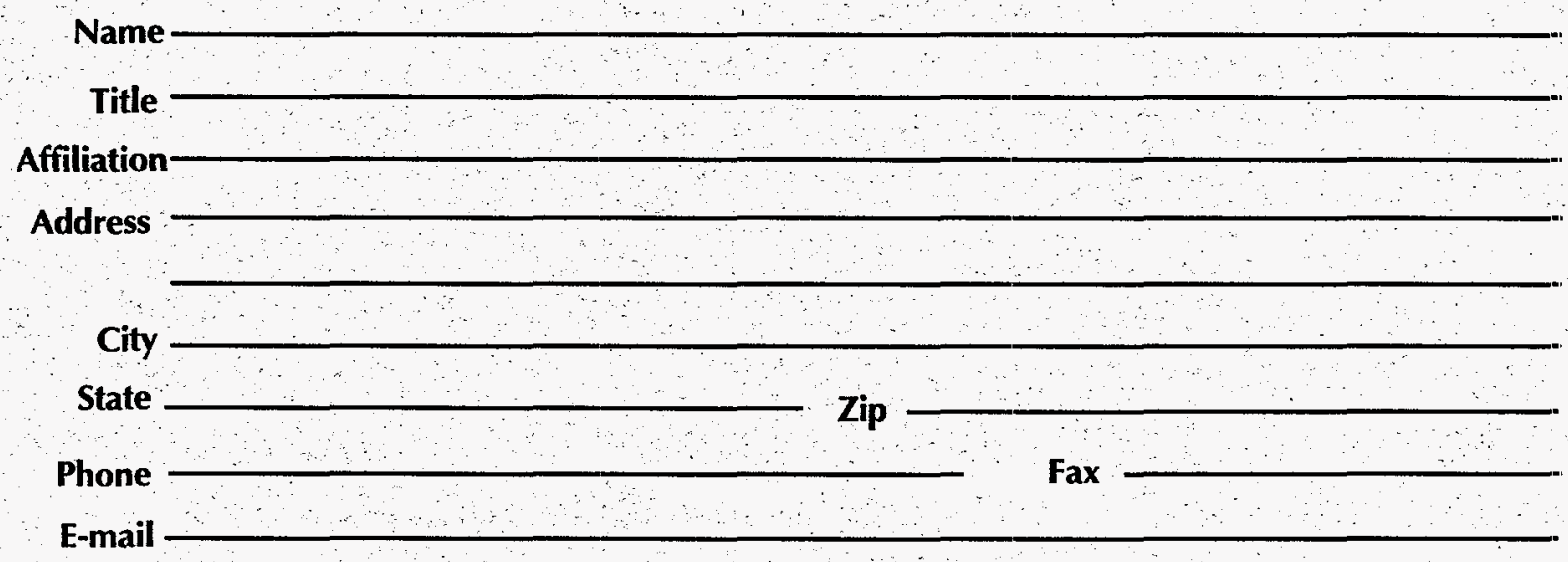


APPENDIX 2

EXAMPLES OF MARKET ASSESSMENTS 


\section{MARKET ASSESSMENT \\ DECONTAMINATION OF RADIOACTIVITY - CONTAMINATED CONCRETE}

Prepared for

Global Environmental Technology Foundation Annandale, Virginia

August 1996

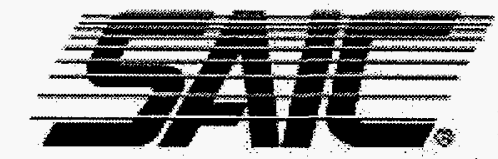

Science Application International Corporation An Employee-Owned Company 
$2.0 \quad$ MARKET DEFINITION

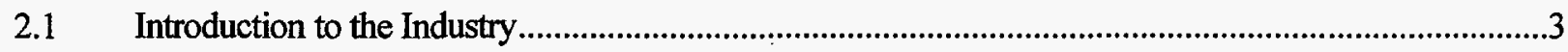

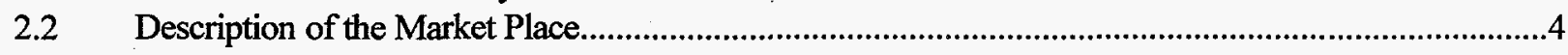

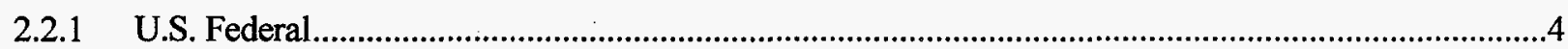

2.2.1.1 U.S. Department of Energy 4

2.2.1.2 Additional Federal Concrete Decontamination Market .......................................................................

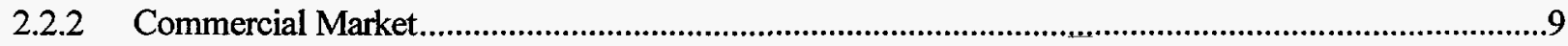

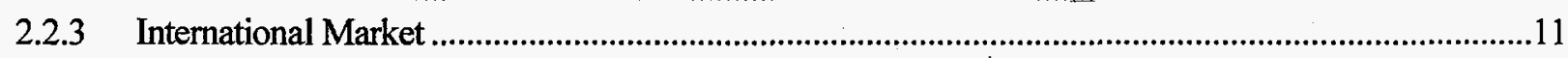

2.3 Baseline and Innovative Technologies Applicable to Decontamination of Concrete...........................11

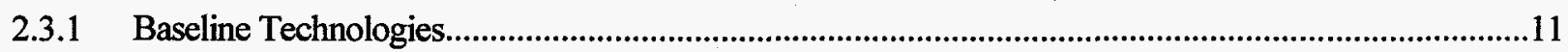

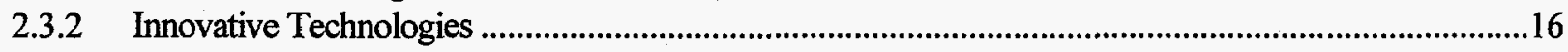

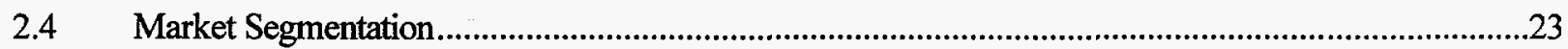

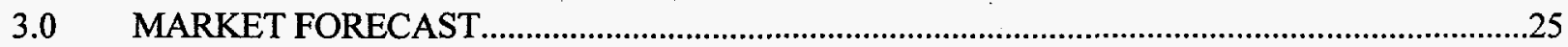

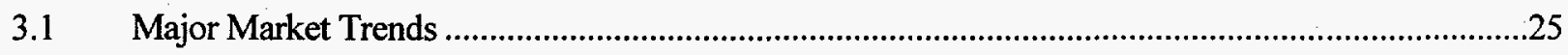

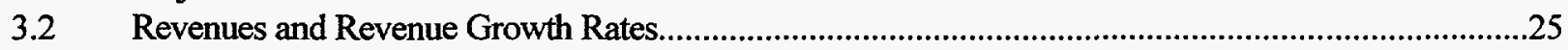

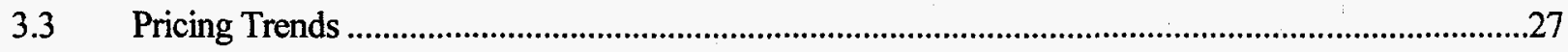

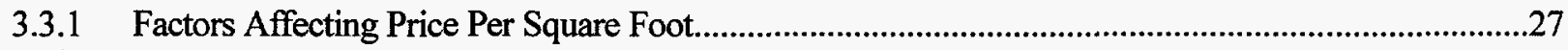

3.3.2 Concrete Decontamination as a Component of D\&D Costs...........................................................28

3.3.3 Price Uncertainties with Innovative Technologies .....................................................................28

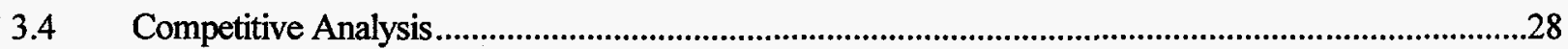

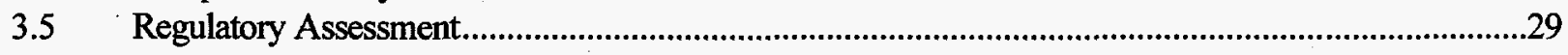

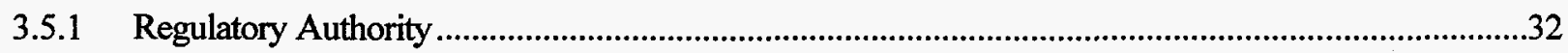

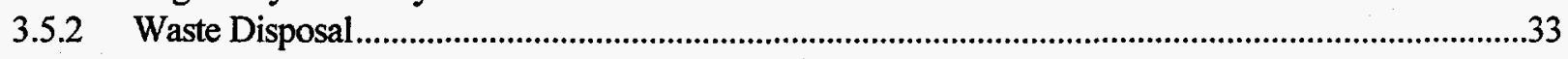

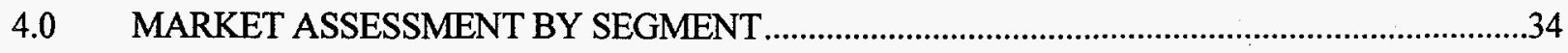

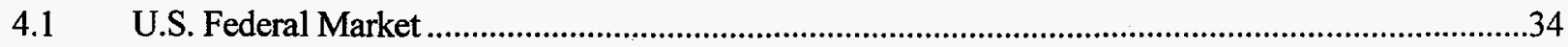

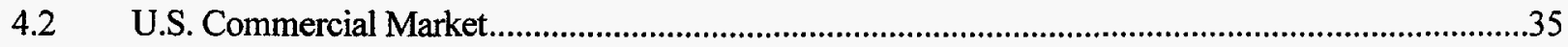

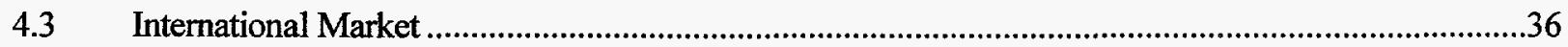


5.0 RECOMMENDED MARKET STRATEGIES

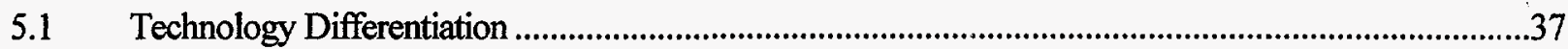

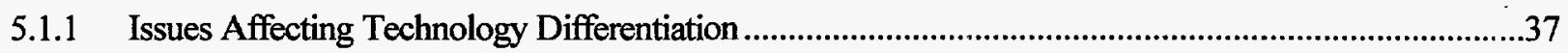

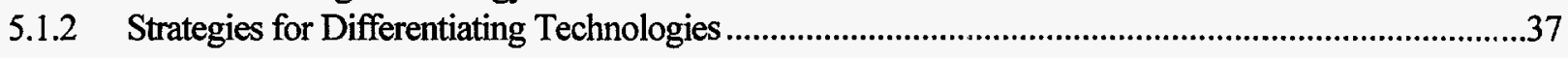

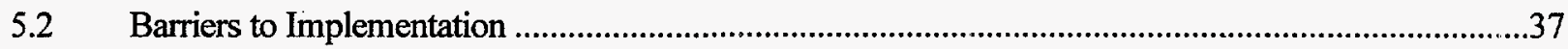

6.0 PERFORMANCE ASSESSMENT OF SELECTED INNOVATIVE TECHNOLOGIES...............40

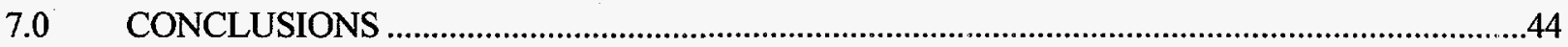

$8.0 \quad$ REFERENCES

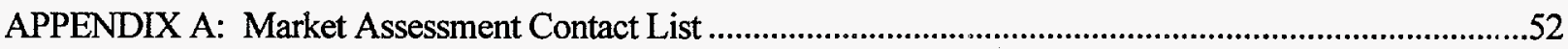

APPENDIX B: Generic/Reference Facility Surface Contamination Estimates..............................................54

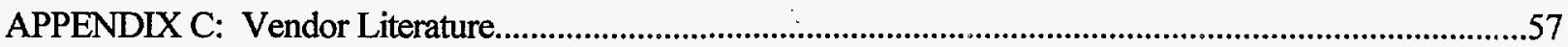




\section{LIST OF TABLES}

Table 2-1 Estimated Floor Contamination and Radionuclides in DOE Facilities. .6

Table 2-2 Ranking of Concrete Problems at DOE Facilities ...............................................................

Table 2-3 Estimated FY96-99 Average Area for Concrete Decontamination ..........................................7

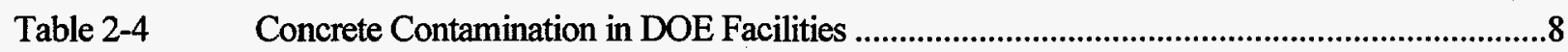

Table 2-5 Total and Contaminated Surface area for Structures at Reference Sites..............................10

Table 2-6 Extent of Surface Radionuclide Contamination in the Reference Pressurized

Table 2-7 Formerly Operated Commercial Nuclear Power Plants.....................................................12

Table 2-8 Countries with Radiologically Contaminated Concrete …................................................13

Table 2-9 Top Ten Countries with Radiologically Contaminated Concrete...........................................13

Table 3-1 Cumulative Decontamination Demand and Revenues .....................................................26

Table 3-2 Illustration of the Range of SIC Codes of Firms in the Concrete Decontamination Market.

Table 3-3 Representative Listing of Companies in the Concrete Decontamination

Market and Their Associated Technologies .30

Table 6-1 Definitions of Performance Attributes .40

Table 6-2 Assessment of Selected Technologies.

Table A-1 Market Assessment Contact List.

Table B-1 Distribution of Contaminated Concrete Surface Areas Within the Reference

Research Reactor .55

Table B-2 Distribution of Contaminated Concrete Surface Areas Within the Reference Research Reactor .55

Table B-3 Distribution of Contaminated Concrete Floor Areas in the Reference Uranium Fuel Fabrication Facility 
LIST OF FIGURES

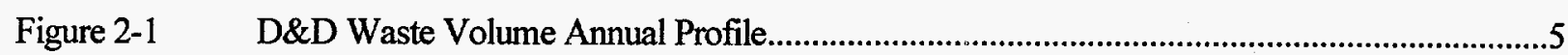




\section{ACRONYMS}

$\begin{array}{ll}\text { ANL } & \text { Argonne National Laboratory } \\ \text { BEMR } & \text { Baseline Environmental Management Report } \\ \text { BNL } & \text { Brookhaven National Laboratory } \\ \text { D\&D } & \text { decontamination and decommissioning } \\ \text { DOD } & \text { U.S. Department of Defense } \\ \text { DOE } & \text { U.S. Department of Energy } \\ \text { DOE/ORO } & \text { U.S. Department of Energy Oak Ridge Operations Office } \\ \text { EET } & \text { Environmental Extraction Technologies for the Future } \\ \text { EM-40 } & \text { DOE Office of Environmental Restoration } \\ \text { EM-60 } & \text { DOE Office of Facility Transition and Management } \\ \text { EPA } & \text { U.S. Environmental Protection Agency } \\ \text { ETEC } & \text { Energy Technology Engineering Center } \\ \text { FEMP } & \text { Fernald Environmental Management Project } \\ \text { FUSRAP } & \text { Formally Utilized Site Remedial Action Program } \\ \text { FY } & \text { fiscal year } \\ \text { HAN } & \text { Hanford Site } \\ \text { HEPA } & \text { High Efficiency Particulate Air } \\ \text { HLR } & \text { High Level Radiation } \\ \text { INEL } & \text { Idaho National Engineering Laboratory } \\ \text { LANL } & \text { Los Alamos National Laboratory } \\ \text { LLR } & \text { low level radiation } \\ \text { LLW } & \text { Low Level Waste } \\ \text { NES } & \text { NES, Inc. } \\ \text { NRC } & \text { U.S. Nuclear Regulatory Commission } \\ \text { NTS } & \text { Nevada Test Site } \\ \text { NUREG } & \text { NRC Nuclear Regulatory Guide } \\ \text { OBG } & \text { O'Brien \& Gere } \\ \text { ORNL } & \text { Oak Ridge National Laboratory } \\ \text { PRADA } & \text { Program Research and Development Announcement } \\ \text { R\&D } & \text { research and development } \\ \text { RCRA } & \text { Resource Conservation and Recovery Act } \\ \text { RFETS } & \text { Rocky Flats Environmental Technology Site } \\ \text { SIC } & \text { Standard Industry Classification } \\ \text { SRS } & \text { Savannah River Site } \\ \text { TRU } & \text { transuranic } \\ \text { TSDF } & \text { Treatment, Storage, Disposal facility } \\ & \end{array}$


UNITS OF MEASURE

$\begin{array}{ll}\mathrm{cm}^{2} & \text { square centimeters } \\ \mathrm{dpm} & \text { disintegrations per minute } \\ \mathrm{ft}^{2} & \text { square foot } \\ \mathrm{ft}^{3} & \text { cubic foot } \\ \mathrm{gpm} & \text { gallons per minute } \\ \mathrm{kW} & \text { kilowatt } \\ \mathrm{lb} & \text { pound } \\ \mathrm{M} & \text { million } \\ \mathrm{psig} & \text { pounds per square inch (gage) }\end{array}$




\section{EXECUTIVE SUMMARY}

The decontamination of radioactivity-contaminated concrete is a potentially large market that is dominated by the facilities in the U.S. Department of Energy (DOE) nuclear complex. So far, some 600 million $\mathrm{ft}^{2}$ of radioactivitycontaminated concrete has been identified within the DOE complex and it is expected that much more could be identified as characterization proceeds. The commercial market potential is smaller by two orders of magnitude.

Despite this potentially large market, the expected demand for concrete decontamination over the next 10-15 years is only about 1.6 million $\mathrm{ft}^{2}$ per year, based on reported plans by DOE sites and electric utilities. At that rate, only 4 percent of the contaminated concrete would be decontaminated by the year 2010 .

This delay of final disposition is a predominant characteristic of both the Federal and the commercial market. Only 3 of 12 retired commercial nuclear power plants are scheduled for decontamination and decommissioning before 2010, suggesting that economics favors delay. The only market force pushing for faster disposition of retired nuclear facilities is the political need for the DOE to show quick results and reduce expenses. The 10-year plan being developed by DOE has the goal of faster results, but would reduce expenditures below those assumed in the 1.6-million- $\mathrm{ft}^{2}$-per-year forecast. Budget realities are more likely to delay decontamination than to speed it up.

At an assumed average cost of $\$ 3$ per $\mathrm{ft}^{2}$, the market looks to be flat at about $\$ 4.8$ million per year for the foreseeable future. If the equipment component is half of the total, the equipment market is only $\$ 2.4$ million per year. A market this small gives private industry little room for investment. Research and development funding for private industry typically runs at a few percent of sales. Assuming 5 percent, a $\$ 2.4$ million annual market would support only $\$ 120,000$ per year in research and development. With 15 to 20 firms in the industry, the market leader would likely have no more than 30 percent of the market, and invest no more than $\$ 36,000$ per year. Thus, the potential is small for cost sharing by private industry in developing advanced concrete decontamination technologies for DOE. 


\subsection{OVERVIEW}

This market assessment is designed to provide both Federal and industry technology managers, investors, and other interested parties the information needed to make technology investment decisions. The primary focus of this assessment is on the U.S. Federal market for services related to decontamination of radioactively contaminated concrete. Other markets are examined also if less rigorously.

From this assessment, DOE's decontamination and decommissioning (D\&D) Focus Area Leadership will have the necessary information to develop an investment strategy which reflects site specific needs, the timing, and cost and technical performance parameters. Technology developers and potential investors will utilize the information on total market size, including the DOE market, market timing, and other factors to enable informed investment and financing decisions.

For the most part, the bulk of the Federal market for the decontamination of radioactively contaminated concrete resides with DOE where it is estimated that 600 million $\mathrm{ft}^{2}$ of concrete will require it. This figure includes concrete located both at DOE National Laboratories and at other DOE facilities across the country. Both the U.S. Army and U.S. Navy contribute, though to a far lesser extent, to the Federal market for concrete decontamination services. The domestic commercial market for concrete decontamination services consists mainly of reactor and fuel fabrication facilities, which are regulated by the U.S. Nuclear Regulatory Commission (NRC).

To scope the size of the Federal market, D\&D information developed by the DOE Office of Environmental Restoration (EM-40) and the DOE Office of Facility Transition \& Management (EM-60) was collected and analyzed. As a part of the DOE Office of Environmental Management (EM), these offices have the primary responsibility for the decontamination of radioactively contaminated concrete within DOE facilities. Individuals within these offices were consulted to establish-where feasible - the time-phased quantity of concrete to be decontaminated by location, the nature of the contaminants, and any physical considerations which could influence decontamination technology such as special coatings.

Some of the more important data sources used in this assessment include the following studies:

- Contaminated Concrete: Occurrence and Emerging Technologies for DOE Decontamination, DOE/ORO/2034, August 1995, (referred to as Oak Ridge National Lab (ORNL) study),

- Decontamination and Decommissioning Technology Assessment, DOE/ORO/1051, March 1993, (referred to as D\&D technology assessment),

- Baseline Environmental Management Report, June 1996,

- NRC Nuclear Regulatory Guide (NUREG)-1496, Generic Environmental Impact Statement in Support of Rulemaking on Radiological Criteria for Decommissioning of NRC-Licensed Nuclear Facilities, Volume 2, August 1994, and

- NUREG-1444, Site Decommissioning Management Plan, November 1995.

Sections 2.3 and 6 draw on work SAIC performed for a yet unpublished Formally Utilized Site Remedial Action Program (FUSRAP) study (original source material is cited in References). These sources were supplemented by telephone interviews with technology and service providers and Federal agencies driving demand for concrete decontamination. 


\subsection{MARKET DEFINITION}

\section{$2.1 \quad$ INTRODUCTION TO THE INDUSTRY}

Concrete has been a predominant structural and shielding material throughout the nuclear industry. With the combination of aging nuclear facilities and the end of the Cold War, both commercial and Government facilities in the U.S. and abroad require closure and decontamination. But, in the majority of cases, closure or transition of a facility cannot take place until contaminated concrete is either disposed of or decontaminated. Decontamination segregates the contaminants and/or the contaminated portion of the concrete from the uncontaminated bulk, greatly reducing the volume of radioactive concrete going to waste disposal. Waste disposal costs, including packaging and transportation, are a major driving factor behind decontamination.

Concrete used in nuclear facilities has been found to contain a myriad of radioactive contaminants, varying from site to site and facility to facility. Most operating or deactivated nuclear facilities - both government and commercial - have yet to undergo complete characterization to detail the full extent of the contamination. However, inventories of radioactively contaminated buildings suggest the potential of an enormous market for concrete decontamination.

The major factors driving the market for concrete decontamination technologies have been defined in several studies including those published by the DOE Oak Ridge Operations Office (DOE/ORO) in June 1995, NRC documents, and the unpublished results of a July 1996 DOE survey of Site Technology Coordination Groups. According to these sources, technologies must meet regulatory guidelines and be acceptable to stakeholders before being considered for use. Once they have been proven to meet acceptable levels of regulatory and stakeholder acceptance, other important factors include secondary waste generation, cost-and scheduleeffectiveness, and any risk to worker safety and health, the public, and the environment.

The presence of coatings on concrete surfaces represents an important technical and economic consideration which affects methods used for concrete decontamination. Fixing or otherwise coating concrete surfaces with sealants and paints has been used extensively in Federal and commercial nuclear facilities to reduce levels of radioactivity and protect concrete surfaces. The types of paints and sealant used for this purpose range from rubber based paints to clear liquid solvents that seal pores to epoxy coatings. If these coatings must be removed prior to the decontamination process, the amount of secondary waste will increase and the cost of decontamination may be impacted. Precise information on the nature of sealants and paints used at nuclear facilities does not currently exist, but the data available suggests widespread coating application. Parenthetically, there appears to be a niche market for technologies addressing coatings within the concrete decontamination market.

Any radioactively contaminated concrete which is not decontaminated may be rubbleized and disposed of as lowlevel waste (LLW) or it may be reused. However, secondary waste generated by the concrete decontamination process often requires disposal in properly licensed disposal sites. The decontamination decision is driven, in part, by the final disposal cost of demolished concrete and/or secondary waste. Final disposal costs are materially impacted by the proximity and availability of disposal sites. Current estimates place disposal costs at commercial sites at up to $\$ 400$ per $\mathrm{ft}^{3}$, not including transportation and packaging. On-site disposal at the Savannah River Site (SRS), Nevada Test Site (NTS), Idaho National Engineering Laboratory (INEL), Los Alamos National Laboratory (LANL), Hanford Site (HAN), Rocky Flats Environmental Technology Site (RFETS), and Fernald Environmental Management Project (FEMP) will likely be less expensive. Especially at the high end, disposal costs makes the minimization of rubble or secondary waste extremely important, and technologies which reduce waste (and ultimately disposal costs) will have a better chance of commercial viability. 
The safe storage or entombment of commercial nuclear facilities is a major consideration affecting the market timing of concrete decontamination services and the need for innovative decontamination technologies. According to NRC guidelines, these facilities may be held in a "safe storage" posture for as much as 60 years. Furthermore, entombing facilities limits the areas needing decontamination and disposal and costs far less than the cost of decontaminating and dismantling. With shrinking Federal budgets and the advent of a 10-year planning horizon for DOE cleanup operations, the "safe storage" alternative may further impact the DOE decontamination market.

The concrete decontamination industry is composed of equipment providers, service providers, and final customers. Final customers may purchase the decontamination service or obtain the equipment (through purchase or lease) and perform the service themselves. Equipment providers may sell or lease their equipment, or use it to perform the service themselves. Independent service providers also obtain equipment and provide the service. The prevailing practice seems to be that management and operating or D\&D contractors purchase or lease technology and become the service provider. These contractors may use or evaluate a number of technologies for any specific application.

Dividing the market into service vs. equipment depends on where the measurement is to take place. At the manufacturers' end of the industry, market demand can be translated into a quantity of equipment required to perform the work while, at the final customers' end, market demand can be translated into a quantity of service required.

\subsection{DESCRIPTION OF THE MARKET PLACE}

This section describes the extent of concrete contamination and the timing of planned decontamination activities for the Federal, commercial, and the international markets. The study period for this market assessment extends to the year 2010 and the first 3 years of this period is considered near-term.

The total concrete decontamination market for the study period is estimated to range between 1.5 and $2.0 \mathrm{M} \mathrm{\textrm {ft } ^ { 2 }}$ per year. The data and information reflected in this section were derived principally from published reports, briefings, and interviews with DOE and NRC personnel. The data and information represents a snapshot of the market in mid-1996. Thus, priorities and ultimately the market needs may change from year to year depending on many factors, including regulatory and public pressures and Federal funding. For this reason, rnarket information beyond the near-term ( 3 years) should be viewed as relatively uncertain.

\subsubsection{U.S. Federal}

The Federal market for concrete decontamination is likely to be dominated by DOE. Although some concrete contamination may be required at certain Department of Defense (DOD) facilities, those total quantities are anticipated to be far outshadowed by the DOE market. The U.S. Army is the tri-service executive agent for radioactive waste management. DOD sources indicate future needs for concrete decontamination services will be identified principally through site surveys for base closures.

\subsubsection{U.S. Department of Energy}

The ORNL study estimated the surface area of contaminated concrete within the DOE complex at 790 million $\mathrm{ft}^{2}$. After adjusting this estimate for an apparent error in the Oak Ridge Y-12 Plant estimate, the total is $\sim 600$ million $\mathrm{ft}^{2}$. Quantities and other relevant information and data for selected DOE sites as derived from the study, are shown in Table 2-1. The ORNL study noted a lack of sufficiently detailed characterization information to more precisely estimate the quantity of radioactively contaminated concrete. Telephone interviews conducted in June and July 1996 with DOE site officials involved in D\&D activities generally supported the ORNL quantity 
findings and ascertained that most sites lacked detailed, long-range D\&D plans. Based on these findings, a conservative view of the market is appropriate. Therefore, the estimate of 600 million $\mathrm{ft}^{2}$ is considered an upper limit for overall DOE market sizing.

The same reference study also included an internal site ranking of concrete problems for 16 sites, which indicates the priority given to this contamination. Ranking information is shown in Table 2-2. This information further supports the above findings and clearly confirms a wide-spread desire to treat concrete decontamination problems.

To gain additional insight into the timing of decontamination activities, a customized report from the Baseline Environmental Management Report (BEMR), showing volume data by fiscal year (FY), was developed and evaluated. This report, based on FY96 data, indicates the bulk of D\&D activities (based on generated waste volumes) occurring after the year 2010. The staff-conducted telephone interviews generally supports the BEMR information with only a few exceptions. Figure 2-1 shows the D\&D volume profile (in $\mathrm{m}^{3}$ ) for EM based on current BEMR data. Concrete decontamination activities are assumed to be closely associated with the D\&D volume estimates since decontamination typically precedes the generation of waste volumes.

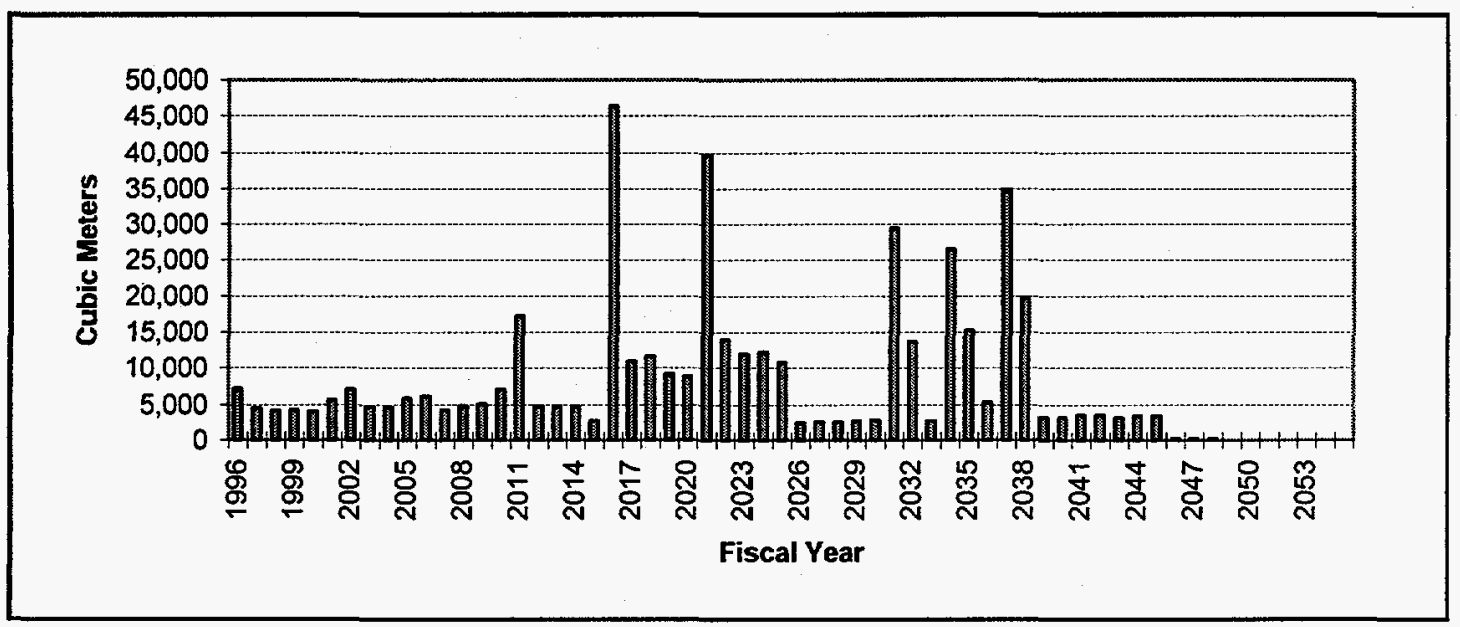

Figure 2-1. D\&D Waste Volume Annual Profile

The information gathered through interviews with site representatives and BEMR indicates a very large market potential for decontamination of concrete in the outyears with a significantly smaller market potential during the next 15 years. Table 2-3 contains selected site estimates which total approximately 1.6 million $\mathrm{ft}^{2}$ annually over the next 3 years. Based on current planning, this rate of decontamination is expected to remain fairly steady through the year 2010 . The 15 year total for the study period $\left(24\right.$ million $\left.\mathrm{ft}^{2}\right)$ is only 4 percent of the 600 million $\mathrm{ft}^{2}$ estimate.

The Surplus Inventory and Assessment data base summarized in the ORNL Study provided information on specific contaminants by site (Table 2-4). 
Table 2-1. Estimated Floor Contamination and Radionuclides in DOE Facilities

\begin{tabular}{|c|c|c|c|}
\hline Installation & $\begin{array}{l}\text { Number of } \\
\text { Buildings }\end{array}$ & $\begin{array}{c}\text { Estimate of Contaminated } \\
\text { floor space, } \mathrm{ft}^{2}\end{array}$ & Primary Radionuclide Contaminants \\
\hline Argonne National Laboratory East & 38 & $19,000,000$ & $\mathrm{Co}, \mathrm{Cs}$, some tritium \\
\hline Argonne National Laboratory West & 1 & 250,000 & $\mathrm{Co}, \mathrm{Cs}$, some tritium \\
\hline Brookhaven National Laboratory & 24 & $20,000,000$ & $\mathrm{U}$ oxide, $\mathrm{Pu}$, tritium, $\mathrm{Co}, \mathrm{Cs}, \mathrm{Sr}, \mathrm{Fe}, \mathrm{Bi}, \mathrm{Na}$ \\
\hline Energy Tech Engineering Center, Area IV & 9 & 690,000 & $\mathrm{Co}, \mathrm{Cs}, \mathrm{Sr} / \mathrm{Y}, \mathrm{Eu}, \mathrm{U}, \mathrm{TRU}$, mixed fission products \\
\hline Formally Utilized Site Remedial Action Program & 6 & $15,000,000$ & Unavailable \\
\hline Hanford Reservation & 181 & $250,000,000$ & $\mathrm{Sr}, \mathrm{Cs}, \mathrm{Pu}, \mathrm{U}, \mathrm{Tc}, \mathrm{Co},{ }^{14} \mathrm{C}, \mathrm{Am}$, others \\
\hline Idaho National Engineering Laboratory & 108 & $7,000,000$ & $\mathrm{Co}, \mathrm{Cs}, \mathrm{Eu}, \mathrm{U}, \mathrm{Sr}, \mathrm{Pu}, \mathrm{Am}$, others \\
\hline Inhalation Toxicology Research Institute & 1 & 68,000 & Unavailable \\
\hline Kansas City Plant & 1 & 220,000 & No rad contamination \\
\hline Lawrence Berkeley Laboratory & 3 & 270,000 & $\mathrm{Co}, \mathrm{Eu}$ \\
\hline Lawrence Livermore National Laboratory & 7 & $3,500,000$ & Unavailable \\
\hline Los Alamos National Laboratory & 16 & $5,700,000$ & $\mathrm{Pu}$ and $\mathrm{U}$ \\
\hline Mound Plant & 4 & $2,900,000$ & $\mathrm{Pu}$, tritium, Th, others \\
\hline Nevada Test Site & 3 & $4,800,000$ & $\mathrm{U}, \mathrm{Pu}, \mathrm{Am}, \mathrm{Sr}, \mathrm{Co}$ \\
\hline Oak Ridge K-25 Site & 4 & $1,600,000$ & $\mathrm{U}, \mathrm{Tc}$ \\
\hline Oak Ridge National Laboratory & 79 & $26,000,000$ & $\mathrm{Cs}, \mathrm{Co}, \mathrm{Sr}, \mathrm{U}, \mathrm{Th}, \mathrm{Eu}, \mathrm{Pu}, \mathrm{Am}$, numerous others \\
\hline Paducah Gaseous Diffusion Plant & 11 & $35,000,000$ & $\mathrm{U}, \mathrm{Tc}$ \\
\hline Pantex Plant & 3 & 85,000 & Unavailable \\
\hline Portsmouth Uranium Enrichment Complex & 1 & $2,300,000$ & $\mathrm{U}, \mathrm{Tc}$ \\
\hline Rocky Flats Environmental Technology Site & 37 & $85,000,000$ & $\mathrm{Pu}, \mathrm{U}$ \\
\hline Sandia National Laboratory, Albuquerque & 8 & $4,500,000$ & Unavailable \\
\hline Savannah River Site & 71 & $52,000,000$ & Tritium, $\mathrm{U}, \mathrm{Pu}$, Fission products \\
\hline Stanford Linear Accelerator Center & 1 & 230,000 & Unavailable \\
\hline Weldon Springs Site & 21 & $54,000,000$ & $\mathrm{U}, \mathrm{Th}$ \\
\hline Oak Ridge Y-12 Plant & 51 & $200,000,000$ & $\mathrm{U}, \mathrm{Th}$ \\
\hline Total & 689 & $790,113,000^{1}$ & 14 \\
\hline
\end{tabular}

Source: ORNL Study DOE/ORO/2034.

1. Without adjustment for a potential estimating error for Oak Ridge $\mathrm{Y}-12$ which may be as low as $2,000,000 \mathrm{ft}^{2}$ (with the adjustment the total is $\left.592,113,000 \mathrm{ft}^{2}\right)$. 
Table 2-2. Ranking of concrete problems at DOE facilities

\begin{tabular}{||l|r||}
\hline Site & Ranking \\
\hline Oak Ridge K-25 Site & 10 \\
\hline Paducah Gaseous Diffusion Plant & 10 \\
\hline Portsmouth Gaseous Diffusion Plant & 10 \\
\hline Hanford Site & 9 \\
\hline Oak Ridge Y-12 Plant & 9 \\
\hline Argonne National Laboratory & 8 \\
\hline Energy Technology Engineering Center & 8 \\
\hline Oak Ridge National Laboratory & 8 \\
\hline Los Alamos National Laboratory & 7 \\
\hline Formally Utilized Site Remedial Action Program & 6 \\
\hline Fernald Environmental Management Project & 6 \\
\hline Idaho National Engineering Laboratory & 6 \\
\hline Savannah River Site & 6 \\
\hline Lawrence Livermore National Laboratory & 5 \\
\hline Mound Plant & 5 \\
\hline Weldon Springs Site & 3 \\
\hline Source: ORNL Study DOE/ORO/2034. & \\
\hline
\end{tabular}

Source: ORNL Study DOE/ORO/2034.

Table 2-3. Estimated FY96-99 Average Area for Concrete Decontamination

\begin{tabular}{||r|r|}
\hline Site & Area (ft') \\
\hline Oak Ridge K-25 Site & 100,000 \\
\hline Paducah Gaseous Diffusion Plant & 12,000 \\
\hline Portsmouth Gaseous Diffusion Plant & 0 \\
\hline Hanford Site & 100,000 \\
\hline Oak Ridge, Y-12 Plant & 250,000 \\
\hline Argonne National Laboratory & 1,000 \\
\hline Lawrence Berkeley Laboratory & 100,000 \\
\hline Batelle Columbus Laboratory & 100,000 \\
\hline Los Alamos National Laboratory & 97,000 \\
\hline Formally Utilized Site Remedial Action Program & $?$ \\
\hline Fernald Environmental Management Project & 300,000 \\
\hline Idaho National Engineering Laboratory & 280,000 \\
\hline Savannah River Site & 85,000 \\
\hline Mound & 11,000 \\
\hline Rocky Flats & 200,000 \\
\hline Approximate Total & $1,600,000$ \\
\hline
\end{tabular}

Source: Phone interviews with site representatives, July 1996. 
Table 2-4. Concrete Contamination in DOE Facilities

\begin{tabular}{|c|c|c|}
\hline Facility type (sites) & Description of concrete contamination & Decontamination comments \\
\hline $\begin{array}{l}\text { Reactors } \\
\text { Argonne National Laboratory, Hanford Site, } \\
\text { Idaho National Engineering Laboratory, } \\
\text { Savannah River Site, Oak Ridge National } \\
\text { Laboratory, Energy Technology Engineering } \\
\text { Center, Los Alamos National Laboratory, } \\
\text { Lawrence Livermore National Laboratory }\end{array}$ & $\begin{array}{l}\text { Activated high level radiation (HLR) in } \\
\text { reactor vessel walls and internals, } \\
\text { biological shields, and beam tubes/ports. }\end{array}$ & $\begin{array}{l}\text { Remote methods required for non- } \\
\text { activated HLR; radiological } \\
\text { contamination often remains after } \\
\text { surface decontamination is performed. }\end{array}$ \\
\hline $\begin{array}{l}\text { Canyon buildings } \\
\text { Hanford Site, Savannah River Site }\end{array}$ & $\begin{array}{l}\text { HLR compounded by spills and leaks; wide } \\
\text { variety of potential contaminants in the } \\
\text { concrete structure of the canyon. }\end{array}$ & $\begin{array}{l}\text { Remote methods required; large } \\
\text { volumes of concrete produced for } \\
\text { disposal. }\end{array}$ \\
\hline $\begin{array}{l}\text { Separation facilities } \\
\text { Energy Technology Engineering Center, } \\
\text { Hanford Site, Los Alamos National Laboratory, } \\
\text { Oak Ridge National Laboratory }\end{array}$ & $\begin{array}{l}\text { HLR associated with structure; wide } \\
\text { variety of contaminants; similar to canyon } \\
\text { facilities. }\end{array}$ & Remote methods required. \\
\hline Fuel fabrication facilities & $\begin{array}{l}\text { Low level radiation (LLR) and hazardous } \\
\text { material associated with concrete floors and } \\
\text { walls and widely dispersed material (fines) } \\
\text { associated with concrete structures. } \\
\text { Possibility of creating a critical mass. }\end{array}$ & $\begin{array}{l}\text { High worker exposure; alphit } \\
\text { contamination and criticality control are } \\
\text { major considerations. }\end{array}$ \\
\hline $\begin{array}{l}\text { Fuel reprocessing facilities } \\
\text { Hanford Site, Oak Ridge National Laboratory, } \\
\text { Savannah River Site, Idaho National } \\
\text { Engineering Laboratory }\end{array}$ & HLR from fissile production material. & $\begin{array}{l}\text { Selection of decontamination method } \\
\text { difficult due to wide variety of potential } \\
\text { contaminants. Selection dependent on } \\
\text { physical structure housing the facility. }\end{array}$ \\
\hline $\begin{array}{l}\text { Hot cells } \\
\text { Idaho National Engineering Laboratory, Pacific } \\
\text { Northwest Laboratory, Oak Ridge National } \\
\text { Laboratory, Savannah River Site, Argonne } \\
\text { National Laboratory East }\end{array}$ & $\begin{array}{l}\text { HLR associated with walls of hot cells and } \\
\text { embedded in cell drains and ventilation } \\
\text { systems. }\end{array}$ & $\begin{array}{l}\text { Remote methods required; embedded } \\
\text { drains difficult to access. }\end{array}$ \\
\hline $\begin{array}{l}\text { Analytical and research and development } \\
\text { (R\&D) facilities } \\
\text { Oak Ridge National Laboratory, Los Alamos } \\
\text { National Laboratory }\end{array}$ & $\begin{array}{l}\text { LLR for the most part associated with } \\
\text { floors and walls. }\end{array}$ & $\begin{array}{l}\text { A wide range of equipment must be } \\
\text { removed before decontamination of } \\
\text { concrete. }\end{array}$ \\
\hline $\begin{array}{l}\text { Weapons materials production facilities } \\
\text { Y-12 Plant, Fernald Environmental } \\
\text { Management Project, Formally Utilized Site } \\
\text { Remedial Action Program, Los Alamos } \\
\text { National Laboratory, Idaho National } \\
\text { Engineering Laboratory }\end{array}$ & $\begin{array}{l}\text { LLR alpha-emitting contamination } \\
\text { (machining waste) associated with floors } \\
\text { and walls. Tritium is present at some sites } \\
\text { and penetrates deeply into concrete. }\end{array}$ & $\begin{array}{l}\text { Methods needed that penetrate deeply } \\
\text { to reach tritium and mercury } \\
\text { contamination. }\end{array}$ \\
\hline $\begin{array}{l}\text { Uranium enrichment facilities } \\
\text { (K25 Site, Portsmouth Uranium Enrichment } \\
\text { Complex, Paducah Gaseous Diffusion Plant) }\end{array}$ & $\begin{array}{l}\text { LLR; U and }{ }^{99} \mathrm{Tc} \text { fluorides and oxyfluorides } \\
\text { and hazardous materials associated with } \\
\text { floors and walls. }\end{array}$ & $\begin{array}{l}\text { Facilities are large, with enormous } \\
\text { amounts of concrete for potential } \\
\text { decontamination; most of these } \\
\text { facilities are in the characterization } \\
\text { process. }\end{array}$ \\
\hline
\end{tabular}

Source: ORNL Study DOE/ORO/2034.

HLR: high-level radiation

LLR: low-level radiation

R\&D: research and development 
Of the facilities identifying specific isotopes, Cs-137 was the most abundant, followed by U-238, Co-60, Sr-90, and tritium, all of which account for only 30 percent of the total occurrence. The extent of mixed hazardous and radiological contamination is unknown, although some is certainly present. Decontamination technologies are not generally contaminant-specific except for those employing chemical extraction. Some contaminants are more mobile than others ( $\mathrm{Tc}$, tritium) and are more likely to have penetrated deeply into the substrate.

To summarize, Cs- 137 and Co-60 contaminated concrete associated with reactors and their supporting structures was found at Argonne National Laboratory (ANL), Brookhaven National Laboratory, Energy Technology Engineering Center (ETEC), INEL, Lawrence Berkeley Laboratory, NTS, ORNL, and West Valley Demonstration Project. Isotopes and daughter products of uranium were concrete contaminants at Battelle Columbus Laboratory, FEMP, INEL, LANL, K-25 Site, Y-12 Plant, Paducah Gaseous Diffusion Plant, RFETS, and Weldon Springs Site. Tritium contamination in concrete was found at ETEC, HAN, INEL, LANL, Mound, NTS, ORNL, and RFETS.

\subsubsection{Additional Federal Concrete Decontamination Market}

This part of the Federal market, consisting of the U.S. Army, Navy, and Air Force, is not expected to have significant quantities of contaminated concrete. According to DOD sources, no significant amount of radioactively contaminated concrete has been identified as needing decontamination.

\subsubsection{Commercial Market}

The commercial market has far less contaminated concrete than the Federal market. The types of commercial facilities with significant decontamination of concrete are:

- power reactors,

- uranium fuel fabrication facilities,

- test reactors,

- research reactors,

- uranium hexafluoride plants,

- non-fuel cycle plants,

- uranium mills, and

- spent fuel storage facilities.

Table 2-5 provides concrete contamination estimates for generic or reference facilities for these types of commercial facilities. Additional tables are included in Appendix B which provide greater detail regarding each reference facility estimate.

Power reactors present the greatest opportunity for decontamination services in the near-term. Table 2-6 provides detailed contamination estimates for a power reactor based on NUREG-1496. Based on this information, 23,000 $\mathrm{ft}^{2}$ of contaminated concrete is estimated for each commercial power reactor. Midpoints were used in deriving estimates of buildings where range data were provided.

In addition to power reactors, uranium fuel fabrication facilities have potentially large areas of contaminated concrete. Each of these facilities has approximately $240,000 \mathrm{ft}^{2}$ of concrete surface area. There are eight of these facilities in the country with about $2 \mathrm{M} \mathrm{ft}^{2}$ of which about 50 percent on average is contaminated. 
TABLE 2-5 Total and contaminated Surface Areas for Structures and Soils at Reference Sites ${ }^{(1)}$

\begin{tabular}{|c|c|c|c|c|c|c|c|}
\hline \multirow{3}{*}{$\begin{array}{l}\text { Reference } \\
\text { Facility }\end{array}$} & \multirow{3}{*}{$\begin{array}{c}\text { Structures } \\
\text { Radionuclide } \\
\text { Activity }{ }^{(2)} 9 \\
\text { dpm } 100 \mathrm{~cm}^{2}\end{array}$} & \multicolumn{4}{|c|}{ Structures Surface Areas } & \multicolumn{2}{|c|}{ Soil Surface Area, $\mathrm{fi}^{2}$} \\
\hline & & \multicolumn{2}{|c|}{$\mathrm{ft}^{2}$} & \multicolumn{2}{|c|}{$\%$ Contaminated } & & \\
\hline & & Floor & Wall & Floor & Wall & Total Site & Contaminated $^{(2)}$ \\
\hline Power Reactor & $\begin{array}{l}7.5 \times 10^{660} \mathrm{Co} \\
2.4 \times 10^{6137} \mathrm{Cs}\end{array}$ & 250,000 & 300,000 & 10 & 2 & $50 \times 10^{6}$ & 2,000 \\
\hline Test Reactor & $\begin{array}{l}7.5 \times 10^{660} \mathrm{Co} \\
2.4 \times 10^{6137} \mathrm{Cs}\end{array}$ & 100,000 & 120,000 & 10 & 2 & $50 \times 10^{6}$ & 5,000 \\
\hline $\begin{array}{l}\text { Research } \\
\text { Reactor }\end{array}$ & $\begin{array}{l}102,000{ }^{60} \mathrm{Co} \\
33,300{ }^{137} \mathrm{Cs}\end{array}$ & 35,000 & 40,000 & 10 & 2 & 150,000 & 500 \\
\hline $\begin{array}{l}\text { Uranium Fuel } \\
\text { Fab }\end{array}$ & $18,000 \mathrm{U}$ & 240,000 & 240,000 & 50 & 5 & $4.7 \times 10^{6}$ & 50,000 \\
\hline Hexafluoride & $1.1 \times 10^{6} \mathrm{U}$ & 120,000 & 130,000 & 50 & 45 & $200 \times 10^{6}$ & 100,000 \\
\hline $\begin{array}{l}\text { Sealed Source } \\
\text { Manufacturer }\end{array}$ & $\begin{array}{l}102,000{ }^{60} \mathrm{Co} \\
33,300{ }^{137} \mathrm{Cs}\end{array}$ & 6,000 & 4,600 & 10 & 5 & 40,000 & 5,000 \\
\hline $\begin{array}{l}\text { Rare Metal } \\
\text { Extraction }\end{array}$ & $18,000 \mathrm{Th}$ & 150,000 & 180,000 & 40 & 10 & 740,000 & 100,000 \\
\hline $\begin{array}{l}\text { Broad R\&D } \\
\text { facility } \\
\text { (Generic) }\end{array}$ & $\begin{array}{l}102,000{ }^{60} \mathrm{Co} \\
33,300{ }^{137} \mathrm{Cs}\end{array}$ & 6,000 & 4,600 & 10 & 5 & 40,000 & 5,000 \\
\hline Uranium Mill & $1.1 \times 10^{6} \mathrm{U}$ & 100,000 & 130,000 & 100 & 100 & $1.4 \times 10^{7}$ & $8.8 \times 10^{5}$ \\
\hline Dry ISFSI & $\begin{array}{l}9800^{60} \mathrm{Co} \\
310{ }^{137} \mathrm{Cs}\end{array}$ & 23,000 & 0 & 10 & - & 500,000 & 500 \\
\hline
\end{tabular}

Source: NUREG-1496.

(1) The estimated surface areas listed above are based on very limited information and, in many cases, represent an engineering judgment estimate based on the size of the building structural facilities and types of operations. The estimates are believed to be conservatively large-they probably overestimate the actuall areas involved.

TABLE 2-6 Extent of Surface Radionuclide Contamination in the Typical Pressurized Water Reactor Nuclear Power Station

\begin{tabular}{||l|c|c|c|}
\hline Building & $\begin{array}{c}\text { Appropriate Floor Surface } \\
\text { Area, } \mathrm{ft}^{2}\end{array}$ & $\begin{array}{c}\text { Estimated \% of Floor } \\
\text { Area Contaminated }\end{array}$ & $\begin{array}{c}\text { Estimated Area Cleanup, } \\
\mathrm{ft}^{2}\end{array}$ \\
\hline $\begin{array}{l}\text { Reactor } \\
\text { Containment }\end{array}$ & 20,400 & 100 & 20,400 \\
\hline Auxiliary (6 levels) & 43,000 & $1-5$ & $430-2,200$ \\
\hline $\begin{array}{l}\text { Fuel Building (5 } \\
\text { Levels) }\end{array}$ & 53,800 & $1-5$ & $540-2,690$ \\
\hline Turbine Building & 61,300 per level & 0 & 0 \\
\hline Control Building & 7,500 per level & 0 & 0 \\
\hline
\end{tabular}

Source: NUREG-1496. 
Table 2-7 contains the status of non-operational power reactors licensed by the $\mathrm{NRC}$ and an estimate of concrete contamination by reactor. Concrete contamination estimates are based on the NRC-reference

facility estimates. Most of the these reactors are in safe storage which allows the licensee to wait for a period of up to 60 years prior to dismantlement. Future expectations on the part of the licensee about dismantlement and disposal costs will influence the decision of when to take a reactor out of safe storage and begin dismantlement.

\subsubsection{International Market}

As in the U.S., the international market is dominated by legacies from nuclear weapons programs, with lesser but more widespread contamination from power reactors. Table 2-8 highlights those countries that have either weapons programs and/or commercial/research reactor programs. There have been a number of studies on individual international projects and several broad based environmental management/restoration country specific studies, but, as of this writing, there are no comprehensive, all encompassing studies on international concrete decontamination.

Table 2-9 lists the top ten international concrete decontamination markets by country. Russia is by far the largest potential market and faces many problems in cleaning up its Cold War legacy. The massive contamination at Russia's three production reactor and fuel reprocessing sites, Mayak, Tomsk-7, and Krasnoyarsk-26, dwarfs contamination anywhere else in the world. Over the last several years, the U.S. and Russia have formed agreements to cooperate in developing new technologies and processes to manage and restore the environment. Economic concerns and political issues, however, are having a dampening effect on actual environmental restoration in Russia.

Although there is no specific information available to estimate the quantity of contaminated concrete around the world, the amount is known to be significant. The anticipated global concrete decontamination needs will most likely parallel the U.S. market needs by having a fairly flat market over the next several years and then increasing as facilities begin to deteriorate and regulatory concerns become more pressing.

\subsection{BASELINE AND INNOVATIVE TECHNOLOGIES APPLICABLE TO DECONTAMINATION OF CONCRETE}

The objective of this section is to provide descriptions of mature and innovative technologies applicable to the decontamination of concrete. The mature (baseline) technologies for decontamination of concrete are described in Section 2.3.1. Innovative technologies are described in Section 2.3.2, along with their primary advantages and limitations compared to the baseline technologies. Assessment of specific performance attributes of the innovative technologies is included in Section 6.0.

\subsubsection{Baseline Technologies}

Several limitations characterize the current baseline technologies for concrete decontamination. Available methods are labor intensive, time consuming, and generate a large amount of contaminated waste. Current technologies either clean the surface only or are capable of removal of a small thickness of the subsurface by physical scabbling, but are not effective for in-depth contamination. In-depth contamination in concrete is common because of the porous nature of the material and because of the presence of joints and cracks.

The inability to remove subsurface contamination translates to very few choices available for the ultimate disposition and management of the contaminated concrete: direct entombment in-situ, or reducing concrete structures to segments and rubble, boxing and burial. Both alternatives are limited by diminishing landfill 
Table 2-7. Projected Concrete Decontamination at Formerly Operated Commercial Nuclear Power Plants(a)

\begin{tabular}{|c|c|c|c|c|c|c|c|c|c|c|}
\hline Unit \& Location & $\begin{array}{c}\text { D\&D } \\
\text { Status** }\end{array}$ & $\begin{array}{l}\text { Projected } \\
\text { Decon Start }\end{array}$ & FY 96 & FY 97 & FY 98 & FY 99-08 & FY09 & FY 10 & $\begin{array}{l}\text { Qty of } \\
\text { Rad- } \\
\text { Concrete }\end{array}$ & $\begin{array}{l}\text { Assumed } \\
\text { Decon Phase } \\
\text { Duration }\end{array}$ \\
\hline Trojan, Portand, OR & $\bar{D}$ & 1996 & 3,000 & 10,000 & 10,000 & & & & 23,000 & $2.5 \mathrm{yrs}$ \\
\hline Yankee Rowe, MA & D & 1996 & 3,000 & 10,000 & 10,000 & & & & 23,000 & $2.5 \mathrm{yrs}$ \\
\hline $\begin{array}{l}\text { Rancho Seco, Herald, } \\
\text { CA }\end{array}$ & S/D & 2009 & & & & & 3,000 & 10,000 & 23,000 & $2.5 \mathrm{yrs}$ \\
\hline TOTAL & & & 6,000 & 20,000 & 20,000 & & 3,000 & 10,000 & 69,000 & \\
\hline $\begin{array}{l}\text { San Onofre-1, San } \\
\text { Clemente, CA }\end{array}$ & $\mathrm{S}$ & 2014 & & & & & & & 23,000 & $2.5 \mathrm{yrs}$ \\
\hline $\begin{array}{l}\text { Three Mile Island } 2 \text {, } \\
\text { Londonderry, PA }\end{array}$ & S & TBD & & & & & & & 23,000 & $2.5 \mathrm{yrs}$ \\
\hline $\begin{array}{l}\text { Fermi 1, Lagoona Beach, } \\
\text { MI }\end{array}$ & $\mathrm{S}$ & TBD & & & & & & & 23,000 & $2.5 \mathrm{yrs}$ \\
\hline Indian 1, Buchanan, NY & $\mathbf{S}$ & TBD & & & & & & & 23,000 & $2.5 \mathrm{yrs}$ \\
\hline $\begin{array}{l}\text { Carolina/Virginia Test } \\
\text { Reactor, Parr, SC }\end{array}$ & $S$ & TBD & & & & & & & 23,000 & $2.5 \mathrm{yrs}$ \\
\hline Dresden 1, Morris, IL & $\mathbf{S}$ & TBD & & & & & & & 23,000 & $2.5 \mathrm{yrs}$ \\
\hline $\begin{array}{l}\text { Humbolt Bay, Humbolt } \\
\text { Bay, CA }\end{array}$ & S & TBD & & & & & & & 23,000 & $2.5 \mathrm{yrs}$ \\
\hline $\begin{array}{l}\text { GE VBWR, Pleasanton, } \\
\text { GA }\end{array}$ & $\mathbf{S}$ & TBD & & & & & & & 23,000 & $2.5 \mathrm{yrs}$ \\
\hline Lacrosse, Genoa, WI & $S$ & TBD & & & & & & & 23,000 & $2.5 \mathrm{yrs}$ \\
\hline
\end{tabular}

Source: Personal interviews documented in Appendix A.

* Radioactive concrete quantities in $\mathrm{ft}^{2}$

** $\mathrm{D}=$ Decon $\mathrm{S}=$ Safe storage 
Table 2-8

Countries with Radioactively Contaminated Concrete

\begin{tabular}{|ll|}
\hline \multicolumn{2}{|l|}{ Countries with Known Weapons Programs } \\
\hline United States of America & France \\
Former Soviet Union & China \\
United Kingdom & \\
\hline
\end{tabular}

\begin{tabular}{|ll|}
\hline Countries with Suspected Nuclear Weapons Programs \\
\hline Iraq & India \\
North Korea & Pakistan \\
Israel & \\
\hline
\end{tabular}

\begin{tabular}{|lll|}
\hline \multicolumn{2}{|l|}{$\begin{array}{l}\text { Countries with Power and/or Research Reactor Programs } \\
\text { (including those with known/suspected Nuclear Weapons } \\
\text { Programs) }\end{array}$} & \\
\hline Canada & Jamaica & Columbia \\
United States & Venezuela & Peru - \\
Mexico & Brazil & Chile \\
Uruguay & Argentina & Sweden \\
Denmark & United Kingdom & Netherlands \\
Belgium & France & Switzerland \\
Portugal & Spain & Italy \\
Greece & Finland & Germany \\
Austria & Slovenia & Romania \\
Turkey & Iran & Israel \\
Zaire & South Africa & Pakistan \\
Malaysia & Indonesia & Bangladesh \\
South Korea & Japan & Philippines \\
Australia & & \\
\hline
\end{tabular}

Table 2-9. Top Ten Countries with Radioactively Contaminated Concrete (not ranked)

\begin{tabular}{|ll|}
\hline Former Soviet Union & United States of America \\
United Kingdom & France \\
China & Canada \\
Japan & Netherlands \\
Sweden & Germany \\
\hline
\end{tabular}

space, restrictive environmental regulations, the inability to recycle or reuse buried or entombed waste, and the potential for resurrection of these materials - all of which influence the cost of transportation and disposal. In addition, dismantling by using conventional techniques poses particular problems when handling contaminated concrete, including the difficulty of confining and segregating the contaminated portion of the concrete rubble and its resulting dust. Moreover, if the concrete is contaminated by Resource Conservation and Recovery Act (RCRA) components in addition to the radioactive ones, the resulting rubble cannot be land-disposed without stabilization of the RCRA components; that treatment often doubles the ultimate volume prior to its disposal as LLW. 
The baseline concrete decontamination technologies include:

- shot blasting,

- mechanical scarification (scabbling and needle scaling),

- detergent/surfactant washing,

- hydroblasting (high pressure water washing),

- strippable coatings,

- vacuuming,

- $\mathrm{CO}_{2}$ blasting, and

- grit blasting.

\section{Shot Blasting}

This technology uses iron shot (pellets) which are accelerated mechanically onto a contaminated surface, chipping it. After the shot hits the surface to be cleaned, it is recovered by a magnetic system and recirculated. Shot may be recycled during cleaning (if recontamination is not a concern), but ultimately erodes and becomes part of the waste stream at the rate of approximately $1.1 \mathrm{lb} / \mathrm{ft}^{2}$. Commercial units are available that have been used to prepare large areas of concrete floors in one step for painting, for cleaning rust and marine growth from ship hulls, and for cleaning structural steel elements. This technology, while developed and commercially available, requires systems improvements for processing the resulting solid waste and controlling the generation of dust.

\section{Mechanical Scarification (Scabbling and Needle Scaling)}

Two mechanical scarification methods have been used: scabbling and needle scaling. In scabbling, several pneumatically operated piston heads simultaneously strike and chip a concrete surface. Vacuum attachments and shrouding cocoons are used to control dust. The concrete dust and debris is the only waste stream produced. Scabblers can easily remove up to $1 \mathrm{in}$. of contaminated concrete or cement.

Needle scaling similarly chips the surface of the concrete, but uniform sets of needles, instead of piston heads, are pneumatically driven to chip the surface. Shrouding and vacuum attachments remove dust and debris, which then require proper disposal.

\section{Detergent/Surfactant Washing}

Detergents and surfactants are cheap and safe and can be used to increase the effect of water, solvents, and complexing agents in solubilizing contaminants from the surface. Most commercial detergents involve formulation of a detergent (sodium laurel sulfate, sodium oleate, alkyl aryl sulphonate) that also acts as a wetting agent or surfactant, a phosphorous or carbonate salt $\left(\mathrm{Na}_{3} \mathrm{PO}_{4}, \mathrm{Na}_{2} \mathrm{CO}_{3}\right)$, a thickening agent (carbyl methyl cellulose), and other fillers. Ethylenediaminetetraacetic acid or other complexing agents may also be added. Other detergents that may be utilized with surfactants, or used separately, include various sulfuric acid salts, quaternary ammonium salts, and nonionic alcohol or amine polymers. Detergents produce results by lowering liquid surface tension and providing a better contact between the surface and the liquid. Surfactants typically consist of long carbon to carbon skeletons plus a polar group containing atoms of nitrogen, oxygen, or sulfur. As the polar group is hydrophilic (water loving) and the hydrocarbon part is hydrophobic (water hating), these molecules (or ions) tend to migrate to water-oil/grease interfaces where the polar group will be attracted to the water phase and the hydrocarbon residue will interact with the organic contaminant (oil/grease) phase. The effectiveness of detergents and surfactants is increased by mechanical agitation. Their disadvantages include 
limited effectiveness for many surfaces and contaminants, possible foaming or ammonia release in waste treatment systems, and difficulty in subsequent dewatering to concentrate removed contamination (e.g., foaming in evaporation equipment).

\section{Hydroblasting (High Pressure Water Washing)}

High pressure (5000-20000 psig) water blasting has been successfully used to decontaminate various large and complex surfaces at nuclear facilities. Experience has demonstrated that blasting effectiveness becomes very poor when the cleaning nozzle is more than 10-12 in. away from the surface being cleaned. Splashing can be extensive and, if proper precautions are not taken, it can result in the recontamination of clean surfaces. A large amount of waste water is generated; the waste generation rate is essentially the same as the water application rate, which can range from 4 to $>100$ gallons per minute (gpm).

\section{Strippable Coatings}

A polymer mixture is applied to a contaminated surface. As the polymer reacts, the contaminants are stabilized and become entrained in the polymer. In general, the contaminated layer is pulled off, containerized, and disposed of, although a polymer can be applied as a fixative. Secondary treatment may be needed, depending upon how effective the polymer is in removing the contaminant and how deeply the contaminant has penetrated the material. The polymer may also bind to the surface of the item on which it is applied. In this instance, large volumes of waste may result and the building or surface may be damaged (DOE 1994a).

\section{Dusting/Vacuuming/Wiping}

Vacuuming is performed using an industrial vacuum equipped with a high-efficiency particulate air (HEPA) filter (DOE 1994a). Surfaces that cannot be reached with a vacuum can be wiped with a damp cloth. Fugitive dusts may be generated by dusting or vacuuming and spread the contamination. These techniques are applicable to dust and contaminants that are not attached to the surface.

\section{$\mathrm{CO}_{2}$ Blasting}

$\mathrm{CO}_{2}$ pellets are used as the cleaning medium. Small dry-ice pellets are accelerated using compressed air at 50250 psig, which results in chipping and lifting of surface coatings. The dry-ice instantly sublimates, removed debris is collected, and $\mathrm{CO}_{2}$ gas returns to the atmosphere. Use of $\mathrm{CO}_{2}$ is advantageous for removal of radioactive contamination because no secondary waste is generated. However, this technique is not aggressive enough to remove hard coatings. Ventilation and temperature control are needed to prevent $\mathrm{CO}_{2}$ buildup and freezing of the equipment.

\section{Grit Blasting (Sand Blasting, Abrasive Jetting)}

Grit blasting is widely used in industry for removing paint and other surface coatings from a wide range of substrates, including metal, wood and concrete. Grit blasting has also been used in nuclear industry applications, ranging from heavily contaminated pipework with the contamination fixed in the oxide, to lightly contaminated surfaces. Commercial units are readily available. Typical abrasives include sand, glass beads, and soft materials such as nut shells and rice hulls. Abrasive materials are suspended in a medium that is projected onto the surface being treated. It is a slow and labor intensive process in which compressed air or water or some combination of both can be used to carry the abrasive. The abrasive materials can be recycled, but ultimately become a part of 
the waste stream. The technology, while developed, requires improvements in systems to separate and package the contaminants, including dust, gases, and/or fluids.

\subsubsection{Innovative Technologies}

Innovative technologies for decontamination of concrete were identified through vendor contacts, literature and database searches, and professional experience. Technologies were sought which either utilized principles that were completely different from the baseline technologies or were similar in principle, but significantly improved in performance by an innovative modification. Included were innovative demolition technologies applicable to the cases where surface decontamination is not sufficient and where traditional demolition techniques would generate large quantities of waste requiring further handling and ultimate disposal. The following innovate technologies were identified:

- electrokinetic decontamination of concrete, ELECTROSORB ${ }^{\mathrm{TM}}$ by Isotron Corporation;

- soda blasting by O'Brien \& Gere Technical Services, Inc;

- electro-hydraulic scabbling by AVCO/Textron Defense Systems;

- decontamination of concrete surface by AWD Technologies;

- microwave scabbling of concrete under development at ORNL;

- laser decontamination under research by. Westinghouse Hanford Company and Ames Laboratory;

- expansive grout, Bristar ${ }^{\mathrm{TM}}$ by Demolition Technologies, Inc.;

- TECHXTRACT ${ }^{\mathrm{TM}}$ contaminant extraction technology by Environmental Extraction Technologies for the Future (EET), Inc.;

- centrifugal $\mathrm{CO}_{2}$ pellet turbo-blaster by Cryogenic Applications F, Inc.,

- concrete crushing and rebar recycling by Aggregate Machinery, Inc.; and

- $\quad$ Blastox ${ }^{\circledR}$ blended abrasives by TDJ Group, Inc.

\section{Electrokinetic Decontamination of Concrete, ELECTROSORB ${ }^{\mathrm{TM}}$ by Isotron Corporation of New Orleans, Louisiana}

The ELECTROSORB ${ }^{\mathrm{TM}}$ process utilizes an electrode suspended within a polymeric enclosure, to establish an electrokinetic extraction regime which removes contaminants from concrete. The polymer extraction pad is placed in contact with the concrete. A complexant (electrolyte) is circulated through a channel system which is a part of the pad's interior. Electrodes are attached to the channels. The electrolyte soaks the concrete to convert insoluble contaminants into soluble ions, which will migrate in an electric field. For example, for solubilization of uranium, the concrete may be soaked with ammonium bicarbonate. Next, an electric field is applied and contaminants migrate from the bulk contamination zone toward the electrodes. An electrokinetic separation module permits continuous recycle of the electrolyte with simultaneous recovery of the contaminant. 


\section{Advantages and Limitations Compared to Baseline Technologies}

The technology is in the basic research/engineering development stage and will soon move to full scale demonstration status. Information is now available for evaluation of its effectiveness, implementability and cost. The technology is expected to be practical for both hot spots and small area applications, as well as for decontamination of large areas.

Secondary waste generated is much lower than alternative technologies. In recent tests at the K-25 site, an ion exchange bead resin was used to remove the uranium. In a more recent demonstration of thorium decontamination, an alternative waste processing technique was demonstrated which yielded a solidified ceramic wasteform based on technology under development at ANL.

\section{Soda Blasting by O'Brien \& Gere (OBG) Technical Services, Inc. of Syracuse, New York}

Sodium bicarbonate is used as the blasting/abrasive agent. Blasting may be done dry or wet. When wet blasting is used, water and soda bicarbonate are sprayed simultaneously through different nozzles. The water is used as the collection medium for the removed contaminants, particulates, and soda as well as for control of airborne particles during the blasting process. The crystalline structure of sodium bicarbonate, while abrasive enough to remove contaminants, does not degrade blasted surfaces, including concrete and metals. The inherent water solubility of soda results in minimization of waste generated during the decontamination process. Blasting with nonsoluble media results in the blasting media itself becoming contaminated with rad (and requiring disposal as LLW) while, in soda blasting, the contaminants and soda are recovered from the waste water using standard water treatment practices. The added benefit is that sodium bicarbonate is nonhazardous to the operators and the environment.

OBG has recently completed bench- and pilot-scale tests at the K-25 Site. After treatment, surface contamination was reduced to below the unrestricted use release limits set by DOE (O'Brien and Gere, 1995). Overall, soda blasting appears to have a large potential for application to building remediations where treatment and disposal of treated waste water is not a concern.

\section{Advantages and Limitations Compared to Baseline Technologies}

Soda blasting is very effective for mechanical removal of surface contamination while leaving the substrate intact. Sodium bicarbonate is nontoxic and it readily dissolves in water and physically separates contaminants from the blast media. The water must next be treated for removal of the contaminants. Soda blasting is a mature technology with proven industrial applications by the food processing industry, for example.

DOE has included OBG in the Program Research and Development Announcement (PRADA) to evaluate the cost-effectiveness of the process for decontamination of radioactively contaminated sites. According to the developers, soda blasting can be applicable to metals and concrete.

The main advantages of the soda blasting technology over conventional techniques such as sand blasting or ironbead blasting is waste minimization. The primary limitation is that the process may require supplemental processes for on-site treatment and disposal of large quantities of water. Another limitation is that the process cannot be used for removal of in-depth contamination.

\section{Electro-Hydraulic Scabbling by AVCO/Textron Defense Systems, Everett, Massachusetts}


In this device, shock waves and cavitating bubbles are generated in water by strong electric discharge pulses between two mechanically-positioned electrodes. The direct and reflected shock waves impinge on the concrete surfaces, crushing and cracking the concrete. The water efficiently transfers discharge energy and retains debris. The amount of water used is minuscule compared to scabbling with a high pressure jet. Textron estimates that a $32-\mathrm{kW}$ device will scabble concrete at a rate of $12 \mathrm{~m}^{2} / \mathrm{hr}\left(2.2 \mathrm{ft}^{2} / \mathrm{min}\right.$.), about double the scabbling rate for an ultra high-pressure water jet.

\section{Advantages and Limitations Compared to Baseline Technologies}

The technology is in the basic research/engineering development stage and it is not currently available for production use without further study. Although the amount of the primary waste generated is less when compared to other scabbling technologies, generation of secondary waste (water) is comparable. Its effectiveness, implementability, and cost are difficult to estimate because the technology is in an early phase of development.

\section{Decon/Recycle of Concrete by AWD Technologies, Rockville, Maryland}

AWD is developing a process called AWD-CON, which aims at minimizing the volume of secondary waste generated by high-pressure water scabbling by subjecting the concrete surface to a series of cleaning steps. The surface cleaning starts with dry-vacuuming and collection of dust by a HEPA filter. The vacuuming is followed by successive application of a detergent, a caustic solution, and an acid in the form of foamed cleaning agents. The concrete is rinsed after each application with water and characterized for contaminants. If still contaminated, the concrete surface is removed using a high pressure water blast.

\section{Advantages and Limitations Compared to Baseline Technologies}

This is a set of relatively simple processes rather than a new technology. However, information about effectiveness, implementability, and potential cost savings is not available and difficult to estimate and these parameters are expected to be site-specific. The process is expected to be more practical for spot/small area applications rather than for decontamination of large areas.

\section{Microwave Scabbling of Concrete under development at ORNL}

The microwave scabbling technology uses microwave energy directed at the concrete surface to heat the concrete and free water present in the concrete. This produces steam-pressure-induced mechanical stresses that caulse the concrete surface to burst.

\section{Advantages and Limitations Compared to Baseline Technologies}

Microwave scabbling is considered an emerging technology. Effectiveness, implementability, and costs are unknown and difficult to estimate. 


\section{Laser Decontamination under research by Westinghouse Hanford Company and Ames Laboratory at Iowa State University.}

Light ablation, including lasers, uses the absorption of light energy and its conversion to heat (photopyrolysis) to selectively remove surface coatings or contaminants. The contaminated surface coating or film is quickly heated, transforming it from a solid into plasma, which erupts from the surface. Photochemical and thermochemical reactions occurring within the plasma result in destruction of organics with potential metal and radioactive contaminants remaining in the residual ash. The surface coatings that have been removed by high energy light techniques, such as lasers, range from epoxy paints, adhesives, and corrosion products to centuries of accumulated airborne pollutants and up to $1 / 4$-in. layers of concrete.

\section{Advantages and Limitations Compared to Baseline Technologies}

Although lasers are commercially available, their application for decontamination purposes is considered an emerging technology. Available information indicates that laser decontamination can be cost-effective in certain circumstances, especially where liquid-based technologies would not be permitted because of safety (e.g., criticality) considerations. However, pending further research, it is not clear that the laser technology offers advantages in terms of effectiveness, implementation, and cost to sites where criticality is not a concern.

\section{Expansive Grout, Bristar, by Demolition Technologies Incorporated of Greenville, Alabama}

Expansive grout is a material used to fracture concrete. The material, which is similar to Portland cement, is mixed with water and poured into pre-drilled holes where it is allowed to cure. As it cures, it expands, cracking the workplace so that it may be removed. This nonexplosive, vibration-free process may be used to crack concrete of any size, reinforced or nonreinforced, provided it has a free face to which it may expand. This method can also be used for segmenting vitrified blocks, fracturing concrete slabs, and vibration-free removal of thin slabs. The removal rates vary based on application, but can approach those of controlled blasting on large jobs. (DOE 1994a)

As an accepted, proven technology, it was shown effective in decommissioning of the Princeton-Pennsylvania Accelerator, where it was used to separate activated concrete from the remaining concrete blocks, which were removed from the accelerator floor by a diamond-wire saw. This separation allowed for efficient use of burial containers, thereby reducing burial costs.

\section{Advantages and Limitations Compared to Baseline Technologies}

Although the technology is commercially available, it is considered innovative for applications on remedial projects. The process may be used to crack concrete of any size (reinforced and nonreinforced) provided it has a free area into which it may expand. It can also be used for segmenting vitrified blocks, fracturing concrete slabs, and vibration-free removal of thin slabs. Removal rates vary, but can approach those of controlled blasting on large jobs.

This is a nonexplosive, vibration free technology. The advantages of Bristar over traditional explosive demolition methods include elimination of noise, dust, and gas vapors, and a potentially large reduction in the volume of the resulting rubble. The process is free of regulations and does not require any licenses. 


\section{TECHXTRACT ${ }^{\mathrm{TM}}$ Contaminant Extraction Technology by EET, Inc.}

TECHXTRACT ${ }^{\mathrm{TM}}$ is a propriety multistep contaminant extraction process that is developed, owned, and marketed by EET, which claims that the process is effective in the extraction of surface and subsurface contaminants from concrete, steel, brick, and other materials. The contaminants targeted by the technology include radionuclides, polychlorinated biphenyls, heavy metals, and other substances.

While the specific chemicals and cleaning techniques are custom engineered for each project, the basic process remains the same. After cleaning any debris from the surface, the first chemical blend (surface preparation) is applied. After this blend is rinsed and removed from the surface, a second chemical blend (extraction) is applied. This formula actually extracts the contaminants from the surface and the substrate. (In concrete, extraction has been measured at depths in excess of $3 \mathrm{in}$.) At the end of the application, the surface is again rinsed and the liquids are removed. This entire cycle takes 1 day, and may be repeated several times to achieve the desired levels of decontamination.

According to the developer, the process is most cost effective when one or more of the following conditions apply:

- the acceptable level for any residual contaminants is very low;

- subsurface contamination is present;

- the removal and disposal of the entire contaminated surface (and subsurface) is undesirable, either because the volume and resulting disposal and replacement costs are too high, or due to waste minimization objectives;

- significant safety concerns (such as flammability, corrosivity, creation of airborne contaminant particles, or generation of toxic fumes and/or explosive gases) are raised;

- decontamination is to be performed on surfaces that are not readily accessible due to geometry or location such as equipment, walls, ceilings, structural beams, and internal piping; and when

- all other options have failed to achieve the desired objective.

\section{Advantages and Limitations Compared to Baseline Technologies}

The process allows for waste minimization by not removing the entire contaminated surface and subsurface. Liquid wastes are generated by the process at rate of about $0.05 \mathrm{gal} / \mathrm{ft}^{2}$. These liquids require treatment by solidification and disposal as LLW or mixed waste. However, the solidified material typically represents only $1 / 20$ of the volume that would have resulted from scarification and other methods of removal of the contaminated surface/subsurface.

EET has been included in the PRADA program to evaluate effectiveness of the TECHXTRACT ${ }^{\mathrm{TM}}$ process for decontamination of radioactively contaminated sites. Technical literature by EET, Inc. notes the following advantages of TECHXTRACT ${ }^{\mathrm{TM}}$ over the baseline surface/subsurface cleaning technologies (such as high pressure water washing, brushing, vacuuming, chemical decontamination, grit blasting):

- the actual performance parameters described above, 
- cost avoidance due to reduction in generation of secondary waste,

- cost avoidance due to the final disposition of the treatment residuals because of lower liabilities associated with the disposition of smaller waste volumes.

These advantages need to be verified during the testing under the PRADA program. The results also need to be verified for process effectiveness, as well as for quantities and treatment requirements for the generated secondary waste.

\section{Centrifugal $\mathrm{CO}_{2}$ Pellet Turbo-Blaster by Cryogenic Applications F, Inc., Clinton, TN}

The $\mathrm{CO}_{2}$ turbine device replaces the inefficient compressed air delivery system used in pneumatic "sandblast" type cryoblast units. The technology, developed at ORNL, is marketed by Cryogenic Applications F, Inc. under a nonexclusive licensing agreement. The technology includes a method of freezing carbon dioxide and argon gases into pellets and a pellet blasting centrifugal accelerator with an improved rotor and housing. The technology is applicable to metals and concrete. It can be used in nondestructive mode when a contaminated surface coating needs to be removed without damaging the subsurface or it can scarify the subsurface if necessary for removal of in-depth contamination. It has a demonstrated decontamination efficiency of up to 4 $\mathrm{ft}^{2} / \mathrm{min}$.

Application of centrifugal $\mathrm{CO}_{2}$ blasting has been tested on simulated rad-contaminated materials. It appears to have a large potential for application to remediation of buildings as the secondary waste stream generation is dramatically reduced when compared to traditional technologies.

\section{Advantages and Limitations Compared to Baseline Technologies}

Centrifugal $\mathrm{CO}_{2}$ pellet blasting is, in principle, applicable to a variety of media, including metals and concrete. It can be used for removal of contaminated paints and coatings, or, in the case of concrete, for removal of the necessary thickness of subsurface to remove in depth contamination.

A paint-stripping technology that uses compressed air to propel dry ice pellets has been on the market for some time. The Turbo-Blast system has the following advantages over the compressed air based $\mathrm{CO}_{2}$ pellet systems: it is less expensive than compressed air systems, achieves higher pellet velocities, has cleaning rates $2-10$ times faster, has precise and repeatable pellet speed control, and it can be used with existing $\mathrm{CO}_{2}$ pellet making machines. The advantage of the cryoblasting technique over conventional techniques, such as sand blasting or iron-bead blasting, is that it does not leave a waste stream requiring additional cleanup. In cryoblasting, the frozen pellets evaporate into harmless gases and the contaminants freed from the surface can be collected by vacuum systems with high-efficiency particulate absorbent HEPA filters.

In summary, the advantages of the Turbo-Blast system include:

- performance specifications described above;

- cost avoidance due to elimination of generation of secondary waste;

- cost avoidance due to elimination of requirements for treatment of secondary waste; and 
- cost avoidance due to requirements for treatment and the final disposition of the treatment residuals, including lower liabilities associated with the disposition of smaller waste volumes.

The technology has not been portable up to now. However, Cryogenic Applications F is currently in the process of manufacturing a unit with a robotic arm. Other problems with the equipment include the propensity for fogging and/or freezing at the head which disrupts operations; fogging also makes it difficult to guide the equipment manually or robotically. Ventilation and temperature control problems need to be improved for the process to be practical and airborne particulates also need to be isolated and collected at the point of blasting. In addition, the actual effectiveness for decontamination of concrete surfaces needs to be verified.

\section{Thunderbird Concrete Crushing and Rebar Recycling by Aggregate Machinery Inc. of Salem, Oregon}

The Thunderbird Model 13155162IVR3 crushing and recycling plant manufactured by Aggregate Machinery, Inc. is a closed circuit, portable, concrete recycling plant. The plant is designed to crush concrete debris to a soillike material. The objective is to take advantage of the disposal cost of debris at licensed facilities are approximately double the disposal cost for soil; and residual contamination cleanup guidelines, established by DOE Order 5400.5, which includes volumetric criteria for soil, but does not include volumetric criteria for debris.

The disposal cost advantage for soil, along with the volumetric release criteria for soil, can result in substantial cost avoidance if the debris is crushed to a soil-like substance prior to disposal. Frequently, when surface/subsurface contamination is present in concrete structures, upon crushing the concrete to a soil-like consistency, the resulting material is below the volumetric criteria for soil. Consequently, options for disposal other than as LLW may be considered; the crushed and segregated material meeting the DOE cleanup criteria is then suitable for reuse as backfill, or reuse as construction aggregate. Even when the volumetric disposal criterion is not met, and the material requires disposal as LLW, crushing to the soil-like consistency also makes it easier to comply with transportation related regulations and DOE Orders for it significantly reduces the potential for packing failure during loading and transport by eliminating large, sharp-edged materials.

\section{Advantages and Limitations Compared to Baseline Technologies}

The greatest cost benefit from crushing concrete into soil-like material can be achieved when the material is left on-site and when off-site transportation and disposal are not required. Total cost savings (transportation and disposal) for release of crushed material on-site versus disposal offsite could be $\$ 21 / \mathrm{ft}^{3}$ or more.

The Thunderbird crushing and recycling plant has advantages as compared to standard industrial rock crushers, in that it has a capability to recover significant quantities of rebar and other ferrous metals, while maintaining feed rates of $150-200 \mathrm{lbs} / \mathrm{hr}$. The machinery is suitable for highway transportation. The limitation of the plant is that a sizable demolition project would be required to justify the capital expenditures needed for the plant. 


\section{Blastox $\mp$ Blended Abrasives by TDJ Group, Inc. of Cary, Illinois}

Blastox is a blasting additive to grit blasting media that renders lead, or other heavy metal present in the removed paint, nonhazardous under RCRA. As such it can be applicable to situations where concrete surfaces or coatings are contaminated with heavy metals. Since 1991, Blastox technology has been successfully applied for depainting of more than $30,000,000 \mathrm{ft}^{2}$ of metal surfaces contaminated with lead and other heavy metals, without generating of RCRA waste. Satisfied users of the technology include the US Army and the Air Force, along with numerous private concerns (TDJ Group 1996). Although the primary applications so far have been for removal of paints from metals, the technology also works well on concrete, wood, and other surfaces. The technology has not yet been tested for removal of radioactively contaminated painted surfaces; however, there is no reason to expect that it would not perform satisfactorily in such applications. The resultant LLW waste would be easier to handle than mixed waste.

Blastox uses an U.S. Environmental Protection Agency (EPA) best demonstrated available technology stabilization process, assuring that the metals in the removed paint remain stable for at least 500 years in simulated landfill conditions. Blastox guarantees reduction of the leachable lead levels from up to $100 \mathrm{mg} / \mathrm{l}$ to below $5.0 \mathrm{mg} / \mathrm{l}$. This allows disposing the spent abrasives as non-hazardous waste, without any RCRA manifesting, tracking, or permitting.

All of the states and the EPA regions have indicated that as long as Blastoxw is added up front to the abrasives and prior to the waste being generated, the process is not considered treatment. Therefore, no Treatment, Storage, Disposal Facility (TSDF) permits are required. (However, if a waste is already characterized as hazardous waste, and Blastox or another treatment chemistry is to be added after the fact, a TSDF permit is required.) Blastox is always added at 15 percent by weight to the abrasive. It is also available preblended with sandblasting media (for example with Black Beauty) from many regional facilities.

\section{Advantages and Limitations Compared to Baseline Technologies}

The advantage of using Blastox for removal of mixed (RCRA and radioactive) contamination is that the resulting waste is a LLW rather than a mixed waste, which is beneficial as it allows the avoidance of additional treatment of the waste to remove the RCRA components prior to final disposal.

Blastox is not cost-effective as an additive to steel shot or any recyclable depainting medium that requires classification prior to recycling. The cost of Blastox preblended with Black Beauty sandblasting medium is 70 percent higher than Black Beauty alone; however it is more than offset by resulting savings in disposal of the resulting material.

Blastox is a mature technology. Contractors report the same efficiency when blasting, and can achieve the same profiles with Blastox in the blend. No special equipment is required. The innovative aspect is the potential application to radioactively contaminated concrete. While actual applications are needed to confirm its effectiveness, the technology appears to be directly applicable to decontamination of concrete.

\subsection{MARKET SEGMENTATION}

The concrete decontamination market can be segmented by customer type and by the technical characteristics of the contamination. Segmentation by customer type is useful for analyzing the driving forces of decontamination demand, while segmentation by technical characteristics is useful for determining the types of technologies that will be effective. 
The most basic customer type distinction is between government and commencial. DOE dominates the government segment of the market with the DOD as a distant second. The commercial segment is dominated by commercial power reactors and other NRC-licensed facilities.

Technically, the major distinguishing factors are whether the contamination is confined to the surface or has moved into the subsurface of the concrete and whether or not it can be removed without some of the concrete or coatings. The chemical and physical nature of the contaminant plays a role, with some substances such as tritium, mercury, and technicium being more mobile than others. However, the presence of coatings or cracks significantly affects the distribution of contamination so that it is difficult to generalize about whether contaminants will have migrated into the subsurface. 


\subsection{MARKET FORECAST}

\subsection{MAJOR MARKET TRENDS}

The major question for most decontamination work centers on the timing of decontamination work-will it be done as the useful life of the facility is over or delayed? From a purely economic point of view, delay makes sense if the present value cost of delayed cleanup is less than the cost of immediate cleanup. The key variables in the calculation will be the cost of surveillance and maintenance during the delay period and the expected increase (or decrease) in the cost of decontamination and waste disposal. Noneconomic factors, too, may favor delay, such as budget or cash flow constraints, unresolved technical and regulatory issues, and the difficulties of laying off staff and closing down sites.

The circumstantial evidence is that delay is often the reality. The DOE D\&D program, as expressed in the BEMR data, would delay much of the decontamination work beyond 2010 . The majority of formerly operated commercial reactors have been placed into long-term safe storage instead of immediate D\&D (Table 2-7).

Pressures for more immediate and tangible results could affect the pace of decontamination at DOE sites. $\mathrm{DOE} / \mathrm{EM}$ is in the process of developing a plan to accomplish DOE's cleanup within 10 years at constant budget. The schedule goal implies a significant rescheduling of activities into the near term, which could be a positive impact for vendors in the concrete decontamination market. On the other hand, accomplishing the job under the stated budget constraint implies a major rethinking of what to do with contaminated facilities, which could include a downward adjustment of the quantity of concrete requiring decontamination.

Two examples of the latter kind of rethinking illustrate how the concrete decontamination market could shrink. The FUSRAP program has disposed of contaminated concrete at one site by crushing it to the consistency of soil (for which DOE has volumetric free release criteria) and placing it in a conventional landfill. Other FUSRAP sites may follow this strategy. And the $\mathrm{K}-25$ Site is aggressively pursuing a reindustrialization strategy, through which contaminated facilities would be leased to private industry. Some envisioned reindustrialization opportunities include "mining" process buildings for the value of metals contained in their process equipment, and fabricating LLW containers from the recovered metals. Once "mined," the process buildings could be used for other purposes, thus delaying D\&D of the buildings themselves indefinitely.

Thus, while DOE's 10 year plan would appear to bring more of the concrete decontamination work into the near term and afford a quicker payback for developers of innovative technology, the total quantity of concrete to be decontaminated by DOE is likely to shrink, as will the budget to pay for it.

On the commercial side, the salient factors are the rate of retirement, the quantity of contaminated concrete in each reactor, and the tendency to delay D\&D. No foreseeable change in any of these factors is likely to have an impact in any significant way relative to the size of the DOE market.

\subsection{REVENUES AND REVENUE GROWTH RATES}

As explained in Section 2, the demand for concrete decontamination is expected to remain constant at $\sim 1.6$ million $\mathrm{ft}^{2}$ per year. The estimation of revenues is based upon costs per $\mathrm{ft}^{2}$ as reported in the literature and in phone interviews with vendors. Because many of the businesses participating in this market provide a number of products and services, it is not possible to use published financial information (which is reported for the company as a whole) as a revenue baseline. In addition, some of the firms in this market are small and privately held, and are not required to publish their financial information (such as Cryogenic Applications $\mathrm{F}$, Inc.). As the larger companies are participating in a number of other markets with concrete decontamination representing a small 
part of their total revenues (such as Textron Defense Systems), using information from their income statement as an estimate of revenues for the concrete decontamination market would be inappropriate. Therefore, the strategy for the estimation of market revenues is to build on the $\mathrm{ft}^{2}$ estimates and make assumptions regarding probable average cleanup costs.

It is important to emphasize that the focus of these revenue estimates is the market for concrete decontamination involving radioactive components. There is a broader market for concrete decontamination involving hazardous but nonradioactive substances that is currently being handled by a number of companies. In addition, there are markets where companies are providing equipment and/or services to those interested in having their concrete surfaces cleaned of nonhazardous materials (such as dirt and grime). There is also some market overlap of the concrete rad decontamination technologies and services with providing for decontamination of other materials, such as metals, wood, and/or brick. However, the concrete decontamination market involving radicactive components is a unique niche market. Because of the special features of radioactive substances and the need to reduce the contamination level remaining in the concrete to a very small fraction, the technologies selected for concrete decontamination involving radioactivity require a relatively high efficiency rating, providing a high level of contaminant removal. These demands on the technology will tend to make the effective technologies used in this niche more expensive than those used for other applications.

Reported costs of concrete decontamination range from under $\$ 0.50$ per $\mathrm{ft}^{2}$ to over $\$ 50.00$ per $\mathrm{ft}^{2}$, depending upon the technical process selected, the depth of the contamination, whether or not the surface was originally coated, and the chemical structure of the contaminants. These costs include all direct charges (labor, equirment, and material) associated with the decontamination activity. It does not include characterization or disposal costs. For example, PENTEK Inc. has already processed more than $2 \mathrm{M} \mathrm{ft}^{2}$ of concrete at DOE sites using physical/mechanical destructive surface removal processes at a cost of between $\$ 1.85$ and $\$ 2.50$ per $\mathrm{ft}^{2}$ (ORNL Study, p. C-18). We assume an average of $\$ 3$ per $\mathrm{ft}^{2}$, allowing for a somewhat more costly range of future decontamination efforts. The qualitative conclusions of this study are not sensitive to varying this assumption by $\$ 1-2$ in either direction.

Table 3-1 shows cumulative areas and revenues to the year 2010. Total revenues for decontamination services, including equipment amortization, are computed using an average cost of $\$ 3$ per $\mathrm{ft}^{2}$, or $\$ 4.8$ million per year. The equipment portion of this total is assumed to be about one-half, or $\$ 2.4$ million per year.

Table 3-1. Projected Cumulative Decontamination Demand and Revenues

\begin{tabular}{|c|c|c|c|}
\hline Year & $\begin{array}{c}\text { Decontaminated } \\
\left.\text { Area (million } \mathrm{ft}^{2}\right)\end{array}$ & Total Revenues (million \$) & $\begin{array}{c}\text { Equipment Revenues } \\
\text { (million \$) }\end{array}$ \\
\hline 1996 & 1.6 & 4.8 & 2.4 \\
\hline 2000 & 8 & 24 & 12 \\
\hline 2005 & 16 & 48 & 24 \\
\hline 2010 & 24 & 72 & 36 \\
\hline
\end{tabular}




\section{3}

PRICING TRENDS

One of the major uncertainties associated with this market involves the cost of cleaning up and disposing of radcontaminated concrete. However, the total cost of building D\&D is often not very sensitive to the price per $\mathrm{ft}^{2}$ for cleaning and/or removing the concrete surface. The major drivers in the total cost picture for handling radcontaminated concrete are the effectiveness of the technology in reducing the contamination, the amount of secondary waste volumes generated by the process, and whether or not the concrete rubble eventually generated by the D\&D activity can be sent to an unlicensed landfill or recycled.

The decision on whether to go ahead with $D \& D$ for a particular building will rarely hinge on the prices being charged for concrete decontamination. Instead, the $\mathrm{ft}^{2}$ of concrete actually treated will be dictated mainly by governmental timing decisions which, in turn, will be largely determined by DOE's budget allocations for waste management projects and will be affected by stakeholder's concerns.

\subsubsection{Factors Affecting Price Per Square Foot}

As was mentioned above in Section 3.2, it is anticipated that the price per $\mathrm{ft}^{2}$ for rad contaminated concrete decontamination services might range from $\$ 0.50$ to $\$ 50.00$. There are a number of dimensions over which the price will vary:

(1) Depth of Contamination: It will be less expensive to clean the surface than it is to clean up concrete that is contaminated down through several inches or more.

(2) Cracking: If the concrete is cracked or jointed, there is a higher likelihood of deep contamination requiring a deeper level of decontamination than would have been required without cracking.

(3) Surface Coatings: If the concrete were originally treated with a sealant or other coating before it was exposed to radioactivity, it is likely that the depth of contamination will be more shallow.

(4) Type of Contaminants: The characteristics of the contaminants that need to be handled can be very different, and some of these differences affect how deep the resulting contaminated level is. Factors affecting the degree of migration include the $\mathrm{pH}$ value of the chemicals and/or metals, whether or not they are soluble and can travel through the concrete's porous structure, and the relative size and number of the holes in the concrete's matrix.

(5) Flat vs. Curved Surfaces: Many of the processes work well on floors or walls where it is easy to treat the concrete surface. Sometimes a different process is needed in comers or for other areas and processes tailored to treat less accessible areas tend to be more expensive.

(6) Technology Selected: The different technologies being used for decontamination of rad-contaminated concrete can vary significantly in price. For example, Textron Defense Systems Inc. estimates that its electro-hydraulic scabbling process will cost between $\$ 0.65$ to $\$ 1.85$ per $\mathrm{ft}^{2}$, while Environmental Extraction Technologies for the Future, Inc. (EET) estimates that its TECHXTRACT process (based upon chemical extraction) will cost between $\$ 4$ and $\$ 50$ per $\mathrm{ft}^{2}$.

(7) Number of Passes Required: This cost factor is a function of both the depth of contamination and the effectiveness of the technology selected. The deeper the contamination and the smaller the width cleaned by the technology, the more times the equipment would need to be applied. Costs would increase with more passes of the equipment. 
(8) Level of Remaining Contamination: The higher the required percentage of removal of the contaminants, the higher the cleanup cost will be. It may be relatively easy and inexpensive to remove 90 percent of the contamination, but it may be extremely difficult and costly to use a technique that could remove 99.5 percent of the contaminants.

\subsubsection{Concrete Decontamination as a Component of D\&D Costs}

One of the most important features of this market is that the cost of decontaminating rad-contaminated concrete is just one component of a D\&D project that involves demolition of a building with recycle or disposal of the resulting debris. The concrete treatment step is just one of six cost-generating stages directly associated with concrete; the other five are pre-treatment contaminant characterization, cost-benefit assessment of alternative treatments, disposal of radioactive wastes generated, post-treatment contaminant characterization, and disposal or recycle of decontaminated concrete. The costs associated with removal of concrete are part of the whole D\&D effort, which involves selection of technologies for dealing with the range of materials in a building, including metal, wood, and plastic components.

Because concrete decontamination is a relatively small part of the total building D\&D costs, the decision on when to start D\&D activities is not expected to be noticeably affected by the development of lower-cost concrete decontamination technologies. Overall $\mathrm{D} \& \mathrm{D}$ decisions will be dictated by regulatory requirements and budget allocations. However, once the decision to go ahead with a D\&D project has been made, the comparison of the relative effectiveness of the alternative technologies will be conducted. This comparison will be made over the six cost-generating stages mentioned above, not just a narrow comparison of treatment costs per $\mathrm{ft}^{2}$. It is anticipated that the environmental features of each concrete decontamination project will be different and that it will be appropriate to select various technologies to most cost-effectively deal with those differences.

DOE is currently funding the development of a cost model which would incorporate all the activities associated with handling and disposing of rad-contaminated concrete into a single decision-making framework. The model is being developed at the Energy and Environmental Research Center of the University of North Dakota located in Grand Forks, North Dakota and plans call for the completed computer model to be available next year. Ames Grisanti at (701) 777-5158 is the contact for more information about this cost model.

\subsubsection{Price Uncertainties with Innovative Technologies}

Another feature of this market is a number of innovative technologies being developed that have not progressed much beyond the proof-of-concept stage. Therefore, there has been relatively little experience with several of the technologies, making it difficult to predict exactly how well they will operate under different conditions. In addition, it is often hard to estimate how much equipment would cost to manufacture in comparison with their prototype construction costs. As these technologies come closer to commercially viability, the treatment cost estimates can be made with greater reliability.

\subsection{COMPETITIVE ANALYSIS}

This section highlights some of the companies involved in the rad-contaminated concrete decontamination market. The firms tend to be predominately active in other industries and therefore tend to be in competition with each other only in the concrete decontamination market, not across the board for all of their products or services. Table 3-2 gives an illustration of the range of industries [as defined by the six-digit Standard Industry Classification (SIC) code]. 
Table 3-2. Illustration of the Range of SIC Codes of Firms in the Concrete Decontamination Market

\begin{tabular}{|c|c|c|c|}
\hline SIC Code & Industry Description & Firm(s) & $\begin{array}{c}\text { No. of } \\
\text { Listings }\end{array}$ \\
\hline 179500 & Wrecking \& Demolition Work & Demolition Technologies & 5,371 \\
\hline 179908 & Decon. Services & EAI, Inc. & 3,001 \\
\hline 376100 & Guided Missiles/ Space Vehicle Manuf. & Textron Defense Systems, Inc. & 504 \\
\hline 495399 & Refuse Systems, NEC & TDJ Group, Inc. & 11,917 \\
\hline 738999 & Bus. Services, Misc. & Oceaneering Tech. & 60,750 \\
\hline 871199 & Engineering Services, NEC & AWD Technology, Inc. \& PENTEK, Inc. & 33,587 \\
\hline 873103 & Natural Resource Res. & EET Inc. \& NES Inc. & 14,238 \\
\hline 874199 & Management Services, NEC & O'Brien \& Gere Technical Services & 7,836 \\
\hline 899909 & Scientific Consultants & Isotron Corp. & 1,633 \\
\hline
\end{tabular}

Source: Database America Company, PhoneDisc Business, U.S. Business Listings on CD-ROM, Bethesda, MD, 1996.

One issue that will affect the market involves DOE's strategy for selecting contractors. It is likely that the firms operating in the DOE-controlled concrete decontamination market will have to be either an established DOE contractor or a subcontractor to one of those established contractors. The government's procurement practices may limit the actual number of competitors.

Appendix $\mathrm{C}$ contains a compilation of some of the materials distributed by these companies describing their technologies.

The number of listings shown in Table 3-2 indicate the number of offices listed in a national telephone database for companies identified with this SIC code. Since many companies have offices in more than one location, the number of listings does not correspond directly to the number of independent businesses. However, the table indicates that there are a large number of firms operating in markets tangential to the concrete decontamination market and could be poised to enter it should DOE accelerate its plans for D\&D activity.

Table 3-3 gives a listing of companies participating in the rad-contaminated concrete decontamination market. A number of these businesses are small and have fewer than 20 employees, such as Isotron Corp. and TDJ Group, Inc. The research being conducted in these firms tends to be heavily dependent upon the availability of DOE funding support. Some of the larger companies have extensive business operations in other markets, for example, NES is also involved in providing services for lead-based paint removal from concrete and metal surfaces.

\subsection{REGULATORY ASSESSMENT}

This section briefly describes the regulatory environment governing concrete decontamination. The regulatory environment is a significant variable affecting all aspects of the concrete decontamination market. 
Table 3-3. Representative Listing of Companies in the Concrete

Decontamination Market and Their Associated Technologies

\begin{tabular}{|c|c|c|c|c|c|}
\hline Company & Technology/ Product & Status & Also for Metal, Etc. & Cost (\$/sq. ft.) & Notes \\
\hline Isotron Corp. & $\begin{array}{c}\text { Electrokinetic } \\
\text { Decontamination/ELECTROSORB }\end{array}$ & Innovative; Not Commercialized & No & & $1,2,3$ \\
\hline O'Brien \& Gere Technical Services, Inc. & Soda Blasting & $\begin{array}{l}\text { Innovative; Commercialized for } \\
\text { Non-Rad }\end{array}$ & Yes & $\$ 7$ & 1,2 \\
\hline $\begin{array}{l}\text { Textron Defense Systems Inc. \& PENTEK, } \\
\text { Inc. }\end{array}$ & Electro-Hydraulic Scabbling & Innovative; Not Commercialized & No & $\$ 0.65$ to $\$ 1.85$ & 1,2 \\
\hline AWD Technologies & Decon \& Recycle of Concrete/ AWD-CON & Innovative; Not Commercialized & No & & 1 \\
\hline $\begin{array}{c}\text { Lockheed Martin Energy Systems, Oak } \\
\text { Ridge National Laboratory }\end{array}$ & Microwave Scabbing & Innovative; Not Commercialized & No & $\$ 2$ & 1,2 \\
\hline $\begin{array}{l}\text { Westinghouse Hanford Co. \& Ames } \\
\text { Laboratory }\end{array}$ & Laser Decontamination & Innovative; Not Commercialized & Yes & & 1 \\
\hline Demolition Technologies, Inc. & Expansive Grout Technique/Bristar & $\begin{array}{l}\text { Innovative; Commercialized for } \\
\text { Non-Rad }\end{array}$ & No & & 1 \\
\hline $\begin{array}{c}\text { Environmental Extraction Technologies for } \\
\text { the Future, Inc. (EET) }\end{array}$ & $\begin{array}{c}\text { Chemical Extraction Process/ } \\
\text { TECHXTRACT }\end{array}$ & Innovative; Commercialized & Yes & $\$ 4$ to $\$ 50$ & 1,2 \\
\hline Cryogenic Applications, Inc. & $\begin{array}{c}\text { Chemical Extraction Process/Turbo-Blast } \\
\text { System }\end{array}$ & Innovative; Not Commercialized & Yes & & 1 \\
\hline Aggregate Machinery, Inc. & $\begin{array}{c}\text { Thunderbird Concrete Crushing \& Rebar } \\
\text { Recycling }\end{array}$ & Established; Commercialized & No & & 1 \\
\hline TDJ Group Inc. & Blended Abrasives Blasting/Blastox & $\begin{array}{l}\text { Innovative; Commercialized for } \\
\text { Non-Rad }\end{array}$ & Yes & & 1,3 \\
\hline PENTEK Inc. & $\begin{array}{l}\text { Concrete Scabbler/ MOOSE, Corner Cutter } \\
\text { Needle Gun System; High Performance Vac- } \\
\text { Pac Squirrel III Floor Scabbler; \& Roto-Peen }\end{array}$ & Established; Commercialized & Yes & & 2 \\
\hline Corpex Technologies & $\begin{array}{l}\text { Chemical Extraction Process/CORPEX } \\
\text { Nuclear Decontamination Process }\end{array}$ & Innovative; Not Commercialized & Yes & & 2,3 \\
\hline $\begin{array}{c}\text { Lockheed Martin Idaho Technologies \& } \\
\text { British Nuclear Fuels Limited }\end{array}$ & Biological Decontamination & Innovative; Not Commercialized & No & $\$ 2$ to $\$ 3$ & 2 \\
\hline Polygon Industries & Flash Lamp Process/ Starboldt & Innovative; Not Commercialized & Yes & & 2 \\
\hline F2 Associates & Laser Ablation & Innovative; Not Commercialized & Yes & & 2 \\
\hline
\end{tabular}


Table 3-3. Representative Listing of Companies in the Concrete

Decontamination Market and Their Associated Technologies

\begin{tabular}{|c|c|c|c|c|c|}
\hline Company & \begin{tabular}{|c|} 
Technology/ Product \\
\end{tabular} & Status & Also for Metal, Etc. & Cost (\$/sq. ft.) & Notes \\
\hline GenCorp Aerojet & $\begin{array}{c}\text { Soft Fiber Media Blasting/ Advanced Recycle } \\
\text { Media System }\end{array}$ & Established; Commercialized & Yes & $\$ 10$ to $\$ 12$ & 2,3 \\
\hline Environmental Altematives, Inc. (EAI) & $\begin{array}{l}\text { Concrete Scabbling \& other decontamination } \\
\text { processes }\end{array}$ & $\begin{array}{l}\text { Established, Possibly Applicable } \\
\text { to Rad Contamination }\end{array}$ & Yes & & 3 \\
\hline NES, Inc. & Concrete Scabbling/ BlasTrak & $\begin{array}{l}\text { Established, Possibly Applicable } \\
\text { to Rad Contamination }\end{array}$ & Yes & & 3 \\
\hline LTC Americas Inc. & $\begin{array}{l}\text { Vacuum Blasting using Recyclable } \\
\text { Abrasives/LTC Multiple Blasthead Vacuum } \\
\text { Blasting Machines }\end{array}$ & $\begin{array}{l}\text { Established, Possibly Applicable } \\
\text { to Rad Contamination }\end{array}$ & Yes & & 3 \\
\hline Nalco Equipment & Shot Blasting & $\begin{array}{l}\text { Established, Possibly Applicable } \\
\text { to Rad Contamination }\end{array}$ & Yes & $\begin{array}{l}\$ 0.04 \text { to } \$ 0.15 \\
\text { excluding disposal of } \\
\text { waste }\end{array}$ & 3 \\
\hline Oceaneering Technologies, Inc. & $\begin{array}{l}\text { Remote-Operated Vehicle Dry Ice Pellet } \\
\text { Decontamination System/ COYOTEE \& } \\
\text { ROVCO2 }\end{array}$ & $\begin{array}{l}\text { Innovative, Possibly Applicable; } \\
\text { Not Commercialized }\end{array}$ & Yes & & 3 \\
\hline \multicolumn{6}{|c|}{$\begin{array}{l}\text { 1. Description of technology in Section 2.3.2. } \\
\text { 2. Innovative technologies reported in ORNL study of contaminated concrete technologies (DOE/ORO/2034). } \\
\text { 3. Descriptions from Global Environmental Technology Enterprise's Internet World Wide Web page \& telephone questions to firm representatives. }\end{array}$} \\
\hline
\end{tabular}


However, specific cleanup requirements for a site or facility can only be ascertained following decisions on landuse, allowable residual contamination, and waste disposal. These decisions will be based on input from stakeholders, state and local regulators, and Federal agencies. By participating in, or maintaining awareness of, the decision process on a case-by-case basis, technology developers and service providers will be able to focus their marketing efforts appropriately. Because the values of many of the decision variables remain undetermined, this market assessment is not segmented according to level of acceptable contamination.

\subsubsection{Regulatory Authority}

Regulations governing the concrete decontamination market are based on (1) eliminating radiological worker exposure; (2) minimizing disposal cost by limiting the volume of waste; and (3) reducing levels of contamination to below established limits. Determining the disposition of contaminated concrete requires radiological and chemical surveys, in conjunction with historical review of records, to properly identify the concrete's waste category. After concrete has been characterized, the options for final disposition can be identified. These options may include re-use of the building structure intact, recycling of the concrete for other purposes, or waste disposal. Depending on the contamination present, concrete may need to be decontaminated to implement the proposed option.

Regulatory guidelines have been developed by DOE, NRC, and EPA based on the nature of the facility and who has landlord responsibilities for it. DOE Order 5400.5 presents criteria to protect both the public and the environment from radiological contamination release during D\&D activities. The Order also presents the radiological protection requirements and guidelines for cleanup of residual radioactive material and management of the resulting waste residues and release of property. Generic guidelines that are used for residual radioactive material as they potentially apply to the free release of concrete, are as follows:

- Basic dose limit;

- Residual radionuclides in soil;

- Airborne radon-decay products;

- External gamma radiation;

- Surface contamination; and

- Residual radionuclides in air or water.

NRC presently allows decommissioning of a site on a case-by-case basis in accordance with Termination of Operating Licenses for Nuclear Reactors, Regulatory Guide 1.86; Disposal or On-Site Storage of Thorium or Uranium from Post Operation; and Termination of By-Product, Source, or Special Nuclear Materials Licenses, Policy and Guidance Directive. The NRC's proposed decommissioning rule currently addresses the release of lands and structures containing residual radioactivity for unrestricted public use; criteria for recycling material and disposing of very low-level radioactive waste at a non-radioactive disposal facility have not been proposed.

Under the Atomic Energy Act and Reorganization Plan No.3 of 1970, EPA has the statutory responsibility to establish generally applicable standards protecting public health and the environment outside NRC licensee and DOE site boundaries. NRC and DOE are responsible for ensuring that site activities do not lead to radiation doses outside the facilities boundaries that exceed EPA's generally applicable standards. EPA is in the process of developing a new regulation to govern site cleanup activities, Radiation Site Cleanup Regulation. This new regulation would be promulgated as 40CFR 196. 


\subsubsection{Waste Disposal}

If the concrete is to be managed as a radioactive waste, disposal requirements will vary with respect to the level and type of radiological contamination. The disposal of radiologically contaminated concrete and/or decontamination treatment residues will need to follow the requirements of DOE Order 5820.2A. The radioactive waste categories are as follows:

Low-Level Waste (LLW): It is anticipated that most contaminated concrete will need to be managed as LLW. This type of waste can either be disposed of at a DOE disposal facility (e.g., NTS, HAN, or INEL) or at an appropriately permitted/licensed non-DOE facility. Should a NRC-licensed disposal facility be used, the criteria in 10CFR 61 should be evaluated to ensure that the appropriate disposal requirements are met. The disposal requirements for LLW are subdivided into three classes depending on the nature of the waste and the radionuclide concentrations. The requirements are as follows:

- Class A waste consists primarily of short-lived radionuclides and can be disposed with minimal requirements;

- Class B waste contains a greater concentration of radionuclides and needs to be in a stable form prior to disposal; and

- Class $\mathrm{C}$ waste remains radioactive for longer periods of time and requires more stringent waste disposal requirements.

Transuranic (TRU) Waste: It is envisioned that some highly contaminated concrete (e.g., from hot cells) may need to managed as TRU waste.

High-Level Waste and Spent Nuclear Fuel: It is assumed that radiologically contaminated concrete will never be classified as either category. 


\subsection{MARKET ASSESSMENT BY SEGMENT}

As shown in the last chapter, the rad-contaminated concrete decontamination market is probably going to generate revenues of around $\$ 5 \mathrm{M}$ per year. More than 90 percent of those revenues will be associated with cleanup on DOE-owned properties, making DOE the major market driver. Market performance will be dominated by actions taken by this single buyer without the cushioning effects possible when there are a number of buyers operating in the market, each potentially affected by independent forces that can result in offsetting demand swings. The following sections highlight the factors that account for the great level of uncertainty regarding each of the market segments.

\subsection{U.S. FEDERAL MARKET}

DOE properties contain a tremendous amount of rad-contaminated concrete. Given current regulations and the assumption that many of the rad-contaminated buildings will be dismantled, DOE is going to need extensive concrete decontamination services. As mentioned in the beginning of Chapter 3, the question is not if DOE will have a demand for concrete decontamination, only when. The timing of D\&D activities will depend upon factors that are difficult to foresee and could change quickly, such as:

(1) Changing DOE Mission. DOE has historically been commissioned to handle our nuclear-related activities, including weapons manufacture and uranium enrichment. It has also been involved in more general energy research and development. With the transfer of the uranium enrichment task to the U.S. Enrichment Corporation, the cutbacks in weapons manufacture allocations resulting from the end of the Cold War, and the relatively low price of energy worldwide, these three mission areas have become smaller and less urgent concerns on our list of national priorities. DOE's current mission is not considered to be as vital as it once was to either national security or energy independence.

(2) Size of DOE Appropriations. As DOE's identified mission has become smaller, it is reasonable that politicians are expecting to allocate fewer dollars to do the job. Given that the current emphasis at the Federal level is to downsize governmental operations, it is expected that appropriations for DOE will be declining. Although at one time DOE's budget estimates included increasing appropriations to pay for environmental cleanup and D\&D activities, it is now considered unlikely that Congress will be willing to tolerate anything but declining budgets.

(3) Share of $D O E$ Budget to $D \& D$. DOE will be managing a transition to a smaller workforce with a redirection of its mission. Making this transition may require some redirection of funds to pay for Reduction-in-Force programs, renegotiating long term contract arrangements, and other plans to facilitate the orderly downsizing of DOE's activities. With revenue allocations declining (as indicated above) and increased costs associated with downsizing, it is unlikely that $\mathrm{DOE}$ will be able to allocate a greater share of its budget to D\&D, at least over the foreseeable future.

(4) Success of Re-Industrialization Plans. One of DOE's strategies to facilitate its own downsizing while promoting private enterprise is to explore the sale of DOE land and buildings to private businesses. Such sales would provide a substitute economic activity for the curtailed DOE expenditures, helping to sustain local economic health. To the extent that DOE is successful in finding commercial partners who would be willing to conduct their own cleanup of DOE buildings, DOE would find savings in two ways: (1) reduction in current maintenance costs and (2) elimination of the need for DOE to fund D\&D. The re-industrialization schemes are still being developed, and it is uncertain at this time how effective they will be or how often they could be used. If this strategy became widely used and private businesses were interested in having the rad- 
contaminated concrete treated on a more accelerated schedule than currently planned by DOE, the demand for concrete decontamination services could grow at a faster rate then currently estimated.

(5) Political Support/Opposition to DOE Cleanup Plans. As a government agency, DOE is subject to project delays caused by protests and legal petitions from special interest groups. If DOE's D\&D plans became the focus of either local or national debates, there could be additional postponements of cleanup activities.

(6) Changing Regulations. The estimates of the quantity of rad-contaminated concrete developed for DOE are based on current regulatory definitions of what constitutes "contaminated." If that definition were to be redefined, the total volume could change.

\section{2}

\section{U.S. COMMERCIAL MARKET}

There are two central features of the U.S. commercial market: (1) its small size relative to the DOE market, and (2) that it is also subject to impacts from the uncertain environment surrounding the electric utility industry. It is estimated that the average commercial nuclear reactor has approximately $23,000 \mathrm{ft}^{2}$ of rad-contaminated concrete. Assuming that D\&D activities take an average of 3 years, each reactor undergoing D\&D will contribute annual demand for treatment of about $7,667 \mathrm{ft}^{2}$. As discussed in Chapter 2, there are currently 3 shutdown reactors scheduled for D\&D over the immediate future. There are a number of other reactors that have been shut down, but are currently being held in safe storage (which can be extended for 60 years before starting $D \& D)$. In addition, there are a group of other reactors whose permits will expire over the next 15 years. As will DOE, the commercial nuclear generation market will be evaluating its choices on when to start D\&D based upon a number of factors, including:

(1) Relative Success of Operating License Extension Applications. The industry is currently discussing the relative advantages of obtaining operating license extensions from NRC rather than closing some plants whose permits are expiring. The advantage of life extension is to allow depreciation costs to be spread out over a longer period and to delay the costs of D\&D. For example, Virginia Power applied for a 5-year license extension (Bretz, 1994, p. 38). It is uncertain at this point whether or not other utilities will decide to apply for such life extension approval.

(2) Cost/Benefit of Retrofit Options. Some utilities are finding that their nuclear plants have unattractively high costs per $\mathrm{kW}$ hour. Given the relatively low price of natural gas and improvements in gas turbine technologies, some utilities are considering converting their nuclear plants into gas-fired generation units. A conversion would probably require some concrete decontamination work, but may not require cleaning as large an area as under D\&D conditions.

(3) Implications of Electric Industry Deregulation. The electric industry is currently undergoing substantial changes brought about by allowing for competition in the electric generation market. Public utility commissions and the Federal Energy Regulatory Commission are considering how to handle "stranded" investments, which might include nuclear reactors whose generation costs are above the market rates. The decisions made by the Public Utility Commission and Federal Energy Regulatory Commission regarding how to restructure the industry and change the rules under which utilities operate may have an effect on when útilities decide to start $\mathrm{D} \& \mathrm{D}$ activities on any given reactor.

(4) Opportunity Costs of Holding Reactors in Safe Storage. Most of the reactors that have been closed over the last several years are being held in safe storage. This option offers the utilities the most flexibility and possibly the best economics. It allows the site to remain a power-producing site for future re-powering 
within the existing transmission system. It also allows some of the waste-management actions to be postponed until proper facilities are in place to accept all of the waste.

\subsection{INTERNATIONAL MARKET}

There is currently no good picture of international demand for decontamination of rad-contaminated concrete. Although it is recognized that it could be large, we do not have sources that provide an estimate of just how large nor of when D\&D activities might begin.

(1) Uncertainties Regarding Timing of $D \& D$. The foreign utilities will be facing many of the same issues as in the U.S. regarding life extension and opportunity costs associated with a variant of the safe storage option.

(2) Number and Capabilities of Foreign Concrete Decontamination Companies. National parochialism may dictate the development of companies to treat rad-contaminated concrete in each country with a nuclear program. If so, U.S. involvement may require partnerships with foreign companies involving the licensing of technologies originally developed in the U.S.

(3) Standards Established by Regulation. Much of the market in the U.S. is driven by Federal regulations. The volume of rad-contaminated concrete to be treated will depend upon the standards and definitions imposed by the governments of the separate countries. 


\subsection{RECOMMENDED MARKET STRATEGIES}

\subsection{TECHNOLOGY DIFFERENTIATION}

\subsubsection{Issues Affecting Technology Differentiation}

Although non-rad concrete decontamination is an established industry with accepted technologies, the decontamination of radioactively contaminated concrete is an immature industry. The unique hazards, regulatory situation, and costs of disposal that characterize radioactive contamination, along with the potential size of the DOE market, appear to open significant opportunities for new methods, particularly if they can cut disposal volumes, reduce worker exposure, or in some other way affect the cost drivers.

The variety of contaminants and situations affords many opportunities to find and exploit a niche. Niche markets could be based on physical or chemical characteristics of the contaminant or perhaps on the condition of the concrete itself. Some of the technologies described in Section 2.3 are predicated on elimination of secondary waste (soda blasting, $\mathrm{CO}_{2}$ pellets), others on more efficient removal of surface layers (microwave scabbling, expansive grout), others on selective separation of the contaminant from the concrete (laser ablation, ELECTROSORB $^{\mathrm{TM}}$, TECHXTRACT ${ }^{\mathrm{TM}}$ ). Given the variety of contaminants, the early stage of characterization within DOE, and the piecemeal approach to cleanup that DOE is pursuing, it is likely that no technology will dominate the market in the near to midterm and that profitable technological niches will continue to exist.

\subsubsection{Strategies for Differentiating Technologies}

In addition to the technological niches discussed in the preceding section, some firms differentiate themselves by offering decontamination services, and thus becoming a service provider in addition to or in place of the equipment provider role. EET, Inc., has taken this role with its TECHXTRACT ${ }^{\mathrm{TM}}$ chemical extraction process. Selling the decontamination service may be a necessity for technologies requiring considerable training and experience for successful application; it can be a strategic positioning decision for any technology, offering to the customer such benefits as improved integration of the entire decontamination process.

Another differentiation strategy for technology providers may involve teaming with the larger remediation contractor. Clients typically seek a solution involving a single responsible integrating contractor, which simplifies contracting and assignment of responsibility. Small, specialized service providers will be at a disadvantage at DOE sites, given the barriers to contracting and the weight given to the site-specific knowledge of the major contractor.

\subsection{BARRIERS TO IMPLEMENTATION}

There are no significant regulatory barriers to new entrants seeking to sell their services or technologies in this market. The limiting factor appears to be the relatively small size of the near-term market resulting from a severely constrained DOE clean-up budget, and a large number of competing projects with higher priority.

For the past several years, DOE's budget priorities have been oriented towards reduction of health and safety and environmental risks, and in maintaining compliance agreements. D\&D efforts are not closely associated with these priorities, but are oriented towards mortgage reduction, which is currently of lesser importance. Large-scale concrete decontamination efforts are usually part of a comprehensive facility D\&D activity and generally require a large upfront investment with a future benefit of reduced landlord costs. In the short run, it is more costly to D\&D than to place a facility in safe storage. 
The economics associated with D\&D activities and competing priorities have resulted in very limited D\&D activities being performed to date. The bulk of D\&D activities appear to be planned after the year 2010 when there is less competition for scarce DOE resources.

The commercial market appears to be following a similar approach as can be seen from the large number of nuclear power plants in safe storage versus those scheduled for immediate dismantlement.

Other factors potentially affecting technology implementation are the lack of precise characterization information about concrete contamination; sufficiently detailed, formal D\&D plans that project when, where and how much concrete will be decontaminated; and current procurement practices that make it difficult to award contingent cleanup contracts to companies that successfully demonstrate an innovative technology. 


\subsection{PERFORMANCE ASSESSMENT OF SELECTED INNOVATIVE TECHNOLOGIES}

The Treatment Selection Guide (DOE 1994b) was used as guidance for comparing the innovative technologies with the baseline technologies for decontamination of concrete. The innovative technologies are compared to the baseline technologies in terms of regulatory compliance, health and safety, effectiveness and implementability. These performance attributes, are defined in the text and summarized in Table 6.1. Table 6.1 also includes definitions assigned to rankings of high, medium, and low, which are next used to assess the innovative technologies.

Table 6.1 Definitions of Performance Attributes

\begin{tabular}{|c|c|c|c|}
\hline \multirow[b]{2}{*}{ FACTORS } & \multicolumn{3}{|c|}{ SCREENING CRITERIA } \\
\hline & High Score & Medium Score & Low Score \\
\hline Regulatory Compliance & $\begin{array}{l}\text { All process-related regulations } \\
\text { are met. }\end{array}$ & $\begin{array}{l}\text { Most regulations are met, with the } \\
\text { balance possibly being met through } \\
\text { requests for variance. }\end{array}$ & $\begin{array}{l}\text { Majority of regulations } \\
\text { cannot be met without } \\
\text { variances or other extensive } \\
\text { measures. } \\
\end{array}$ \\
\hline \multicolumn{4}{|l|}{ Health \& Safety } \\
\hline $\begin{array}{l}\text { Environment/Public Health \& } \\
\text { Safety }\end{array}$ & $\begin{array}{l}\text { Little or no emissions for } \\
\text { routine operations or under all } \\
\text { but the most catastrophic } \\
\text { accidents. }\end{array}$ & $\begin{array}{l}\text { Little or no emissions for routine } \\
\text { operations but significant releases } \\
\text { under most accident scenarios. }\end{array}$ & $\begin{array}{l}\text { Marginally acceptable } \\
\text { releases under routine } \\
\text { operations and/or extensive } \\
\text { releases under accident } \\
\text { scenario. } \\
\end{array}$ \\
\hline Worker Health \& Safety & $\begin{array}{l}\text { Significantly fewer workers } \\
\text { potentially exposed or } \\
\text { potential exposure much lower } \\
\text { than average exposure with } \\
\text { baseline technologies. }\end{array}$ & $\begin{array}{l}\text { Average number of workers and } \\
\text { potential exposure levels } \\
\text { (comparable to baseline } \\
\text { technologies). }\end{array}$ & $\begin{array}{l}\text { Greater than average number } \\
\text { of workers required or greater } \\
\text { than average potential } \\
\text { exposure to the work force } \\
\text { (as compared to baseline } \\
\text { technologies). }\end{array}$ \\
\hline \multicolumn{4}{|l|}{ Effectiveness } \\
\hline Volume Reduction & $\begin{array}{l}\text { Volume of generated waste is } \\
\text { less than baseline technology. }\end{array}$ & $\begin{array}{l}\text { Volume of generated waste is } \\
\text { comparable to baseline technology. }\end{array}$ & $\begin{array}{l}\text { Volume of generated waste is } \\
\text { greater than baseline } \\
\text { technology. }\end{array}$ \\
\hline Secondary Waste Generation & $\begin{array}{l}\text { Secondary waste is easily } \\
\text { treated or less secondary waste } \\
\text { is generated. }\end{array}$ & $\begin{array}{l}\text { Treatment of secondary waste is } \\
\text { difficult or quantity of secondary } \\
\text { wastes generated is comparable. }\end{array}$ & $\begin{array}{l}\text { Secondary waste is difficult } \\
\text { to treat or more secondary } \\
\text { waste is generated. }\end{array}$ \\
\hline Efficiency & $\begin{array}{l}\text { Technology performs better } \\
\text { than baseline technologies. }\end{array}$ & $\begin{array}{l}\text { Technology comparable to baseline } \\
\text { technologies. }\end{array}$ & $\begin{array}{l}\text { Technology not as effective } \\
\text { as baseline technologies. }\end{array}$ \\
\hline Flexibility & $\begin{array}{l}\text { Technology capable of use on } \\
\text { a wide variety of media. }\end{array}$ & $\begin{array}{l}\text { Technology applicable to limited } \\
\text { media. }\end{array}$ & $\begin{array}{l}\text { Technology applicable to a } \\
\text { specific medium. }\end{array}$ \\
\hline Implementability & $\begin{array}{l}\text { Most of the equipment and the } \\
\text { process has been previously } \\
\text { demonstrated. }\end{array}$ & $\begin{array}{l}50 \% \text { or less of the equipment/ } \\
\text { components have been previously } \\
\text { demonstrated. }\end{array}$ & $\begin{array}{l}\text { The technology is in the basic } \\
\text { research stage. Further } \\
\text { research is needed prior to a } \\
\text { pilot scale demonstration. }\end{array}$ \\
\hline
\end{tabular}

\section{Regulatory Compliance}

This factor assesses the ease with which Federal, state, and local regulations and DOE Orders are satisfied by application of the technology. The regulatory requirements specifically include state and local laws and regulations, U.S. Environmental Protection Agency (EPA), NRC, Department of Transportation (DOT regulations), and DOE Orders. High rankings are given to D\&D technologies that have been previously permitted and are relatively straightforward and lower rankings to those technologies that require regulatory exemptions or demonstrations of equivalency that may pose additional permitting difficulties. 


\section{Health and Safety}

The health and safety factor consists of two sub-factors-(1) environment/public health and safety; and (2) worker health and safety. This factor gives high rankings to technologies posing little or no additional risk to the public or remedial workers.

\section{Environment/Public Health and Safety}

This sub-factor assesses risk to all off-site populations due to the proposed technology. This assessment includes routine emissions (radiological and hazardous) under normal operating conditions, under less than ideal conditions (e.g., contaminants marginally characterized or overly aggressive production schedules), and accident scenarios.

\section{Worker Health and Safety}

This sub-factor assesses occupational risks to all on-site workers due to routine operations, including radiological and hazardous chemical exposure during the actual decontamination/ demolition operation, handling of the waste, treatment of the waste, packaging of the waste and/or treatment residuals, and routine equipment maintenance. Risks due to accidents include radiological and hazardous substance exposure resulting from equipment failure (with possible associated fires or explosions) or worker error.

\section{Effectiveness}

The effectiveness factor assesses how well the proposed technology performs technically and what the anticipated advantages or limitations are compared to baseline (conventional) technologies. The effectiveness factor consists of four sub-factors: volume reduction, secondary waste generation, efficiency, and flexibility.

\section{Volume Reduction}

This sub-factor assesses the ability of the innovative technology to reduce the volume of waste generated (i.e., waste minimization or waste disposal cost avoidance) as compared to the baseline methods.

\section{Secondary Waste Generation}

This sub-factor assesses the difficulty of managing material that becomes contaminated during the D\&D activities. Secondary waste may have additional chemical or other characteristics providing new problems relating to treatment and disposal, including contaminated filters, contaminated protective equipment, used oil, and/or gases. The relative ranking should be assigned based on the level of difficulty associated with managing the secondary waste.

\section{Efficiency}

This sub-factor assesses the relative ability of the innovative technology to remove contamination or denolish structures as compared to the baseline technologies. 


\section{Flexibility}

This sub-factor rates the ability of the D\&D technology to decontaminate or demolish a variety of media. Technologies effective for various media (i.e., steel, concrete, wood) would be ranked higher than those limited to one media.

Implementability

The implementability factor assesses the ease and likelihood of bringing the D\&D technology into full-scale operation. The implementability element gives high rankings to technologies that can be designed, built, demonstrated, and availability. Preference was given to technologies proven effective in pilot or full-scale applications under conditions similar to those anticipated.

Key performance attributes and advantages of innovative technologies for decontamination of concrete are summarized in Table 6.2. Due to the limited availability of actual decontamination cost data at this time, no conclusions can be reached on the potential cost effectiveness of the technologies, although the potential for cost avoidance is typically one of the primary objectives of all the included innovative technologies. Therefore, the cost factor was not included in Table 6.2. Stakeholders' objectives are also not well defined at this time; however, none of the existing baseline technologies are known to be adversely perceived by the public. The innovative technologies are generally sufficiently similar to the baseline technologies, so it can be speculated that they also should not meet significant objections from the public. Because of this, the stakeholders objectives were also not included in Table 6.2. 
Table 6.2 Assessment of Selected Technologies

\begin{tabular}{|c|c|c|c|c|c|c|c|c|}
\hline \multirow[b]{2}{*}{ Technology } & \multirow{2}{*}{$\begin{array}{l}\text { Regulatory } \\
\text { Compliance }\end{array}$} & \multicolumn{2}{|c|}{ Environmental Health \& Safety } & \multicolumn{4}{|c|}{ Effectiveness } & \multirow[t]{2}{*}{ Implementability } \\
\hline & & $\begin{array}{l}\text { Environment/ } \\
\text { Public Health }\end{array}$ & $\begin{array}{c}\text { Worker Health } \\
\text { and Safety }\end{array}$ & $\begin{array}{l}\text { Volume } \\
\text { Reduction }\end{array}$ & $\begin{array}{l}\text { Secondary } \\
\text { Waste } \\
\text { Generation }\end{array}$ & Efficiency & Flexibility & \\
\hline $\begin{array}{l}\text { Electrokinetic Decontamination of Concrete - } \\
\text { Isotron Corp. }\end{array}$ & High & High & High & High & Medium & Low & Medium & Low \\
\hline Soda Blasting - O'Brien \& Gore & High & High & High & High & High & Medium & Medium & High \\
\hline $\begin{array}{l}\text { Electro-Hydraulic Scabbing - } \\
\text { AVCO/TEXTRON Defense Systems }\end{array}$ & High & High & Medium & Medium & Low & Low & Medium & Low \\
\hline $\begin{array}{l}\text { Decon/Recycle of Concrete AWD-CON } \\
\text { Process - AWD Technology }\end{array}$ & High & High & Medium & High & Medium & Medium & Medium & Medium \\
\hline Microwave Scabbling of Concrete & High & High & High & High & High & Unknown & Unknown & Low \\
\hline Laser Decontamination & High & High & High & High & High & Unknown & Unknown & Medium \\
\hline Expansive Grout & High & High & High & Medium & High & High & Low & High \\
\hline TECHXTRACT - EET & High & High & High & High & Medium & Medium & High & High \\
\hline $\begin{array}{l}\text { Centrifugal Carbon Dioxide Pellet Turbo- } \\
\text { Blaster - Cryogenic Applications, Inc. }\end{array}$ & High & High & High & High & High & High & High & High \\
\hline Concrete Crushing Aggregate Machinery & Medium & High & High & High & High & High & Medium & High \\
\hline $\begin{array}{l}\text { Blastox Blended Abrasives - TDY Group, } \\
\text { Inc. }\end{array}$ & High & High & High & High & High & High & High & High \\
\hline
\end{tabular}




\subsection{CONCLUSIONS}

The decontamination of radioactivity-contaminated concrete is a potentially large market dominated by the facilities in the DOE nuclear complex. So far, some 600 million $\mathrm{ft}^{2}$ of radioactivity-contaminated concrete has been identified within the DOE complex, with the expectation that much more could be identified as characterization proceeds. The commercial market potential is smaller by two orders of magnitude.

Despite this potentially large market, the expected demand for concrete decontamination over the next $10-15$ years is only about 1.6 million $\mathrm{ft}^{2}$ per year, based on reported plans by DOE sites and electric utilities. At that rate, only 4 percent of the contaminated concrete would be decontaminated by the year 2010 .

This delay of final disposition is a predominant characteristic of both the Federal and the commercial market. Only 3 of 12 retired commercial nuclear power plants are scheduled for decontamination and decommissioning before 2010, suggesting that economics favors delay. The only market force pushing for faster disposition of retired nuclear facilities is the political need for the DOE to show quick results and reduce expenses. The 10-year plan being developed by DOE has the goal of faster results, but would reduce expenditures below those assumed in the 1.6-million- $\mathrm{ft}^{2}$-per-year forecast. Budget realities are more likely to delay decontamination than to speed it up.

At an assumed average cost of $\$ 3$ per $\mathrm{ft}^{2}$, the market looks to be flat at about $\$ 4.8$ million per year for the foreseeable future. If the equipment component is half of the total, the equipment market is only $\$ 2.4$ million per year. A market this small gives private industry little room for investment. Research and development (R\&D) funding for private industry typically runs at a few percent of sales. Assuming 5 percent, a $\$ 2.4$ million annual market would support only $\$ 120,000$ per year in R\&D. With 15 to 20 firms in the industry, the market leader would likely have no more than 30 percent of the market, and invest no more than $\$ 36,000$ per year. Thus, the potential is small for cost sharing by private industry in developing advanced concrete decontamination technologies for DOE. 


\subsection{REFERENCES}

Aerojet Tennessee Environmental Services. 1993. Sponge-Jet Decontamination at Aerojet. $D$ \& $D$ Technologies. Volume 1. Issue 1. Jonesborough, Tennessee. May.

Amrit, S. 1995. BNI, Oak Ridge, TN. Teleconference from S. Amrit (Innovative D \& D practices at Colonie) to M. Skorsak, SAIC Oak Ridge, TN, June 30.

Amrit, S., B. Kapoor, R., Foster, E. Newberry \& M. Jocelyn (BNI). 1995. Removal of Regulated Organic Compounds from a Tarlike Mixed-Waste Matrix. DOE ER ‘95 Conference. CCN 117791.

Archibald, K.E. 1995. Concrete Decontamination Scoping Tests. Idaho National Engineering Laboratory. Lockheed Idaho Technologies Co. INEL-94/0022. Idaho Falls, Idaho. January.

Bartlett Services, Inc. Plymouth, Massachusetts.

Beck, D. 1995. Lockheed-Martin, Oak Ridge, TN. Teleconference to D. Beck (Liquid phase decontamination methods) from M. Skorska, SAIC Oak Ridge, TN. July 10.

Bonem, M.W. \& R.E. Borah. Innovative Approaches to Improve Decontamination - the TECHXTRACT Process for Unrestricted Recycle or Reuse of Radioactively-Contaminated Metals. Beneficial Reuse '95. Third Annual Conference on the Recycle and Reuse of Radioactive Scrap Metal. Knoxville, Tennessee. July 31 August 3.

Borah, R.E. \& M.W. Bonem. 1994. Innovative Approaches to Improve Decontamination - the TECHXTRACT ${ }^{T M}$ Technology. Hazardous Materials Control Research Institute. Federal Environmental Restoration III Conference. New Orleans, Louisiana. April.

Bosch, L. 1995. Aggregate Machinery, Inc., Salem, OR. Teleconference to L. Bosch (Information about rebar separation machinery - Thunderbird Recycling Plant) from S. Lanter, SAIC Oak Ridge, TN. CCN 1044.950816.019. August 2.

Bossant, S.J. \& J. Moore. Innovative Technologies for Recycling Contaminated Concrete and Scrap Metal.

Bostick, W.D., S.A. Bush, G.C. Marsh, H.M. Henson, W.D. Box \& I.L. Morgan. 1993. Electroosmotic Decontamination of Concrete. Contract DE-AC05-84OR21400. March.

Bracke, T. 1994. Report of the Decontamination of B-151 Hallway Closet. Radiation Science, Inc. June.

Bretz, Elizabeth A., 1994. "Special Report on Nuclear Power: Is Decommissioning all that Remains for the Industry? Or will License Renewal Become a Reality?" Electrical World, Vol. 208, Issue 7, July, pp. 27-41.

Bundy, R. 1995. Battelle, Oak Ridge, Tennessee.

Byrne, M. 1995. Manufacturing Sciences Corporation, Oak Ridge, TN. Teleconference to M. Byrne (Discussion of general cost data for MSC decon methods) from S. Lanter, SAIC Oak Ridge, TN. June 22.

Carder, B. 1995. SEG, Oak Ridge, TN. Teleconference to B. Carder (Processing of radiologically contaminated scrap metal) from S. Lanter, SAIC Oak Ridge, TN. May 24. 
Castleberry, E. 1995. Battelle, Columbus, Ohio. Teleconference to E. Castleberry (Cost data for D \& D) from S. Lanter, SAIC Oak Ridge, TN. June 20.

Catlett, K. 1995. DOE Waste Program Integration Branch. Oak Ridge, TN. Teleconference to K. Catlett from R. Wright, SAIC Oak Ridge, TN. CCN 1044.950825.002.

Chiacos, C. 1995. Polygon Industries. San Francisco, CA.

Church, D. 1995. Fabtec, Inc. Idaho. Teleconference to D. Church (Discussion of BNI rock crusher system) from S. Lanter, SAIC Oak Ridge, TN. May 24.

Compere, A.L., W.L. Griffith, H.W. Hayden, J.S. Johnson \& D.F. Wilson. 1994. Contaminated Nickel Scrap Processing. ORNL/TM-12900. Oak Ridge, TN. December.

Cyro Dynamics, Inc. Bangor, Maine.

D \& D Integrated Demonstration Technical Support Group, 1994. Technical Program Plan for the Transitioning, Decommissioning, and Final Disposition Focus Area. DOE/NBM-1101. Revision 0. January.

D \& D News. 1995. Volume 2:1. January.

Davenport, D. \& T. Houk. 1995. Evaluation of the TECHXTRACT ${ }^{T M}$ Surface Decontamination Process. DOEF-MMES-04. Piketon, Ohio. April.

Demolition Technologies Incorporated (DTI). 1993. Non-explosive Demolition Agent. Super Bristar 2000. Greenville, Alabama.

Direnbower, C. 1995. BNI, Oak Ridge, TN. Teleconference to C. Direnbower (Query about engineering drawings for MSP) from S. Lanter, SAIC Oak Ridge, TN. CCN 1044.950712.007. July 12.

DOE. 1993. $D \& D$ Technologies. The Decommissioning and Decontamination Briefing. Richland, Washington. Kaiser Engineers Hanford Co. Volume 1, Issue 1.

DOE. 1994. Decommissioning Handbook. DOE/EM-0142P. Oak Ridge, TN. March.

DOE Office of Environmental Restoration (EM-40). 1994a. Decontamination and Decommissioning Guidance Document. January 14.

DOE Office of Environmental Restoration. 1994b. Office of Technology Development: Office of Research \& Development. Office of Demonstration, Testing and Evaluation. FY 1994 Program Summary. Decontamination and Decommissioning of Facilities. DOE/EM-0216. October.

Edelson, M. 1995. AIMES Laboratory, Iowa. Metal Decontamination using high power lasers.

EET, Inc. (Environmental Extraction Technologies for the Future). 1995. An Introduction to the TECHXTRACT ${ }^{T M}$ Contaminant Extraction Technology. Bellaire, Texas. June. 
Environmental Alternatives, Inc. Carbon Dioxide Blasting as a Non-Destructive Method for Nuclear Material Decontamination. West Chesterfield, New Hampshire.

Escue, L. 1995. O’Brien \& Gere Engineers, Inc. Oak Ridge, TN. Teleconference from L. Escue (Discussion on PRDA contract; also blasting techniques and demo lead) to S. Lanter, SAIC Oak Ridge, TN. CCN 1044.950619.004. June 20.

Fab Tec, Inc. 1995. The Fab Tec Self Contained AX Torgerson Impactor Plant. Moscow, Idaho.

Foster, C.A., 1995. Cyrogenic Applications F, Inc.

Generic Environmental Impact Statement in Support of Rulemaking on Radiological Criteria for Decommissioning of NRC-Licensed Nuclear Facilities, Volume 2: Appendices.

Gernsky, T.M. 1995. Facility Deactivation, Decommissioning and Material Disposition Focus Area. DOE EM-452. April.

Goldfarb, V. 1995. Textron Defense Systems, Everett, MA.

Hashish, M. 1989. Machining of Advanced Composites with Abrasive-Waterjets Quest Integrated, Inc. Kent, Washington. Washington Review, Vol. 2., No. 2. June.

Hensley, L.C., D.C. Haley \& J.R. Hale. 1995. Dismantlement Scenario for Massive Facilities with Low Levels of Contamination. TTP No. OR1-5-20-05 and TTP No. OR1-5-20-06. Oak Ridge, TN. March.

IceSolv, Inc. Dry Ice Blast Cleaning Services. Palmyra, Pennsylvania.

Jevec, J. 1995. Babcock \& Wilcox, Alliance, Ohio. Teleconference to J. Jevec (Discussion on technology for chelating chemicals to remove heavy metals and radioactive contamination) from A. Bahl, SAIC Oak Ridge, TN. CCN 1044.950627.006. June 21.

Johnston, H. \& W.R. Mincks. 1995. Cost Effective Waste Minimization for Construction Managers. Irn: The Change Notice R.S. Means Company, Inc. Kingston, Massachusetts. Second Quarter.

Kaye, M.E., J.H. Wright \& J.L. Davis (BNI). 1988. Post-Remedial Action Report for the Albany Research Center, Albany, Oregon. DOE/OR/20722-207. Oak Ridge, TN. December.

Kibbe, K. 1994. Battelle, Oak Ridge, TN. Memorandum from K. Kibbe (Transmittal of Revised Cost Savings Information for D \& D Focus Area for GDPs) to J. Hyde, DOE-OR, TN. f:112994-3.19

Kibbe, K. 1995. Battelle, Oak Ridge, TN. Teleconference to K. Kibbe (Cost Data and other information for Building D \& D) from S. Lanter, SAIC Oak Ridge, TN CCN 1044.950619.009. June 19.

Large, D. 1995. SEG, Oak Ridge, TN. Teleconference to D. Large (Discussion of EPA cost data report) from S. Lanter, SAIC Oak Ridge, TN. CCN 1044.950619.007. June 13.

Liby, A. 1995. Manufacturing Sciences Corp., Oak Ridge, TN. Teleconference to A. Liby (Information on MSC projects related to Building Decontamination and Decommissioning) from S. Lanter, SAIC Oak Ridge, TN. May 23. 
Lien, S.C.T. 1995. The Problem, Driver and Strategy of Facility Deactivation, Decommissioning, and Material Disposition Focus Area. WGB95-0188. DOE Office of Technology Development. April.

Lomasney, H. 1995. Isotron Corp., New Orleans, LA. Teleconference to H. Lomasney (Technical information and cost data on Isotron's ELECTROSORB process) from S. Lanter, SAIC Oak Ridge, TN.

Loosemore, R. 1995. EET, Inc., Oak Ridge, TN. Teleconference to R. Loosemore (EET Surface Decontamination Process) from M. Skorska, SAIC Oak Ridge, TN. July 24.

Manufacturing Sciences Corporation. Oak Ridge, Tennessee.

McCracken, S. 1995. DOE Weldon Springs, MO. Teleconference to S. McCracken (Discussion on Building D \& D) for R. Wright, SAIC Oak Ridge, TN. CCN 1044.950825.003. August 24.

Meservey, R.H., D.S. Vandel, M. Little \& J.S. Ferguson. 1994a. Idaho National Engineering Laboratory Decontamination and Decommissioning Technology Logic Diagram. Volume I. EGG-WTG-11104. Idaho Falls, Idaho. January.

Meservey, R.H., D.S. Vandel, M. Little \& J.S. Ferguson. 1994b. Idaho National Engineering Laboratory Decontamination and Decommissioning Technology Logic Diagram. Volume II. EGG-WTG-11104. Idaho Falls, Idaho. January.

Meservey, R.H., D.S. Vandel, M. Little \& J.S. Ferguson. 1994c. Idaho National Engineering Laboratory Decontamination and Decommissioning Technology Logic Diagram. Volume III. EGG-WTG-11104. Idaho Falls, Idaho. January.

Meyer, R. 1995. SEG Oak Ridge, TN. Teleconference to R. Meyer (Cost data for SEG PRDA contracts) from S. Lanter, SAIC Oak Ridge, TN. CCN 1044.950619.010. June 19.

MMES, 1993a. Oak Ridge K-25 Site Technology Logic Diagram. Volume 1. Technology Evaluation. K2073. Oak Ridge, TN. February 26.

MMES, 1993b. Oak Ridge K-25 Site Technology Logic Diagram. Volume 2. Technology Logic Diagrams. K-2073. Oak Ridge, TN. February 26.

MMES, 1993c. Oak Ridge K-25 Site Technology Logic Diagram. Volume 3. Technology Evaluation Data Sheets. Part A. Characterization, Decontamination, Dismantlement. K-2073. Oak Ridge, TN. February 26.

MMES, 1993d. Electroosmotic Decontamination of Concrete. DE-AC05-84OR21400. Oak Ridge, TN. March.

MMES, 1993e. Oak Ridge National Laboratory Technology Logic Diagram. Volume 1. Technology Evaluation. Part A. Decontamination and Decommissioning. ORNL/M-2751/V1/Pt.A. Oak Ridge, TN. September.

MMES, 1993f. Oak Ridge National Laboratory Technology Logic Diagram. Volume 1. Technology Evaluation. Part B. Remedial Action. ORNL/M-2751/V1/Pt.B. Oak Ridge, TN. September. 
MMES, 1993g. Oak Ridge National Laboratory Technology Logic Diagram. Volume 2. Technology Logic Diagram. Part A. Decontamination and Decommissioning. ORNL/M-2751/V2/Pt.A. Oak Ridge, TN. September.

MMES, 1993h. Oak Ridge National Laboratory Technology Logic Diagram. Volume 2. Technology Logic Diagram. Part B. Remedial Action. ORNL/M-2751/V2/Pt.B. Oak Ridge, TN. September.

MMES, 1993i. Oak Ridge National Laboratory Technology Logic Diagram. Volume 3. Technology Evaluation Data Sheets. Part B. Dismantlement, Remedial Action. ORNL/M-2751/N3/Pt.B. Oak Ridge, TN. September.

MMES, 1993j. Oak Ridge National Laboratory Technology Logic Diagram. Indexes. ORIVL/M2751/V1/Pt.B. Oak Ridge, TN. September.

MMES, 1994. Environmental Technologies and Applications: Materials and Chemistry Laboratory at the Oak Ridge K-25 Site. K/TCD-1110. July.

Moore, J., D.W. Neiswander \& G.A. Person. 1995. PRDA Programs at the Oak Ridge K-25 Site. Oak Ridge, TN.

Morgan Energy Technology/R.C. Bedick. 1995. Implementation of Facility Deactivation, Decommissioning \& Materials Disposition Focus Area. M95001807W.

Neiswander, D. 1995. Lockheed-Martin, Oak Ridge, TN. Teleconference to D. Neiswander (Discussion of cost data for D \& D techniques used for PRDA contract at K-25) from S. Lanter, SAIC Oak Ridge, TN. CCN 1044.950619.006. June 19.

Newberry, E.T. 1995. BNI, Oak Ridge, TN. Teleconference to E. Newberry (Innovative D \& D practices at Colonie) from M. Skorska, SAIC Oak Ridge, TN. June 30.

Newberry, E.T. M. Kaye \& G. Borden. 1995. The Colonie Condition: A case Study in Managing Small Quantities of Mixed Wastes. BNI 139-0050, Oak Ridge, TN. June 9.

Noell. SuperCompaction System. Wurzberg, Germany.

Nondestructive Cleaning, Inc. NDC No. 92-435. Walpole, Massachusetts.

O'Brien \& Gere Companies. 1995. Remediation Technologies: Classification, Media and Status. Poster.

O'Brien \& Gere Companies/Grieco, S.A., E.D. Neubauer \& J.R. Rhea. 1995 Removal and Treatment of Radioactive and Treatment of Radioactive, Organochlorine, and Heavy Metal Contaminants from Solid Surfaces. HM CRI '95.

O’Brien \& Gere Engineers, Inc. 1995. Qualifications: Technical Capabilities. DOE.

O'Brien \& Gere Technical Services. 1995. Radioactive and Hazardous Surface Decontamination Utilizing Soda Blasting. Syracuse, New York. March.

Price, G. 1995. Battelle, Oak Ridge, TN. 
Proceedings from Spectrum '94, Nuclear and Hazardous Waste Management International Topical Meeting. August 13-18, 1994.

Proceedings from DOE ER ‘93 Environmental Remediation Conference. October 24-28, 1993.

Quest Integrated, Inc. Kent, Washington.

Resnik, A. 1995. Oceaneering Technologies, Upper Marlboro, MD. Teleconference to A. Resnik (Discussion of new $\mathrm{ROVCO}_{2}$ system for decontamination of concrete) from A. Bahl, SAIC Oak Ridge, TN. CCN 1044950627.005. June 21.

SanGiovanni, M.L. 1993. Dry Ice Pellet Blasting... a cool alternative. Industrial Cleaning Contractor. March.

Scientific Ecology Group (SEG), Inc. 1995. Statement of Qualifications: Remediation and Decommissioning Services. Rev. 011395-PUB/SOQ/STA/TOC.R14. January 10.

Scientific Ecology Group (SEG), Inc. 1995. Statement of Qualifications:_Radiological Engineering Services. Rev. 012095-PUB/SOQ/RAD_ENG/TOC.R1. January 30.

Scientific Ecology Group (SEG), Inc. 1995. Statement of Qualifications: Radioactive Waste Management and Facility Design. Rev. 013095-PUB/SOQ/SANDIA/TOC.R1. Oak Ridge, TN. February 2.

Seay, W.M., J.D. Kopotic \& P.W. McDaniel. 1995. Crushing Leads to Waste Disposal Savings for FUSRAP. CCN 128357. GN-0145. Oak Ridge, TN. March 23.

Seay, W.M. \& L. Price. 1995. FSRD, Oak Ridge, TN. Meeting (Need for Cost Data for Waste Minimization Task) with R. Wright, SAIC Oak Ridge, TN. CCN 1044.9505030.002. June 26.

Sylvester, M. 1995. Dow Environmental. Rockville, MD.

TDJ Group 1996: Letter to M. Skorska of SAIC from Terrance P. Tripp of TDJ Group, Inc., June 21, 1996.

Textron Defense Systems. Electrohydraulic $(\mathrm{EH})$ process. Everett, Massachusetts.

Thunderbird Industries. 1995. Recycle Plants. Aggregate processing and recycling equipment. Pamphlets. Salem, Oregon.

Thunderbird Industries. 1995. Recycling Plant. Model \#131551621 VR3. Video. Salem, Oregon.

Vacu-Blast Corporation. Kenilworth, New Jersey.

Welch, K. 1995. M4 Technologies, Oak Ridge, TN. Teleconference to K. Welch (Request for cost estimate/cost data for M4 catalytic extraction process for recycling metal) from S. Lanter, SAIC Oak Ridge, TN. CCN 1044.950619.005.

Wheelabrator Corporation. Blastrac Portable Blast Cleaning Systems. Shenandoah, Georgia. 
Williams, S. 1995. Dow Environmental. Teleconference to S. Williams (Request for information on Decontamination/Recycling of concrete PRDA contract) from S. Lanter, SAIC Oak Ridge, TN. 
APPENDIX A

MARKET ASSESSMENT CONTACT LIST 
TABLE A-1 MARKET ASSESSMENT CONTACT LIST

\begin{tabular}{|c|c|c|}
\hline Organization & Name & Telephone Number \\
\hline Adtex, a JCG affiliate & Jim Cross & (423) 481-0422 \\
\hline Aggregate Machinery, Inc. & Steve Cowden & (503) $390-6284$ \\
\hline Atomic Energy of Canada, Ltd. & Ross Meadowcroft & (613) 584-3311 \\
\hline Babcock \& Wilcox & Chuck Peach & (804) 522-6239 \\
\hline CASS Corporation, Nelco Div. & Chris Nighbor & (800) 256-3440. \\
\hline Corpex Technologies & Vance Syphers & (919) 941-0847 \\
\hline Demolition Technologies & Tony Niehans & (334) $382-1000$ \\
\hline Duke Engineering \& Services & Dennis Skrincosky & (703) 713-9000 \\
\hline F2 Associates & Joyce Freiwald & $(505) 271-0260$ \\
\hline Fernald Environmental Management Project & Ms. L. Miller & (513) $648-4104$ \\
\hline GenCorp Aerojet & Charles McCary & (423) $753-1388$ \\
\hline Hanford Site & Mr. M. Mihalik & (509) 373-1382 \\
\hline ISOTRON Corp & Henry Lomasney & (504) 254-4624 \\
\hline NES, Inc. & Karen Craig & (203) 796-5298 \\
\hline O'Brien \& Gere Technical Services & Eric Newbauer & (315) 437-6400 \\
\hline Oak Ridge Gaseous Diffusion Plant, K-25 & Mr. R. McMahon & (423) 576-9979 \\
\hline Oak Ridge, Y-12 Plant & Mr. B. Walton & (423) $241-2695$ \\
\hline PENTEK, Inc. & Ben Nichols & (412) $262-0725$ \\
\hline Polygon Industries & Mitzy Frizell & (415) 391-6063 \\
\hline Portsmouth Gaseous Diffusion Plant & Mr. B. Partane & (614) 897-4374 \\
\hline Rocky Flats & Mr. J. Chapin & (303) 966-3018 \\
\hline $\begin{array}{l}\text { Rocky Mountain Remediation Services, a } \\
\text { BNFL/MK Ferguson affiliate }\end{array}$ & Noresh Jain & (704) $382-5935$ \\
\hline Savannah River Site & $\begin{array}{l}\text { Ms. H. Dukes } \\
\text { Mr. B. Austin } \\
\text { Mr. T. Butcher }\end{array}$ & $\begin{array}{l}(803) 557-3729 \\
(803) 557-9455 \\
(803) 725-5810 \\
\end{array}$ \\
\hline TDJ Group, Inc. & James Lively & $(847 /) 639-1113$ \\
\hline Textron Defense Systems & Victor Goldfarb & $(508) 657-5111$ \\
\hline $\begin{array}{l}\text { U.S. Army, Radioactive Waste Disposal } \\
\text { Division }\end{array}$ & Mr. S. Mapely & (309) $782-2933$ \\
\hline U.S. Nuclear Regulatory Commission & $\begin{array}{l}\text { Mr. B. Wood } \\
\text { Mr. M. Webb } \\
\text { Mr. R. Dudley }\end{array}$ & $\begin{array}{l}(301) 415-1183 \\
(301) 415-1347 \\
(301) 415-1116\end{array}$ \\
\hline University of North Dakota & Ames Grisanti & (701) $777-5158$ \\
\hline Westinghouse Hanford & Jim Berger & (509) 376-9942 \\
\hline
\end{tabular}


APPENDIX B

GENERIC/REFERENCE FACILITY SURFACE CONTAMINATION ESTIMATES 
TABLE B-1

DISTRIBUTION OF CONTAMINATED CONCRETE SURFACE AREAS WITHIN THE REFERENCE RESEARCH REACTOR ${ }^{(a)}$

\begin{tabular}{|l|c|}
\hline \multicolumn{1}{|c|}{ Location } & Estimated Surface Area, $\mathbf{f t}^{2}$ \\
\hline Reactor Building and Containment Vessel & 61,000 \\
\hline Hot Laboratory Building & 24,000 \\
\hline Fan House & 750 \\
\hline Waste Handling Building & 4,230 \\
\hline Primary Pump House & 2,500 \\
\hline Hot Retention Area & 450 \\
\hline Cold Retention Area & 13,470 \\
\hline Office and Laboratory Building and Sumps & 1,100 \\
\hline Total & 107,500 \\
\hline
\end{tabular}

Source: NUREG-1496

(a) Estimates of percent of surface area contaminated given in Konzek 1982 are considered to be too high for an operating plant. An average value of 10 percent is used in Table 7.1.1 based on operating data from power reactors.

TABLE B-2

DISTRIBUTION OF CONTAMINATED CONCRETE SURFACE AREAS WITHIN THE REFERENCE RESEARCH REACTOR

\begin{tabular}{|c|c|c|}
\hline Location & Estimated Surface Area, $\mathrm{ft}^{2}$ & Estimated Area Contaminated, \% \\
\hline \multicolumn{3}{|l|}{ Reactor Building } \\
\hline Surfaces & 1050 & 100 \\
\hline Reactor Top & 100 & 20 \\
\hline Fuel Storage Pits & 5 & 100 \\
\hline \multicolumn{3}{|l|}{ Annex } \\
\hline Hot Cell & 145 & 100 \\
\hline Hot Lab & 430 & 10 \\
\hline Hot Lab Sump & 16 & 100 \\
\hline \multicolumn{3}{|l|}{ Heat Exchange Building } \\
\hline Floor & 580 & 10 \\
\hline Sump & 160 & 100 \\
\hline \multicolumn{3}{|l|}{ Pump House } \\
\hline Concrete Floor & 645 & 10 \\
\hline Sump & 160 & 100 \\
\hline \multicolumn{3}{|l|}{ Waste Storage Room } \\
\hline Concrete Floor & 410 & 10 \\
\hline Sump & 160 & 100 \\
\hline Radiation Center Building & 30,000 & 4 \\
\hline Total & 35,005 & 10 \\
\hline
\end{tabular}

Source: Nureg-1496 
TABLE B-3

DISTRIBUTION OF CONTAMINATED CONCRETE FLOOR AREAS IN THE REFERENCE URANIUM FUEL FABRICATION FACILITY

\begin{tabular}{|c|c|c|c|}
\hline Location & $\begin{array}{c}\text { Estimated Surface } \\
\text { Area, } \mathrm{ft}^{2}\end{array}$ & $\begin{array}{c}\text { Estimated Area } \\
\text { Contaminated, \% }\end{array}$ & $\begin{array}{c}\text { Contamination Level, } \\
\mathrm{pCi} / \mathrm{cm}^{3}\end{array}$ \\
\hline $\begin{array}{l}\text { Fuel Manufacturing } \\
\text { Building }\end{array}$ & 208,000 & 50 & 73 \\
\hline $\begin{array}{l}\text { Chemical Metallurgical } \\
\text { Laboratory }\end{array}$ & 8,300 & 40 & 73 \\
\hline $\begin{array}{l}\text { Uranium Scrap } \\
\text { Recovery Room }\end{array}$ & 3,700 & 90 & 73 \\
\hline $\mathrm{UO}_{2}$ Powder Warehouse & 8,700 & 30 & 73 \\
\hline $\begin{array}{l}\text { Contaminated Waste } \\
\text { Incinerator }\end{array}$ & 2,400 & 100 & 73 \\
\hline $\begin{array}{l}\text { Fluoride and Nitrate } \\
\text { Waste Treatment Plant }\end{array}$ & 2,500 & 100 & 73 \\
\hline Boiler Steam House & 1,100 & 0 & 0 \\
\hline Total & 234,700 & 50 & - \\
\hline
\end{tabular}

Source: NUREG-1496 
APPENDIX C

VENDOR LITERATURE 


\section{MARKET ASSESSMENT \\ PROTECTIVE UNDERGROUND BARRIER TECHNOLOGIES}

Prepared for

U.S. Department of Energy

Prepared By

Global Environment \& Technology Foundation 7010 Little River Turnpike

Annandale, VA 22003 


\section{EXECUTIVE SUMMARY}

Underground contaminants pose a continuing risk to public health and environmental safety. Contaminants in liquid form may spread or migrate, while solid and semi-solid contaminants may be dispersed by groundwater through drainage and runoff. Cleanup activities to deal with these contaminants are expensive and have often lagged behind public expectations. Policy makers, regulators and legislators are now beginning to search for less expensive and immediate options that will protect the public and the environment while more cost-effective, long-term approaches are developed. Underground barriers may be part of this solution because they protect the environment by containing or vectoring the flow of contaminants. Barriers may be used either as a temporary solution until further remedial action can be taken, or installed on a permanent basis. In some cases, barriers can be used to contain environmental problems while natural processes provide a long-term solution. To date, however, they have tended to be used mostly in environmental situations where no other near-term solutions are available.

This market assessment reviews the existing and projected long-term markets for underground barrier technologies. It should be used to provide an initial basis for planning activities that support businesses and investors interested in these technologies and their related markets. During the research for this assessment no other similar studies were identified, thus suggesting that the underground barrier market is in a highly developmental stage; and, once existing impediments to the widespread use of barriers are removed, is poised for substantial growth.

The key steps in selecting barriers for a particular application tend to be characterization, barrier performance requirements, and selecting the optimized barrier type to be used from the range of available alternatives. Technical challenges that require additional work include improved characterization and post-installation monitoring. Ongoing developments are likely to offer significant improvements in these areas in the next few years.

Most existing barrier technologies evolved from techniques used in the heavy construction industry for applications such as dam building, bridge construction, and pipeline development. In environmental applications, barriers tend to be engineered solutions to specific technical problems which vary considerably according to application. Impermeable barriers, for example, do not allow liquid to flow across their perimeters. Permeable barriers are designed to allow liquid flow through the barriers, while incorporating a reaction that cleans up the contaminants of concern. For barriers that must surround contaminants completely, a key design and implementation factor is the method of preventing contaminant from not only the sides but to bottom out its contaminated area. There are significant technical developments ongoing to provide improved methods of sealing these contaminant flows.

The U.S. Department of Energy (DOE) is a primary funding source for advanced barrier technology development. Among the top ten environmental priorities identified, three are 
related to barriers, including cryogenic barriers, viscous liquid barriers, and subsurface barrier emplacement technologies. Cryogenic barriers use freezing to form the barrier system while viscous liquid barriers use injectable, nonreactive fluids to trap contaminants and, a variety of subsurface emplacement technologies have been examined, including jet grouting. As of the writing of this report, each of these three technology development activities have major demonstration projects underway. Because their final performance criteria and costs are as yet unreported, it is premature to attempt to forecast their individual expected market penetration across the broader market segments. Other notable barrier technology development projects include chemical barriers, angular drilling techniques, and bio-filters which use microbial action to purify water passing through the filter medium. The level of funding by DOE is currently estimated at less than $\$ 10$ million.

Barrier technology development activity is led by the Air Force, but work is also being performed by the Navy. The Army Corps of Engineers has also performed barrier work, but primarily as an agent for the U.S. Environmental Protection Agency (EPA) on Superfund sites. Most Department of Defense (DoD) barrier work currently focuses on containing the problems of trichloroethylene and other solvents; it is estimated that $\mathrm{DcD}$ funding of barrier technology amounts to approximately $\$ 3$ million.

A number of notable barrier technology developments have come from private industry, although most eventually seek DOE or DoD funding. Two developments of significant interest include a rapid deep drilling and wall emplacement technology using sonic vibration and a barrier membrane emplacement technology.

The existing and projected underground barrier technology consist of four primary segments, two of which are the responsibility of the United States government. The evolution and growth of the market beyond the current developmental stage will depend heavily upon increased regulatory acceptance of barriers as both permanent and interim solutions. As this occurs, each of the four markets can be expected to grow rapidly. Internationally, barriers already have a higher level of regulatory acceptance. This is based primarily because barriers are viewed as being more affordable than other, remedial approaches. Although it is not fully developed, the barrier technology market is expanding in Germany and the United Kingdom.

The most significant market for barrier technology companies over the near term is likely to be DOE, because of the sheer enormity and complexity of the problems for which it is responsible. DOE environmental needs are in the area of heavy metals and organic contaminants. Presuming accelerated regulatory acceptance of barrier approaches, it is our opinion the total DOE market for barrier technologies is estimated at approximately $\$ 20$ billion over the next 5 to 15 years. The adoption of risk-based criteria and in situ isolation approaches in decision making across the DOE complex could increase the market size by as much as an additional 50 percent.

With 44 percent of the total DOE environmental spending slated for two installations, Hanford Nuclear Reservation and the Savannah River Site, these represent the best near- 
term opportunities for barrier technologies. Significant resources are also to be devoted to the Oak Ridge Reservation and the Idaho National Engineering Laboratory, so these four sites together dominate the market. However, other DOE sites will offer opportunities, as well. Priority problems at each of the four major sites are briefly discussed in the report. In a recent analysis of needs across the DOE complex, the "Contaminant Plume Containment and Remediation Focus Area" (now termed "SubCon") identified 40 priority containment needs. Each of these represents a significant opportunity for barrier technologies.

Of the over 8,500 sites in the DoD arena requiring remediation, 37 percent are Army, 26 percent Air Force, 16 percent Navy, and 20 percent Formerly Used Defense Sites. Each military service has its own independent environmental hierarchy, requiring flexibility on the part of a technology developer. Predominant problems are heavy metals, petroleum/oil, lubricants, solvents, polychlorinated biphenyls and pesticides. This report lists 20 opportunity areas among the military bases.

Due to the lack of extensive data on barrier technology performance and a regulatoryinduced wariness of new technologies, commercial market for barrier technologies will likely lag the government markets. Of the 50 states, 4 are likely to be the most promising target markets for barriers - Texas, Michigan, Louisiana, and New Jersey. The three most significant corporate targets for marketing activities are Dow Chemical Company, Amoco Oil Company, and E.I. DuPont. An examination of the market for metals-specific barrier opportunities reveals that Louisiana and Texas are the most likely opportunity areas for related technologies. Contacts with industry revealed 41 priority sites for early consideration in marketing activities.

A brief review of the international markets was done. Based upon extensive international work and the published information of others, it is forecast that the international market for barrier technologies will develop in parallel, but will not be dependent upon the U.S. market. These markets represent significant opportunities for U.S. companies. The most significant international market over the next 15 years is likely to be Germany, where environmental remediation costs are running as high as $\$ 17$ billion per year. Poland, Hungary, and the Czech and Slovak Republics each represent significant opportunities, but these are heavily dependent upon funding from international aid organizations, as are the nations of the Newly Independent States of the former Soviet Union. In Latin America, the nations of Mexico, Brazil and Argentina offer the most near-term market promise. South Korea will also be important as a market in the near-term, while China is considered a long-term, but highly significant market opportunity.

Section 6 of this report examines "barriers to barriers" and discusses some of the many issues affecting market development. The key impediments to implementation include the early stage of development of many barrier technologies; the lack of extensive performance data; regulatory reluctance to accept barrier-related solutions, and previous emphasis on making environmental sites pristine clean. Trends are in motion that would remove many of these barriers, but the end result remains to be seen. Key laws affecting 
barrier market growth are highlighted and briefly discussed, as well as potential actions to improve market growth.

Most indicators examined in this assessment point to a barrier market that is poised for significant, if not enormous growth. However, this will only happen given increased acceptance by regulators, policy makers, and the public. 
APPENDIX 3

\section{EXAMPLES OF MINI-MARKET ASSESSMENTS}


Date: November 7, 1996

\section{GETE ID Number: 1}

Technology Name: Asbestos conversion and recycling.

Description: The technology is a transportable thermochemical asbestos conversion process which totally destroys asbestos fibers while reducing waste volumes. The asbestos conversion systems are believed to be the only economically viable technology available today that completely converts asbestos materials into non-fibrous and nontoxic minerals.

Advantage Over Baseline: This technology is the first of its kind in that it converts asbestos containing materials into a non-fibrous non-toxic mineral, terminating asbestos liabilities while reducing waste stream. Asbestos Recycling, Incorporated claims that this system represents the Best Available Developed Technology (BADT) and that no other technologies destroy asbestos. Independent laboratory reports document total destruction (non-detection) of asbestos fibers.

Use: This technology can be used in a variety of applications such as closing military installations, naval ship decommissioning, residential and commercial site demolitions and renovations, landfill reclamations. "This asbestos conversion system has been determined by the U.S. EPA to be an alternative method of asbestos disposal pursuant to the requirements of 40 CFR 61 Subpart M, Section 152, as stated by the local Air Pollution Control Authorities.

Cost: This information is pending. The final results of the on site, pay-for-performance contract at Hanford.

Markets: Asbestos revolutionized the construction industry in the 1930s and was used as a primary building product in homes, schools, offices, hospitals, churches, and public institutions. It was used in over 3000 building products. During the post World War II building and baby boom, thousands of structures were constructed completely surrounded by asbestos; floors, walls, ceilings, and trim. Approximately 5.7 million cubic feet of regulated asbestos-containing materials (RACM) is disposed of annually and asbestos abatement generates large volumes of potentially hazardous materials which requires safe disposal. Traditionally, the only accepted disposal method consists of sealing the material in disposal containers and placing it in designs asbestos landfills. If reclamation of the landfill is ever required, waste generators will he held financially responsible for clean up costs. However, once the waste has been converted into asbestos-free materials, regulations no longer apply, and the generators can no longer be held liable for clean up costs. In essence, future liability is eliminated. With current and future projected regulations, asbestos conversion systems are in a position to become the dominate means of asbestos waste disposal resulting in increased demand for asbestos conversion units. 
DOE: Interest in Decontamination and Decommissioning (D\&D) focus area.

Other U.S. Government: U.S. Military bases (all services), Naval ship decommissioning, roofing, siding, tiles, pipe insulation, nuclear reactors, etc. Other Government Service Administration (G.S.A.) buildings built before 1971.

Domestic Commercial: Landfills and older building renovations.

International: To date there has been European interests developed in England, Germany, Italy, Holland and Belgium. It is very attractive where there are limited or no landfills.

Known Barriers to Use: Reliance on traditional landfill dumping, while it may be cheaper in the short run is likely to be more expensive in the long run.

For more information contact: Alan Foltz

Marketing Manager

Asbestos Recycling, Incorporated

$12212^{\mathrm{ND}}$ Avenue North

Kent, WA 98032

(206) 328-1355 
Date: November 7, 1996

\section{GETE ID Number: 2}

Technology Name: ResonantSonic $\circledast$ Remediation Wall and ResonantSonic ${ }^{\circledR}$ Containment Barrier

Description: The ResonantSonic ${ }^{\circledR}$ Remediation Wall and ResonantSonic ${ }^{\circledR}$ Containment Barrier is a patent pending technology developed by Waste Protection International. ResonantSonic ${ }^{\circledR}$ is the application of creating sound waves to perform work. In the case of Resonant Sonic $\odot$ Drilling, waves are transmitted down the drill pipe to the drill bit to allow it to rapidly penetrate the subsurface while minimizing the generation of secondary wastes and providing excellent control of the surface and subsurface contamination. This power source is utilized to install a subsurface barrier that can be either utilized for containment of contamination or to house reactive barrier constituents that will allow the groundwater to flow through the barrier, trapping the contaminants within the barrier matrix. The barrier can be installed in numerous configurations, can be used to divert or direct groundwater flow paths, is able to be installed to depths in excess of 100 feet and can be installed at an angle so as to provide full-surround enclosure if required. Unique features of the subsurface barrier include its ability to be used for containment or remediation purposes; the purposes are interchangeable; the subsurface barrier can easily be removed when containment or cleanup is no longer required; various reactive materials can be "housed" within the wall to treat select contaminants; material can be removed and exchanged when it becomes saturated with the contaminant.

Advantage Over Baseline: ResonantSonic $\circledast$ power has proven to enhance penetration rates when applied to several drilling methods. The ResonantSonic $\circledast$ dry coring method has demonstrated considerable savings in generation of secondary wastes from the drilling process and has proven to be cost competitive. These are documented in the Innovative Technology Summary Reports and in a cost analysis prepared by Los Alamos National Laboratory. It is believed ResonantSonic $\circledast$ Containment Barrier and ResonantSonic ${ }^{\circledR}$ Remediation Wall have several advantages over most existing technologies however, these advantages have not yet been demonstrated through a field test.

Cost: The cost of initiating a barrier, based on initial calculations, is a cost competitive, favorable alternative to other containment systems. ResonantSonic $\circledast$ assisted drilling has been demonstrated to be cost favorable due to the rapid penetration which decreases the schedule and due to a significantly less amount of secondary waste that is generated. The cost effectiveness of the technology (cost vs. application) is defined and reasonable while other cost profiles for acquiring, building, operating, maintaining and dismantling the technology are reasonable in view of the potential market. The cost effectiveness of the ResonantSonic $\otimes$ Drilling has been documented in published reports including an analysis by Los Alamos National Lab. The cost effectiveness of the ResonantSonic ${ }^{\circledR}$ 
Containment Barriers has not undergone a similar analysis however basic research on the subject of cost effectiveness of ResonantSonic ${ }^{\circledR}$ Containment Barrier installations is not well documented such that side by side comparisons can be made.

Use: Applications of ResonantSonic $\circledast$ technology address expedited site characterization of contaminated sites; contaminant containment and/or remediation; and drilling or earth penetration requirements for environmental and civil applications.

Markets: There is a large suite of applications for ResonantSonic $\odot$ power including pile driving; earth penetrations, for environmental and civil applications; processing and mixing in the chemical or mineral industry; for breaking ice in shipping canals or lakes, etc. Near term opportunities lie in characterization, remediation and containment of existing hazardous waste sites within the federal complex. The market is influenced by public/stakeholder perceptions and needs, allocation of federal funds, enforcement of cleanup actions, and shifts in regulatory policies. Internationally, these factors also apply as does the lack of knowledge relative to protecting the fragile environment, therefore pollution prevention or cleanup is of lessor importance than other more essential items.

DOE: The technology is applicable at virtually every DOE site. The company has successfully completed numerous DOE contracts including an ongoing multi-year contract at Hanford. Other sites include Sandia, Savannah River, Rocky Flats and the Pantex facility.

Other U.S. Government: The technology is applicable at virtually any government site with environmental restoration concerns such as DOD, NATO, or EPA sites. The current market trends, baseline costs, and potential work scope are unknown.

Domestic Commercial: The technology is applicable at commercial sites such as pertchemical plants, landfills, and other hazardous waste sites.

International: The international market remains to be explored.

Known Barriers to Use: The regulators and environmertal engineering firms must be exposed to the technology to cause them to consider ResonantSonic @ Drilling as a preferred alternative for closure or remediation of hazardous sites. There must be defensible data, obtained from demonstrations with unbiased performance objectives and results that are well documented. The technology must be life cycle cost competitive . There must be several clients willing to take the initial risk so the contractor's technology and credibility are validated before the market can be penetrated with sufficient strength.

For more information contact: Don Moak

Waste Protection International

P.O. Box 4194

W. Richland, WA 99353

(509) 377-3977 
Date: 7 November, 1996

\section{GETE ID Number: 3}

\section{Technology Name: Advanced Electrokinetic Technology}

Description: Electrokinetics is a process that separates and extracts heavy metals, radionuclides, inorganic and organic contaminants from saturated or unsaturated soils, sludges, and sediments. The process uses both electroosmosis and ion migration to move aqueous phase contaminants in the subsurface. By applying a low intensity direct current across electrodes which have been implanted on opposite sides of the contaminated soil mass, contaminants are transported to one of the electrodes depending on their electrical charge. Contaminants can then be extracted to a recovery system. Complexing agents and surfactants can be introduced which can increase solubility and assist in the movement of the contaminant as well as reagents that can enhance contaminant removal rates.

Advantage Over Baseline: Electroremediation's major advantages include its inherent ability to work in low-permeability soils and its applicability to a wide range of metallic and organic impurities. Contamination of concrete by radioactive isotopes, heavy metals and organics creates severe problems for traditional decontamination methods. These processes generate large quantities Electrokinetics is a viable alternative to scabbling or physical abrasion. Specific advantages include: potential cleanup of concrete surfaces without mechanical and physical damage to the concrete; removal of contaminants diffused deeply into the concrete; no airborne particulate; improved cost efficiency; minimizes generation of secondary wastes and resulting secondary wastes compatible with radwaste disposal technologies. The secondary by products of his process, contaminated electrolyte solutions, or other ion-sorbent material (i.e. ion exchange material) are readily disposed of by conventional ion immobilization technologies.

Cost: The estimated cost of electroremediation range between $\$ 86$ and $\$ 260$ per $\mathrm{m} 3$ of soil, which is equivalent to approximately $\$ 43-130 / t$ of dry soil. The power costs are estimated at $\$ 2$ to $\$ 16$ per ton. However, only one of the group's figures are based on actual field experience and thus considered to be the most reliable. These figures are $\$ 75 / t$ total and $\$ 15 / t$ for energy consumption. Costs will also be highly site specific depending on factors such as the initial and required final contaminant concentrations and their distribution; soil conductivity, water content, $\mathrm{pH}$ and buffer capacity; $\mathrm{pH}$ and purge solutions; and the number and spacing of the electrodes.

Use: Electrokinetics can be used at any facility where contaminated concrete, soils, sludges, and/or sediments must be dealt with.

Markets: There are at least 4000 hazardous waste sites in the United States alone where Electrokinetics can be applied (Removing...., C\&I, 5/5/95). The primary market for electrokinetics is the U.S. Department of Energy's Weapons Complex. Within the 
complex are thousands of facilities including some large nuclear weapon production facilities. DOE has estimated that the total cleanup costs of the entire Nuclear Weapons Complex would exceed $\$ 200$ billion and require 40 years to complete. The secondary markets include:

- Radioactive waste processors

- Nuclear power plants

- Superfund sites

- Water processing activities

- Mine waste sites

- Environmental remediation firms

DOE: DOE estimates that it has over $200,000,000$ tons of contaminated soils of which Isotron estimates that $10,000,000$ could be treated using the electrokinetics process. Isotron estimates that its process should save DOE an average of $\$ 150$ per ton (over burial in commercial landfills). Therefore, the potential savings for DOE could be 1.5 billion if DOE used the electrokinetics cleaning process extensively (the saving to DOE are not the revenues to Isotron). Isotron estimates that the cost to clean a ton of soil with electrokinetics is $\$ 250$ per ton thus the total market is 2.5 billion. If Isotron achieves $40 \%$ of the possible revenue, the total share realized by electrokinetics would be 1.0 billion. At an estimated market life of 40 years, the annual market is $\$ 25$ million.

Field tests have been demonstrated at Savannah River, Oak Ridge, Paducah, U.S. Waterways Experiment Station, Sandia; with future research being conducted at Argonne.

Other U.S. Government: Any facility where contaminated soils must be dealt with.

Domestic Commercial: The early markets for the commercial technologies analytical laboratory services, environmentally friendly fertilizers, farmers, highway departments (stabilizing rights of way), and commercial marketers of soil supplements to the general public such as Ortho and Fertiloam. The analytical laboratory market is highly competitive, thus Isotron has initially targeted the red lead abatement "niche" which currently alights with protective coating replacement in elevated water storage tanks. This "niche" market is expected to consume most of Isotron's currently available laboratory capacity. No significant growth is expected in the market, however, it is easily available to Isotron in the short run. The environmentally friendly fertilizer market is currently under evaluation, as is the water cleanup.

Electrokinetics has been tested by Environment \& Technology Services, Louisiana State University, DuPont, Monosanto and General Electric.

International: Same as the domestic market.

Known Barriers to Use: The decision to use electrokinetics rather than conventional methods such as "dig and haul" or soil washing will be driven primarily by economics. Opportunity costs will be used as the deciding factor. Adverse public opinion could also 
play a role in the technology's commercialization. Another barrier to use are the influencers including: the project engineering staff responsible for the budget, schedule, and program deliverables, the regulatory community (Federal, State, and Local Agencies), and the stakeholders (this includes everyone who has an interest in the site and its surrounding community). Another area of concern is the purchasing process that continues throughout the cleanup. The process requires the continual demand for ELECTROSORB cylinders, SEEC pads, extraction canisters, ESM modules, replacement electrodes, etc. 


\section{APPENDIX 4}

\section{GETE SCREENING METHODOLOGY}




\section{A: BASIC}

\section{GETE ID:}

Date:

Technology:

IP Holder:

Interviewer:

\section{Affiliation:}

1. What is the the relative importance, priority or significance of the technology to the focus area?

2. Is there a private sector company already involved with the technology? (If the answer is yes then proceed; if the answer is no, then the focus area must decide whether there is sufficient interest to warrant the search for a partner, and if so with what urgency.)

3. Is the technology nearing commercial readiness? (This requires a definition of the status of the technology as defined by the DOE (EM-50) Technology Decision Model. The CAC can become involved early or late in the process depending on EM's needs for a particular technology).

4. Is the company bringing the technology to market one that requires no assistance? (This requires a decision whether the commercial partner requires assistance in the commercialization process. If there is a strong commercial partner for example, fewer commercialization activities are likely to be required. Some of the considerations for this evaluation are as follows).

a) What size is the company?

Employees:

Offices:

b) is it publicly or privately owned?

c) Is an annual report available?

d) What are the annual revenues?

e) What relevant experience does the company possess?

f) What is the company's capability and interest in commercializing the technology?

g) Has the company a previous track record commercializing environmental technologies?
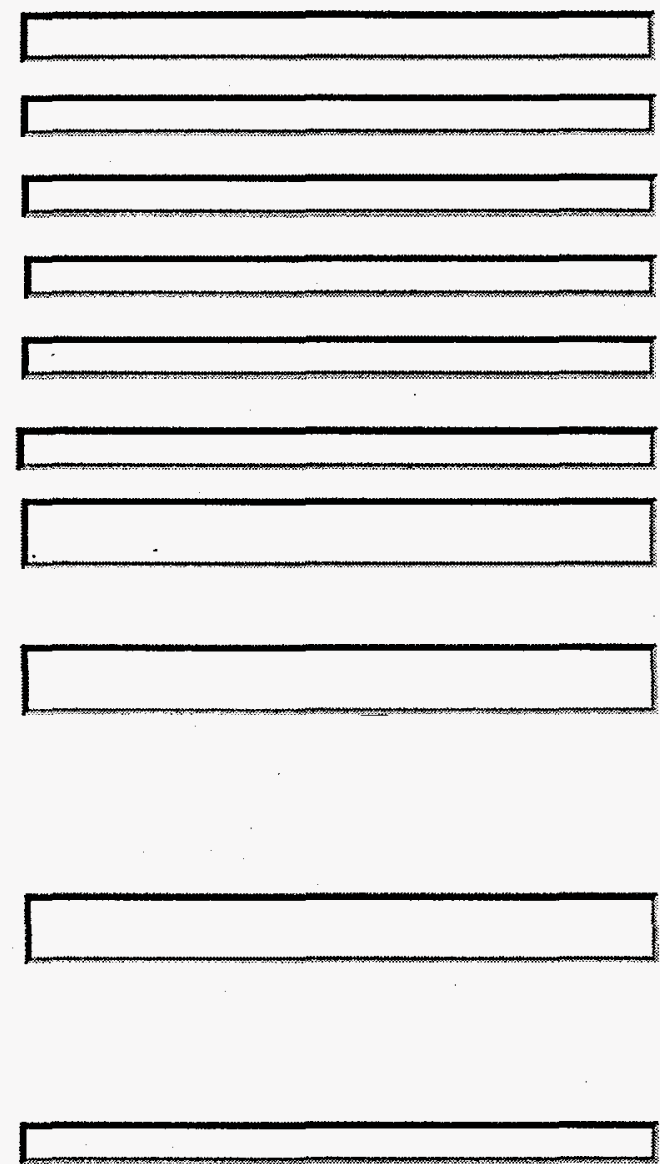

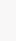


h) Has the company a track record working in the DOE complex?

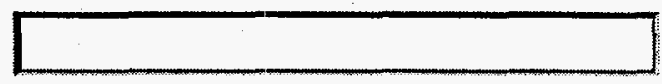

If yes, explain
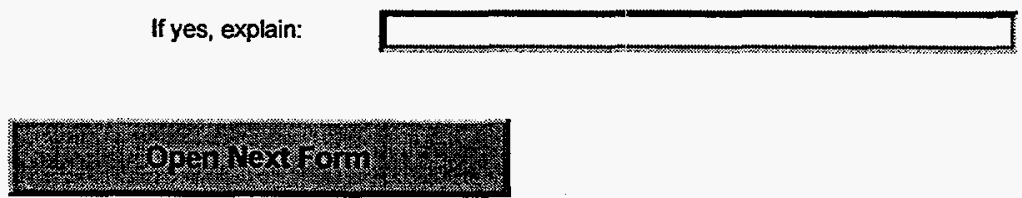


\section{B: TECHNOLOGY}

GETE ID:

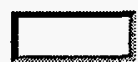

Technology:

1. What is the technology? (Defined and described in simple non-scientific terms.)

2. What primary problem areas does this technology address?

3. Have realistic potential secondary applications been identified?(List)

4. Is data available that supports the developers' claims regarding the effectiveness of the technology? Can that data be readily obtained?

5. Is adequate information available about the technology in order to allow the investigator to define the market(s) into which the technology can be sold?

6. Are test/demonstration results available?

7. In what stage of development is the technology?

8. Is the technology ready for examination and review by potential licensees/users?

9. How does new technology compare to current technologies doing the same job? (Quantify)

10. How readily can it be modified to address additional markets?

11. What problems have occurred in the development cycle?

How were they addressed?

12. What are the limitations of the technology?

13. How else is this technology unique?

14. How difficult is it to "try before you buy"?
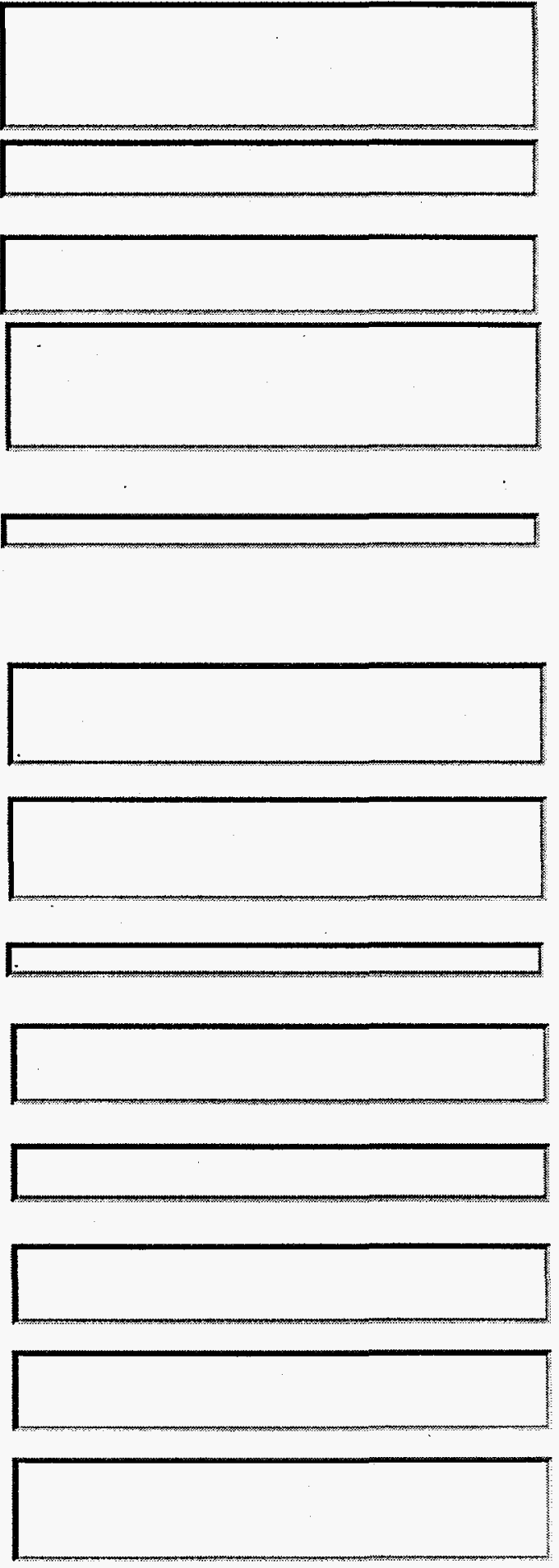
15. Where can it be viewed?
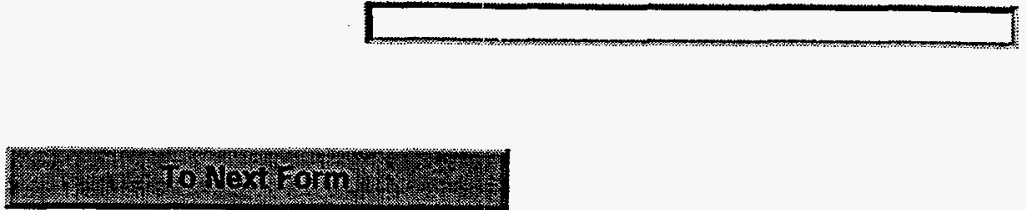


\section{C: INTELLECTUAL PROPERTY}

GETE ID:

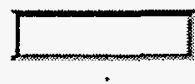

Technology:

1. Who holds the Intellectual Property?

2. Is the developer (principal investigator) of the technology easily identifiable?

3. Who are the other team

members/partners government.

commercial or otherwise?

4. What is the attitude of the intellectual property holder(s) towards commercialization?

5. Is the intellectual property custody trail well-documented and are there no serious impediments apparent to the use/licensing of the patents by commercial for-profit parties?

6. Is the technology eligible for a patent?

7. Have patents been applied for (or issued)?

8. Does DOE have the rights (or can expeditiously obtain the rights) to license (or otherwise transfer) the technology and is a clear process to do so defined?

9. Who has already licensed the technology?

10. Can the intellectual property team be reached by parties seeking to commercialize the technology?

11. What are the intellectual property team views on how this

product can be privatized?
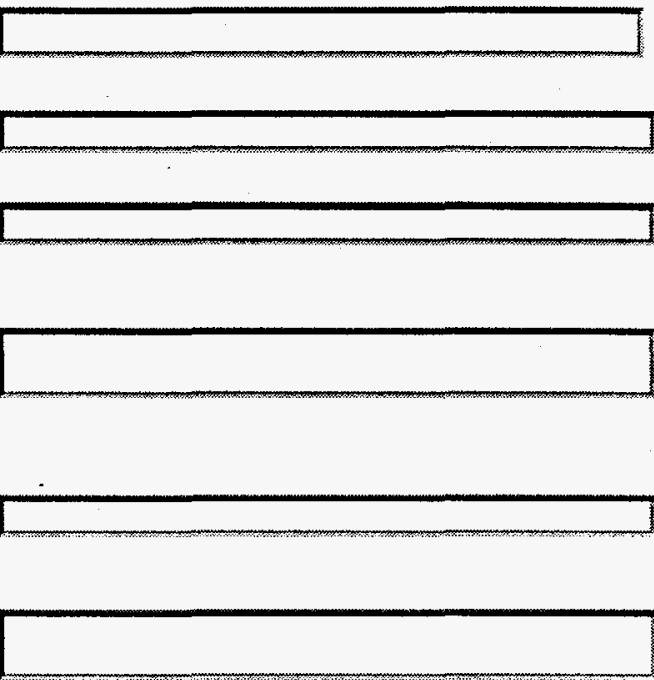

$\cdot$

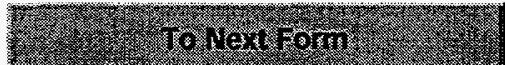




\section{D: MARKET}

GETE ID

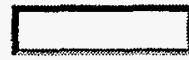

Technology:

1. The DOE market for the technology is understood, and there are near term (within the next two years) real opportunities for the technology?

2. Preliminary market reviews indicates a substantial market la markel targe enough to justify a company entering into iv relative to the investment and operating costs of the technology?

3. What other technologies that solve this problem is DOE supporting?

\section{a. Where?}

b. With what resources?

4. Barriers to market entry are understood and are determined to be surmountable within a reasonable cost.

5. Markets are not limited strictly to DOE activities, i.e., the technology is believed to have significant commercial, international, or "other government" market. Note:while the DOE market is of primary importance to commercialization activities, the other markets will add to the technology's attractiveness to private companies.

6. How widespread is knowledge about this technology in DOE market?

\section{a. Other markets?}

7. Does the technology have the potential for capturing significant market share, or in opening new markets in a reasonable period of time? (This is important in showing the size of the market to a private company).

8. What specifics are known about the market for this technology?
a) DOE?
b) Other government?
c) Domestic commercial?
d) International? 
e) How big is the market?

Total/Each Segment?

f) How diversified?

g) What primary forces influence it? (Federal, State, Local, Intemational)

h) How is the market segmented?

i) Is it mature, saturated, fragmented?

j) Where do the specific near term opportunities lie for this technology?

k) What market advantage does this technology have? (Estimate value)

1) Who are the primary competitors? (US, Foreign)

m) Who are "easy competitors (i.e. who has ready access to the market this technology will address)?"

n) What are the market barriers to entry?
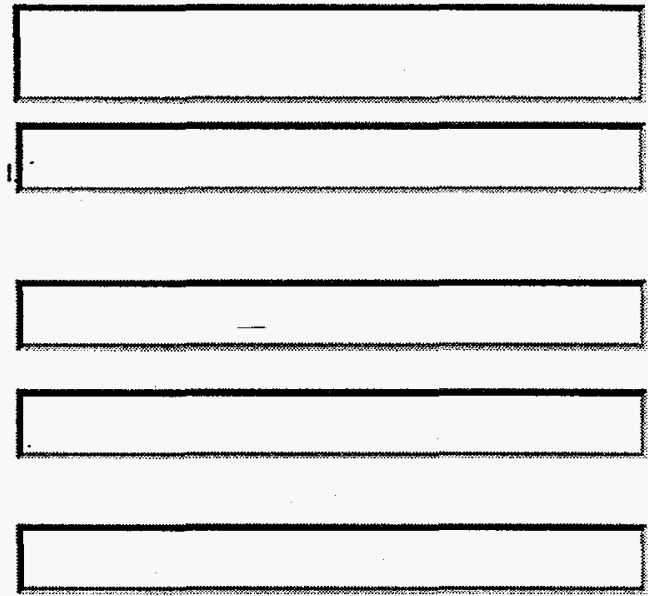

9. How can this lechnology be marketed?

10. Does this technology have any "leverage" in opening new markets?

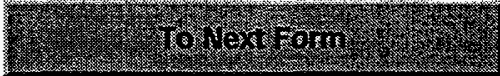




\section{E: COMPETITIVENESS}

GETE ID:

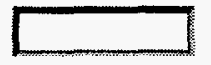

Technology:

1. The technology can be clearly differentiated from existing in-use technology, has a clear competitive advanlage over other

competition. and the by products/residues and final treatment and disposal costs are significantly lower than existing or competitive technologies.

a) What are the by products?

b) What are the residues?

c) What additional treatment is required?

d) What is the final disposal cost?

2. What are the specific competitive advantages of this product?

a) Cost

b) Simplicity

c) Pollution prevention features $\therefore \cdots$

d) Risk

e) Maintenance

n) Waste stream quality (amount)

g) Remediation properties

h) Safety/Health (any obvious deal breakers)

3. DOE is not supporting other directly competitive approaches to this technology's targeted applications. A technology selected by the commercialization activity should have a clear market niche and be supported by DOE

4. The cost effectiveness of the technology (cost vs. application) is defined and reasonable, while other cost profiles for acquiring building, operating, maintaining and dismantling the technology are reasonable in view of the potential market applications and regulatory standards.

5. These cost drivers are understood by the principal investigators (PIs) and documented in the data.
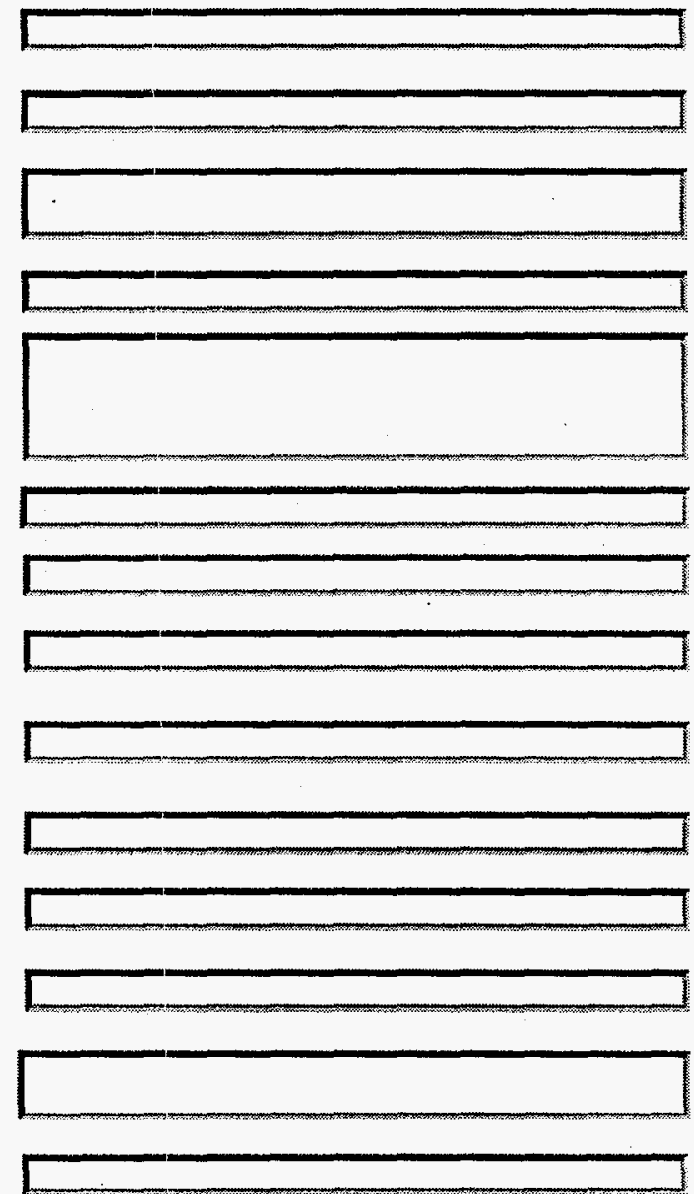


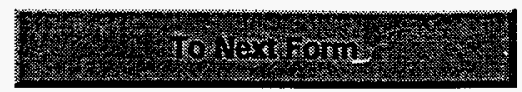




\section{F: COMMITMENT}

GETE ID:

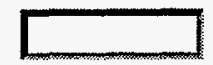

Technology:

1. The principal investigator and team (to inciude commercial and other partners) remain committed to commercializing the technology and will support/ cooperate with innovative commercialization. approaches.

2. The technology has an active supporter within the government. establishment.

3. The intellectual property holder is supportive and committed to commercializing the technology?

4. Who is sponsoring/supporting the technology (By Name)?
a) EM50
b) EM30
c) EM40
d) DP
e) LAB
n) $M$ and $O$
g) DOE Regional Office
h) University
i) Industrial Partner
j) Small companies
k) Foreign partners
D) Other government

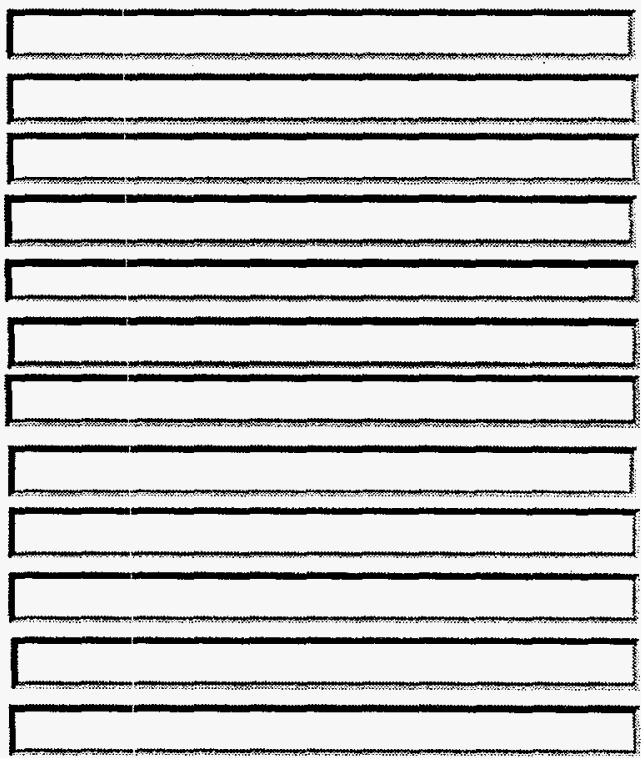

5. What is the committed future funding line for this technology? If any, by year?

6. The investment profile of the technology is documented. Is the investment significant, relative to the size of the overall market, and the problem(s) to be solved?

7. The resources and financial ability of the "supporters" relative to this technology are known and documented and indicate an ability to follow through on a commercialization initiative? 
8. What are the resources of any proposed "commercializer" of the technology and are they

financially capable of following through on their commitments?

9. What is the initial non-government investment in this technology, if any?
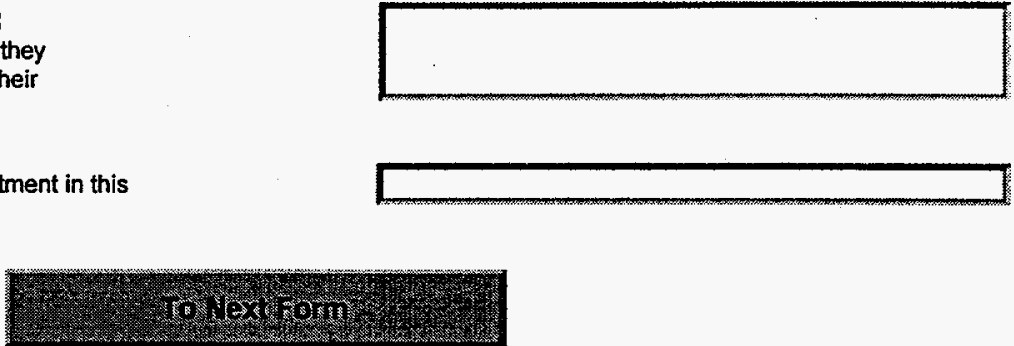


\section{G: REGULATORY ISSUES}

GETE ID: Technology:

1. The product meets or exceeds the approved regulatory standards for the problem (market(s)) for which it was developed.)

2. Are there unique regulatory barriers that exist to prohibit the use of this technology?

3. Are all anticipated barriers to progress judged to be surmountable by the technology developers?

4. Has any regulatory body reviewed the technology, and if so what has been the response?

5. What are the liability issues and are they judged by the principal investigator $(\mathrm{PI})$ to be reasonable.

6. What are the regulatory "clean" standards for the specific markets to be addressed?

7. What permits/certificates have been approved for this technology?

8. Is the technology included in any Records of Decision (ROD's)? Where?
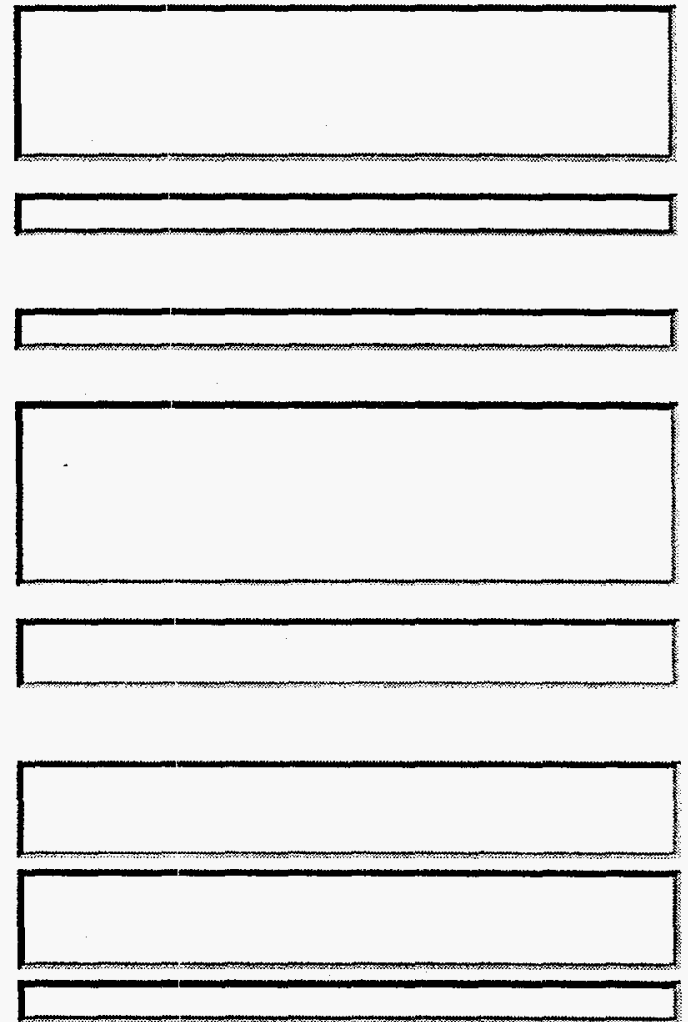

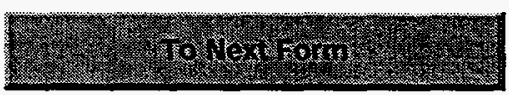




\section{H: COST INFORMATION}

GETE ID:

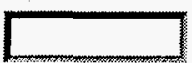

Technology:

1. What information is available on cost effectiveness?

2. What are the cost profiles?

a) To acquire intellectual property rights?

b) To build?

c) To operate? (utilities, equipment, disposable supplies, time, etc.)

d) To train personnel?

e) To maintain?

f) What unique materials are required for the design?

g) What unique equipment is required for the design?

h) What is product's projected operating lifetime? Projected technology lifetime?

3. What are the cost drivers for use of this technology?

a) Materials?

b) Equipment?

c) Software?

d) Hardware?

e) Labor?

f) Time?

g) Oand $M$ ?

h) Digging/Drilling/Fabrication/Installation?

i) Disposal?

j) Regulations?
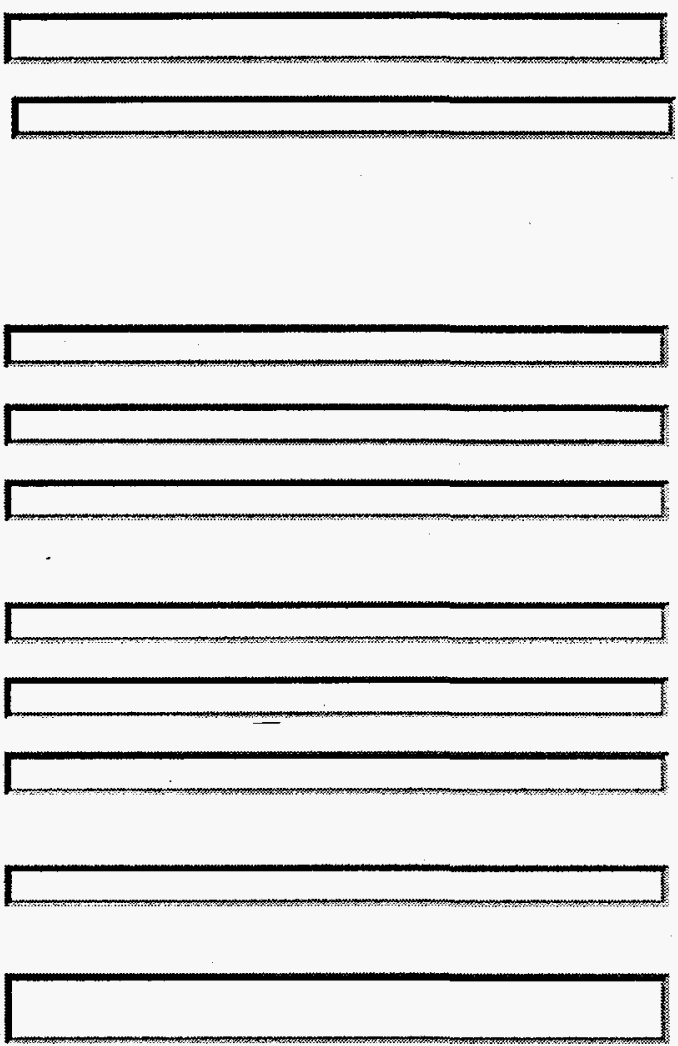
4. What are the resources of the "partners" sponsoring this technology (i.e. company, government agency, financiers)?

5. How rapidly is assistance required?

6. What defines a "good" result in the target market (minimum standards)?

7. How is the company "getting by" in the interim period (before full financing)?

8. Are there significant stockholder concerns about the product/procedures? Should there be?
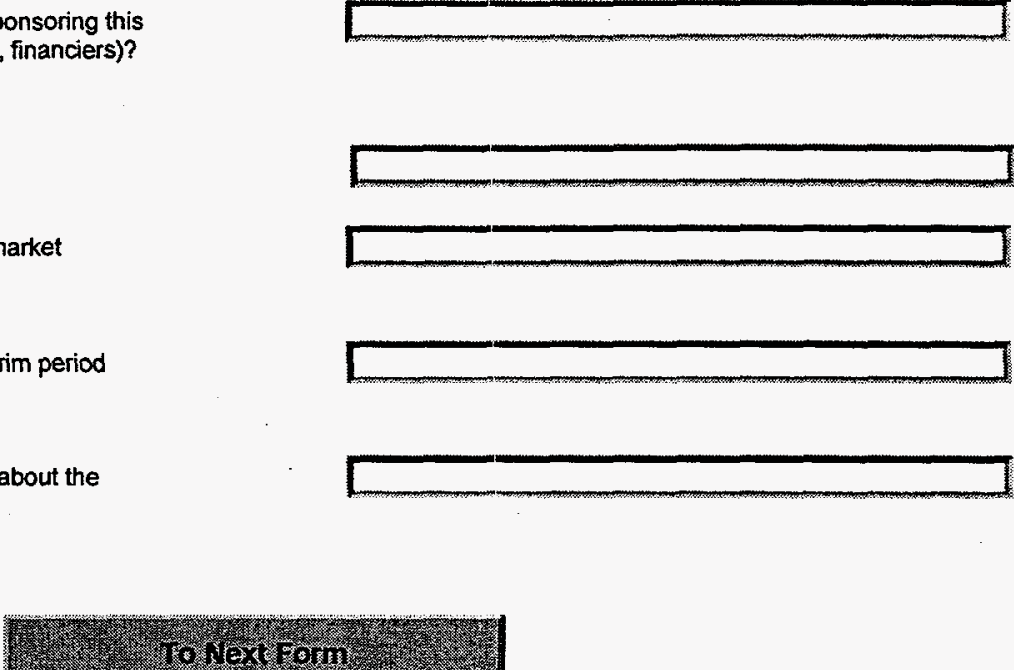


\section{I: FUTURE PLANNED ACTIVITIES}

GETE ID:

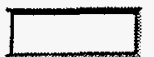

Technology:

1. What further demonstrations are planned or necessary?

2. What is needed before the technology is available in the field as an offthe-shelf item or service?

3. Is the technology dependent on any seperate developing technology prior to implementation?

4. Are there any other critical issues that remain to be addressed (science, technology, scale-up, environmental, other)?
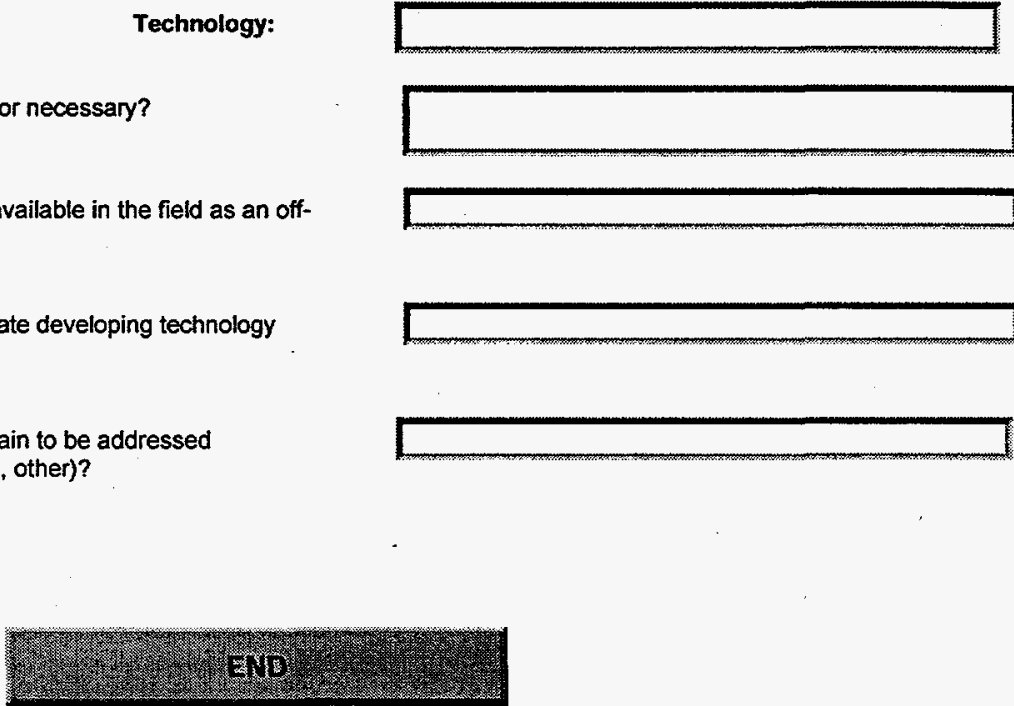


\section{APPENDIX 5}

GETE BUSINESS PLAN FORMAT 
Sample Business Plan

(Disclaimer: Every business plan is different, as is every company and the particular situation. The business plan that this outline was taken from received consideration from a very respected investment house. The deal, still in progress, is for a $\$ 4.5$ million dollar investment in the company. Every investor, large or small, is likely to ask these questions. Providing answers up front and in sufficient detail is critical to obtaining investment.)

Cover Sheet

\author{
Company Name \\ Contact Information \\ Technology Name \\ Title, Business Plan/Strategic Plan/Financial Plan \\ Prepared by (Names) \\ Date
}

Warning Statement "This document contains proprietary and confidential information, etc ,"

First Page

\author{
Company Name \\ Technology
}

Table of Contents

I. Executive Summary (5-8 pages)

The company

Product Concept

Goals

The Market

Competitive Analysis

Marketing Strategy

Sales Plan

Manufacturing

Management/Organization

Ownership

Financial Requirements

Financial Projections

II. General Company Description (2 pages) 
Primary Company

Associate Company (if applicable)

III. Product Concepts (6-8 pages)

Basic System

Product Line

Small System

Medium System

Large System

Development vehicle (IE CRADE with DOE, etc.)

Intellectual Property/Patents

Development Plan

Development Costs

Future Products

IV. The Market ( 8 - 10 pages)

Market Overview

Environmental Quality

Remediation and Restoration

Nuclear Waste Storage \& Disposal

Market Segmentation

DOE

US Government

Domestic Commercial

International

V. Marketing Strategies ( 3 - 4 pages)

The Short Term and Long Term

Teaming/Strategic Alliances

Permitting

Certification

Demonstration

VI. Sales Plan (4 - 6 pages)

Target Customers

Pricing and the Cost-to-treat

Competition

Distribution

Sales Organization

VII. Manufacturing ( 2 - 4 pages) 
Manufacturing Plan

Facility Requirements

VIII. Management ( 3 - 4 pages)

Organization

The Team

Management

Ownership

Business \& Legal Advisors

Remuneration of Management

IX. Capitalization and Financial Requirements (1 page)

X. Financial Projections ( 7 -8 pages)

Business Plan Assumptions

Balance Sheet

Income Statement

Cash Flow Analysis

Source and Use of Funds

Costs and Revenues

Cumulative Costs \& Revenues (Break Even Analysis)

XI. Attachments (as required)

Management Resumes 


\section{APPENDIX 6}

GETE WORK PLAN FORMAT 
DRAFT

\section{THE GLOBAL ENVIRONMENTAL TECHNOLOGY ENTERPRISE (GETE)}

COMMERCIALIZATION WORK PLAN

for the

TECHNOLOGY

and the

CORPORATION

(DATE)

comments to

Victor Failmezger

the Global Environmental Technology Enterprise (GETE)

c/o Global Environment \& Technology Foundation

703-750-6401 (Tel)

703-750-6506 (fax)

victor.failmezger@gnet.org

gete@gnet.org 
THE GLOBAL ENVIRONMENTAL TECHNOLOGY ENTERPRISE (GETE)

\author{
COMMERCIALIZATION WORK PLAN
}

for the
TECHNOLOGY
and the
CORPORATION

\title{
1.0 INTRODUCTION
}

The technology has been demonstrated and deployed as an innovative tool to access the subsurface for installation of monitoring and/or remediation wells and for collection of subsurface materials for environmental restoration applications. This technology has been develop by industry with assistance from the U.S. Department of Energy (DOE) Office of Technology Development to ensure it meets the needs of the environmental restoration market. A promising future application of this technology is in the field of underground barrier emplacement.

\subsection{PURPOSE}

The purpose of this Workplan is to guide the efforts of the GETE Team in the performance of value added services to facilitate the implementation of the technology within a SubCon project on a DOE site. GETE, working with the focus area and the Corporation, reviewed the suite of potential services, listed below:

- Planning Activities

- Commercial Viability

- Market Pull Assessment

- Strategic/Business Plan

- Financial Plan

- Licensing Assistance

- Fairness of Opportunity

- Partnering

- Testing

- Brokering

Specific services judged to be most appropriate and relevant, considering on-going Corporation activities and the level of technical maturity of the technology were selected. For these selected activities, this workplan describes the specific actions to be accomplished. It specifies the organizational resources, lists responsibilities and includes major milestones. When a menu item was judged not to be appropriate for inclusion into the workplan, a brief explanation has been 
given. The GETE program Work Breakdown Structure (WBS) number is the number in parentheses after the activity.

\subsection{ACTIVITIES}

Specific commercialization activities are described in detail below under the appropriate heading, after a brief description (in italics) of that activity.

\subsection{Planning Activity (2.7.4)}

Planning contributes to the identification and evaluation of risks associated with the commercialization of technologies and the development of strategies to overcome identified risks.

GETE intends to be an active participant in the planning process for this technology. This will include:

- Several telephone calls per week

- On-call response to query

- Washington DC area liaison activities

- Focus Area Liaison

\subsection{Commercial Viability Activity (2.2.1)}

This activity consists of an independent evaluation of competing technologies and other such factors in order to determine if the technology is viable for the commercial marketplace.

Both the basic technology and the related technologies rely upon already established basic concepts with proven potential for DOE applications, therefore, this activity will not be conducted.

\subsection{Market Pull Assessment Activity (2.5.3)}

The purpose of this activity is to conduct a market study to determine the size and scope of the potential market for a specific technology or specific market sector (the DOE market; the non-DOE government market; the domestic commercial market and the international marketplace can all be evaluated).

The basic technology can support a wide number of differing Technologies, therefore it is proposed that a major market study be accomplished for the barrier/containment market sector. This market study would support not only this technology but also other barrier technologies funded by the DOE and with applicability at DOE SubCon Focus Area sites.

\subsection{Strategic/Business Plan (2.7.1)}


The commercialization team will work with the company to provide input into their planning process and may offer to review and comment on this effort.

GETE will review the company's business plan, especially in relationship to how they intend to access new markets, both in and outside of DOE. Emphasis will be placed on their technology. This bulk of this activity is likely to take place upon the completion of the barrier market study.

\subsection{Financial Plan (2.8.1)}

Usually an integral part of the Strategic or Business Plan, this plan sometimes requires special emphasis. It will address potential sources of capital and the projected amount and timing of financing for commercial development. Only when all the details are in place will active solicitations of investment begin.

Depending on the results of the market study and the strategic planning activities mentioned above this activity will commence as deemed best to me company and DOE objectives. Will like happen after the first of the fiscal year.

\subsection{Licensing Assistance Activity (2.6.1)}

Assistance to the holders of intellectual property rights can be provided during the development of licensing strategies and during licensing negotiations. Thorough various dissemination methods, information about licensing procedures, opportunities, points of contact, and other relevant information can be made available.

The license is in the hands of a private company which is also an equipment manufacturer, therefore there are no anticipated actions under this activity.

\subsection{Fairness of Opportunity (3.2.2)}

When requested to find a commercial partner, consideration must be given to ensuring that there is fairness of opportunity built into the partnering process. GETE has developed a model for such a plan that can serve as a prototype

Since this technology is wholly held by a private company, this is not a GETE issue.

\subsection{Partnering (2.6.2)}

The review, selection, and scoring process used to find suitable partners will be documented for each specific technology/technology application. Partners will be selected on the basis of an established criteria.

Since the technology is already in the hands of a private company, activities related to finding additional partners will be accomplished under activity 3.10 Brokering 


\subsection{Testing Activity (2.7.2)}

As appropriate, commercialization activities will facilitate the location of testing sites and help make arrangements to perform tests, pursue the participation of interested parties, assist in the development of the testing and performance criteria to produce acceptable data, communicate the results, and seek widespread acceptance of results by. interested parties.

If the wall barrier technology is judged to be of interest to the focus area, this activity will be accomplished to facilitate test and demonstrations.

\subsection{Brokering Activity (2.6.2)}

Commercialization Activities will assist companies seek and find strategic and financial partners. This process for locating partners will be open and equitable, and partners will be sought that can contribute to the best interests of the company and to DOE's interest in facilitating use of the technology being commercialized.

The company is actively negotiating partner agreements and GETE expects to be asked to review their partner selection and perhaps offer opinions on related activities.

\subsection{ORGANIZATION AND APPROACH}

The activities for this Commercialization Work Plan can be met with GETE resources. Primary point of contact for these activities will be Mr. Victor Failmezger and he will be responsible to coordinate all technology activity requirements.

\subsection{SCHEDULE/MAJOR MILESTONES:}

1. June 4, 1996: Focus Area Review of Progress. Complete.

2. Jun 19, 1996: Visit Hanford Drilling Site, workplan presented and company revision. Complete.

3. July 1, 1996: Draft work plan submitted.

4. July 3, 1996: Market Study commences.

5. July 26, 1996: Market Study 50\% complete, status presented.

6. Aug 16, 1996: Final Draft Market Study.

7. August, 1996: Strategy Meeting in conjunction with Spectrum 96.

8. Sep 13, 1996: Final METC review of Market Study

9. Sep 30, 1996: Final Market Study Released

10. Oct 1, 1996: New fiscal year activities commence. 


\subsection{ESTIMATED RESOURCE REQUIREMENTS* (1 JULY - 30 SEP 96; 18 WEEKS) FOR INTERNAL USE ONLY.}

61. Personnel Requirements by Activity:

Executive Staff: E Senior Staff: S Junior Staff: J Researcher: $\mathbf{R}$ Clerical: $\quad \mathbf{C}$

Planning Activity: 60 hours S.

Commercial Viability Activity: none.

Market Pull Assessment Activity: TBD by PSII

Strategic/Business Plan: 12 hours $S$

Financial Plan: next fiscal year.

Licensing Assistance Activity: none.

Fairness of Opportunity: none.

Partnering: none.

Testing Activity: next fiscal year.

Brokering Activity: 12 hours S.

Miscellaneous: 4 hours $\mathrm{C}$.

Total Hours: $84 \mathrm{~S}: 4 \mathrm{C}$ : plus 1 TBD activities

* Does not include general program support.

\subsection{Travel:}

Combined trip to Seattle/California (August) $\$ 700.00$ 


\section{APPENDIX 8 \\ GETF/WSRC \\ MEMORANDUM OF UNDERSTANDING}




\section{MEMO OF UNDERSTANDING \\ BETWEEN \\ GETF AND WSRC}

THIS MEMO OF UNDERSTANDING entered into this 26th day of February, 1996, by and between the Global Environmental \& Technology Foundation (hereafter referred to as GETF), a non-profit foundation with offices located at 7010 Little River Turnpike, Suite 300 Annandale, Virginia 22003-9998, and Westinghouse Savannah River Company, the management and operations (M\&O) contractor for the Department of Energy's (DOE) Savannah River site (SRS) (hereafter referred to as WSRC), with principal offices located in Aiken, South Carolina.

WHEREAS, GETF and WSRC have substantial expertise and experience with environmental projects including technology commercialization; technology transfer; technology demonstrations and verification; and technology partnerships.

WHEREAS, GETF and WSRC may wish to work together on various projects as mutually agreed; and

NOW, THEREFORE, for and in consideration of the mutual benefits to the respective parties, the parties hereto agree as follows:

\section{Scope of Cooperation and Performance}

1.1 GETF and WSRC shall work together, as appropriate, on various projects as mutually agreed upon, including, but not limited to the following specific activities:

1.1.1. The Global Environmental Technology Enterprise (GETE), a project of the GETF, seeks to inform government agencies, commercial entities or potential investors and environmental problem holders about WSRC developed technologies to fit the specific problem area or business stream of the company or site.

1.1.2. WSRC agrees to provide GETF with all publicly available information about its technologies in order to perform activity 1.1.1 above.

1.1.3. WSRC agrees to allow GETF to place publicly available information about WSRC developed technology on the GETF developed Global Network for Environmental Technology (GNET) to facilitate the activity addressed in 1.1.1. above.

\subsubsection{Upon Agreement between GETF and WSRC, WSRC agrees to set up} specific meetings for those individuals and/or organizations interested in WSRC technologies, either for licensing or investment by them. These meetings can address a variety of topics, but will likely include, as mutually agreed, discussions of the technology and the site specific technology commercialization (including licensing) procedures. 
1.1.5 Both WSRC and GETF will recognize each other in those activities which they have agreed to work together and will offer the opportunity for GETF to formally participate in technology transfer strategies that they sponsor or organize. These activities could include space at technology exhibitions; inclusion of GETF representatives as invited speakers, discussion panel members, or the like.

1.1.6. As appropriate, GETF will seek to inform technology holders about the potential use of SRS for appropriate technology demonstrations or other uses of available facilities and/or personnel.

1.2 GETF and WSRC shall: (i) use their best efforts to identify and notify one another of projects on which they can collaborate as agreed by the parties; (ii) provide each other with all information and support reasonably requested by the other party to facilitate the performance of the services and tasks described herein; and (iii) collaborate, where feasible to identify WSRC remediation technology needs and promote the availability of emerging technologies to complete or enhance ongoing site remediation projects. The provision of this information will be in accordance with the information protection requirements of the parties and may be subject to a specific and separate non-disclosure agreement

1.3. GETF and WSRC shall work with each other as may be agreed between them from time to time, on an exclusive or non-exclusive basis, under the terms of this Agreement.

\section{Compensation}

2.1 At this time there is no compensation anticipated under this agreement. It should however, be noted that GETF performs GETE activities under a US DOE Cooperative Agreement \# DE-FC21-94MC31179 and is tasked with becoming a self-sustaining entity. Therefore in order to effect continuation of services provided by GETE, GETF reserves the right to propose for consideration by WSRC appropriate levels of compensation for the performance services covered under this Memo of Understanding. Should an acceptable compensation formula be agreed upon, a separate agreement would be mutually executed in advance of any such activity.

\section{Confidentiality; Proprietary Information; Non-Circumvention}

3.1 The parties hereto acknowledge and agree that during the course of this Agreement they shall exchange confidential and proprietary technical and business information ("Information"). Such information shall be identified clearly in writing (or verbal and followed-up in writing within two weeks) as proprietary or confidential by the disclosing party at the time of disclosure. Neither party nor their subsidiaries, divisions, ernployees, agents, representatives, independent contractors or other persons or organizations over which they have control will at any time during the term of this Agreement directly or indirectly disclose such Information to any third parties for any purposes without prior written agreement of the other party. Should the 
proprietary or confidential status of any such information be disputed, the parties agree to work in good faith to reach a mutually satisfactory disposition.

3.2 Notwithstanding the expiration of other parts of this Agreement, the obligations and provisions of this Section 3 shall continue for two (2) years after the termination of this Agreement unless otherwise agreed by the parties or when a longer time is required by statute, pre-existing contract or other obligation.

\section{Relationships}

4.1 This Agreement does not make either party the employee, agent or legal representative of the other for any purpose whatsoever. In fulfilling its obligations pursuant to this Agreement, each party shall be acting as an independent contractor and neither party shall have the authority to bind the other without the prior written consent of such other party.

4.2 Each party hereto shall be independently responsible for compliance with all federal, state and local laws and regulations.

\section{5. $\quad$ Costs}

5.1 Any and all costs, expenses or liability to any parties caused or arising out of this Agreement, its implementation, amendment or expansion, shall be borne by each party separately and individually and no party shall be liable or obligated to the other for any such cost, expense or liability unless agreed to in advance in writing.

\section{Term}

6.1. The term of this Agreement shall be one (1) year from the effective date first above written ("initial term"), but it may be renewed annually for an additional one-year term at the expiration of any preceding term. Either party, however, may terminate this agreement in writing, at any time by giving thirty (30) days written notice.

\section{Termination}

7.1 This Agreement may be terminated by the parties hereto under the following circumstances:

(a). the mutual written agreement of the parties;

(b). automatically by the petition by one of the parties for bankruptcy or reorganization under bankruptcy laws or any assignment for the benefit of creditors;

(c). by one party if the other party commits a material breach or is in default of the provisions hereof, which material breaches and events of default shall include: (i) breach of 
the confidentiality and non-circumvention provisions hereof, (ii) failure to perform agreed upon services or work, (iii) failure to pay promptly any amounts which may be owed by one party to the other.

(d) for purposes relating to the national security of the United States of

America.

7.2 Upon a material breach or default of the provisions as provided herein, the injured party may give written notice to the party in breach or default of intent to terminate this Agreement, specifying the breach or default, and if the breach or default is not cured within thirty (30) days after giving such notice, then the injured party may terminate this Agreement forthwith by written notice to such effect to the breaching or defaulting party.

7.3 Upon the termination of this Agreement, the parties shall continue to be obligated to divide and pay all commissions and fees accrued to the date mutually agreed by the parties even though it may be later than the date of termination in accordance with the terms of this Agreement.

\section{8. $\quad$ Disputes}

Any disagreements arising under the provisions of this Agreement will be decided by arbitration in accordance with the American Arbitration Association Rules of Arbitration, each party to appoint an arbitrator, and the two thus selected to designate a third. If either of the parties fails to appoint its arbitrator within fifteen (15) days after receipt of notice of the appointment by the other of its arbitrator, or if the arbitrators fail to appoint a third, then the President of the American Arbitration Association will have the power, on the request of either party, to make the appointments which have not been made as contemplated above. The arbitration will be held as promptly as possible at such time and place as the arbitrators may determine. The decision of a majority of the arbitrators will be final and binding upon the parties hereto, and each party will bear its own expenses of the arbitration.

\section{9. $\quad$ Assignment}

9.1 This Agreement, and the rights and obligations of the parties hereunder, may not be assigned to any other party, with the exception of WSRC to the US Department of Energy, without the express prior written agreement of the other party hereto. This Agreement shall be binding upon and shall inure to the benefit of the successors or assigns of the parties hereto.

\section{Entire Agreement}

10.1 This Agreement represents the entire agreement of the parties hereto, and all previous agreements, whether oral or written, are expressly superseded hereby and merged herein. 


\section{Governing Law}

11. This Agreement shall be governed by the laws of the Commonwealth of Virginia, USA

IN WITNESS WHEREOF, the parties hereto have caused this Agreement to be executed as of the effective date first above written.

Global Environment \&

Technology Foundation

By:

Steve Wassersug

President, GETF

Date:

Date:

Company
By:

Ambrose Schwallie

President, WSRC

Westinghouse Savannah River 
APPENDIX 9

EXAMPLE OF FOCUS AREA ON GNET 


\section{Subsurface \\ Contaminanis}

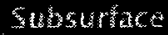

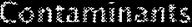

Technologises
Subsurestes?
Contumburs
Forvirio

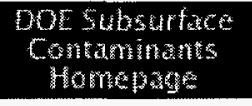

Mer.

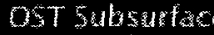

contartarastes Page

\section{About This Center}

\section{Subsurface Contaminants News:}

Updated February 21, 1997

- Soil Contamination: Dealing with Petroleum Spills

- Superfund's Fate Is Unclear

Subsurface Contaminants News Archives

GETE Update:

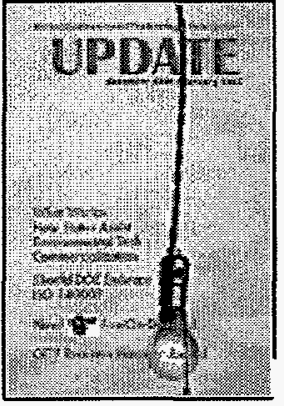


Links:

NWOMTHE TECHOLOOY sumarT REPOTTS

- TEOHOLOBY 都EEDS

- Call for Technologies to the Subsurface Contaminants and Crosscutting Technologies Focus Groups

- Subsurface Contaminants Technologies

Comprehensive list of subsurface contaminant-related technologies

- DOE Subsurface Contaminants Homepage

The Subsurface Contaminants page contains administrative information, product line information, innovative technology summaries, and area contacts.

- Containment and Remediation Focus Area

The Environmental Restoration Technologies Department 6621 (SNL/ERT) develops, demonstrates, and transfers containment, in situ remediation, and monitoring and verification technologies for environmental problems owners such as DOE-EM40 in order to provide better, faster, cheaper, cleaner solutions to DOE's problems. Development and application of technological solutions to meet DOE's highest priorities and broaden its focus from react-cure to anticipate-prevent policies has been accelerated through this focus area and program.

- Interactive Modeling of Leachate Migration NE

This document allows you to operate a simple computer model of groundwater contaminant transport. The model used in this example predicts the downward migration of leachate from a landfill to an underlying aquifer. While the example is hypothetical, it illustrates a number of the real world concerns that are associated with the operation of municipal and industrial landfills.

- Chemical Movement, Fate, and

Treatment MEH

Twelve research projects are outlined in this

\section{Journals:}

- Soils and Groundwater Cleanup Magazine, June-July 1996

- Initiatives Online, Volume 3, December 1996

- Oak Ridge National Laboratory Review. Vol. 28, No.2 \& 3

- Direct Contact Toll Free Environmental Directory

- The Green Business Letter

\section{Listserves:}

\section{Groundwater Listserv}

Send mail to:

majordomo@ias.champlain.edu. In the message write: subscribe groundwater. This is a high traffic list at times so there is a digest version for those that want to receive all of the day's postings in one piece of mail. To join the digest, you mecsane shnuld rearl silherrihe 
excerpt from the Western Region Hazardous Substance Research Center, including Aquifer Remediation Design in the Presence of Kinetic Limitations, Radon-222 Method for Locating and Quantifying Contamination by Residual Non-Aqueous Phase Liquids in the Subsurface, and Three-phase Flow in Fractured Media.

\section{- Napl-contaminated Soil/groundwater} Remediation Using Foams NEG.

The use of foams is being examined in bench-scale treatability studies as a means to release and mobilize dense nonaqueous phase liquids (DNAPLs) and to couple with bioremediation techniques. The foams can either be produced in situ or above ground and injected in the contaminated zone. Injection/production wells (either horizontal or vertical) can be used to assist in the delivery, transport, and monitoring of foams through the subsurface.

\section{- Dynamic Underground Stripping}

Dynamic Underground Stripping (DUS) is a combination of several technologies targeted to remediate soil and ground water contaminated with organic compounds. DUS is effective both above and below the water table and is especially well suited for sites with interbedded sand and clay layers.

- Alka/Sorb Process for Off-Gas

\section{Treatment}

The Beco "Alka/Sorb" process was developed initially in 1985 for a hazardous fume process at a major glass manufacturer. The process has been refined over the years to provide maximum control efficiency on all typical off-gas contaminants, including: acid gases, flyash, heavy metals (including mercury and cadmium) and dioxins/furans. The process can be adapted for use in soil vapor extraction, thermal desorption, or chemical treatment.

\section{- In Situ Microbial Filter}

This permeable reactive barrier/filter system, composed of trichloroethylene- (TCE-) degrading microorganisms, is created by injecting microorganisms into the subsurface, forming a wall to intercept contaminated ground water. As the ground water flows through the biofilter, the contaminants are degraded by the enzymatic action of the bacteria.

\section{- RESONANTSONIC DRILLING}

ResonantSonic Drilling has been demonstrated and deployed as an innovative tool to access the subsurface for installation of monitoring and/or remediation wells and for collection of subsurface materials for environmental groundwater-digest.

2. Bioremediation Listserv

Send an e-mail message to

listserver@gzea.com. Please,don't

include a subject line in your message.

The body of your message should say:subscribe bioremediation. You will receive a notification if you were successful. Post your messages to bioremediation@gzea.com.

3. Pollution and Ground Water Discharge Mail the command "info Aquifer" to listserv@ibacsata.bitnet.

4. Environmental Engineering Topics Including Water and Wastewater Mail the command "info Enveng-I" to listproc@pan.cedar.univie.ac.at. 


\section{APPENDIX 10}

\section{EXAMPLE OF GETE UPDATE}

$$
\text { no pages for Cupp. } 10
$$

